\title{
Therapeutic Strategies of COVID-19: from Natural Compounds to Vaccine Trials
}

\author{
Abdelhakim Bouyahya $^{1, *(i)}$, Nasreddine El Omari ${ }^{2(D)}$, Nawal Elmenyiy ${ }^{3}$ (D), Maryam Hakkour ${ }^{4(D)}$, \\ Abdelaali Balahbib $4^{(i)}$, Fatima-Ezzahrae Guaouguaou ${ }^{5}$ (D), Taoufiq Benali ${ }^{(i D}$, Aicha El Baaboua ${ }^{7}$ (iD), \\ Omar Belmehdi ${ }^{7}$ (i)
}

1 Laboratory of Human Pathologies Biology, Department of Biology, Faculty of Sciences, and Genomic Center of Human Pathologies, Faculty of Medicine and Pharmacy, Mohammed V University in Rabat, Morocco

2 Laboratory of Histology, Embryology, and Cytogenetic, Faculty of Medicine and Pharmacy, Mohammed V University in Rabat, Morocco

3 Laboratory of Physiology, Pharmacology \& Environmental Health, Faculty of Science, University Sidi Mohamed Ben Abdellah, Fez, Morocco

4 Laboratory of Zoology and General Biology, Faculty of Sciences, Mohammed V University in Rabat, Rabat, Morocco

5 Mohammed V University in Rabat, LPCMIO, Materials Science Center (MSC), Ecole Normale Supérieure, Rabat, Morocco

6 Laboratory of Natural Resources and Environment, Polydisciplinary Faculty of Taza, Sidi Mohamed Ben Abdellah University of Fez B.P.: 1223, Taza-Gare. Taza, Morocco

7 Biology and Health Laboratory, Biotechnology and Applied Microbiology Team, Department of Biology, Faculty of Science, Abdelmalek-Essaadi University, Tetouan, Morocco

* Correspondence: boyahyaa-90@ hotmail.fr;

Received: 15.06.2020; Revised: 17.07.2020; Accepted: 18.07.2020; Published: 22.07.2020

\begin{abstract}
Severe Acute Respiratory Syndrome-Coronavirus 2 (SARS-CoV-2) is a novel coronavirus that caused a global epidemic named COVID-19. This disease continues to kill thousands of people around the world. Physiopathological studies showed that different organs such as lungs, brain, kidneys, immune system, and heart are affected directly and/or indirectly by this disease. With the absence of a vaccine, several treatments have been proposed, including old antiviral drugs, synthetic pharmacophores, and natural antiviral bioactive compounds. These molecules presented promising results with specific action on the virus. Moreover, other strategies are underway, such as the use of monoclonal antibodies, cell therapy, plasma therapy, and vaccine trials. In this work, we highlight the therapeutic strategies of COVID-19 natural compounds to vaccine trials.
\end{abstract}

Keywords: COVID-19; SARS-CoV-2; bioactive molecules; antiviral drug; targeted therapy.

(C) 2020 by the authors. This article is an open-access article distributed under the terms and conditions of the Creative Commons Attribution (CC BY) license (https://creativecommons.org/licenses/by/4.0/).

\section{Introduction}

Recently, a worldwide epidemic named COVID-19 (Coronavirus disease 2019) was produced by a novel virus named Severe Acute Respiratory Syndrome- Coronavirus 2 (SARSCoV-2) [1, 2]. This virus belongs to the Coronaviridae family, SARS-CoV-2, and $\beta$ coronavirus genus with MERS-CoV and SARS-CoV $[1,2]$. Molecularly, it is a positivestranded RNA and contains four structural proteins on their surface (the membrane protein $\mathrm{M}$, the envelope protein $\mathrm{E}$, and the spicule $\mathrm{S}$ ). The spike protein is involved in virus tropism by its binding to host cell surfaces. 
The rapid transmission of SARS-CoV-2 from human-to-human continues to cause real health dangers (cause the death of many people and causing enormous social, psychological, and economic impacts) $[3,4,5]$.

With the absence of efficacy treatments, COVID-19 induces several clinical symptoms of patients infected by SARS-CoV-2 are different and include dry cough, high fever $\left(>38^{\circ} \mathrm{C}\right)$, fatigue, and some other symptoms such as vomiting myalgia, dyspnea, hemoptysis, sputum production, headache, and diarrhea [6-8]. Moreover, the detection of SARS-CoV-2 is based essentially on molecular diagnosis using on Real-Time Polymerase Chain Reaction (RT-PCR) technique [9].

Pharmacological strategies revealed the in vitro and in vivo efficacy drugs from different sources, while specific antiviral therapeutics and vaccines are the most effective methods to prevent and treat a viral infection. Up to date, there is any specific drug against the new coronavirus [10]. The lockdoAAAAAwn is the only alternative solution to prevent and reduce the risk of transmission of this virus. Moreover, several studies are now being undertaken to set up treatments that target virus checkpoints such as penetration, deencapsulation, transcription, replication, and assembly.

In this review, the latest advances in vitro and in vivo researches about anti-SARSCOV-2 active drugs such as natural bioactive compounds and synthetic pharmacophores are scientifically explored and give promising results. Finally, all anti-COVID-19 therapeutic strategies at clinical trials using synthetic drugs, old antivirals, antibodies, cell therapy, plasma therapy, and current vaccine trials are also highlighted and critically discussed.

\section{Preclinical therapeutic strategies}

\subsection{Natural bioactive compounds as possible drugs against SARS-CoV-2.}

Since the outbreak of SARS, many researches dedicated themselves in order to find anti coronavirus agents, including the secondary metabolites as alkaloids, flavonoids, terpenoids, glycosides, tannins, etc., that exist in herbal medicines. In all studies, the hypothesizes suggest that the receptor inhibitors, and the inhibition of proteins, which are essential for viral entry and replication of SARS-CoV, are the main attractive targets to discover a potential antiviral treatment for the human pathogen coronavirus. Table 1 summarizes all studies screened and confirmed the direct inhibition of SARS-CoV by some natural compounds in silico, in vitro, and in vivo.

Table 1. Anti-COVID effects of natural compounds isolated from medicinal plants

\begin{tabular}{|c|c|c|c|c|c|}
\hline $\begin{array}{l}\text { Chemical } \\
\text { family }\end{array}$ & Compounds & Source & $\begin{array}{l}\text { Experimental } \\
\text { system (model cell line, } \\
\text { in silico, in vivo) }\end{array}$ & $\begin{array}{l}\text { Keys } \\
\text { findings/mechanisms } \\
\text { insights }\end{array}$ & References \\
\hline \multirow[t]{3}{*}{ Alkaloids } & Capsaicin & Allium sativum & $\begin{array}{lr}\text { SARS-CoV-2 Protease } \\
\text { Molecular } \quad \text { Docking } \\
\text { Analysis using MVD } \\
\text { (molegro virtual dockers) } \\
\text { software. } \\
\end{array}$ & $\begin{array}{l}\text { Stronger bond and high } \\
\text { affinity to protease }\end{array}$ & [11] \\
\hline & $\begin{array}{l}\text { Bromocriptine, } \\
\text { Celsentri, Delavirdine, } \\
\text { Emend, Golvatinib, } \\
\text { Maraviroc, Olysio, } \\
\text { Saquinavir, } \\
\text { Sovaprevir, } \\
\text { Tanespimycin } \\
\end{array}$ & - & $\begin{array}{ll}\text { SARS-CoV-2 } & \\
\text { Molecular } & \text { Docking } \\
\text { Analysis } & \end{array}$ & $\begin{array}{l}\text { Stronger bind the N- } \\
\text { terminus and C-terminus } \\
\text { of the homology model of } \\
\text { SARS-CoV-2 } \\
\text { Nsp14 }\end{array}$ & [12] \\
\hline & Agglutinin, nelfinavir & $\begin{array}{l}\text { Galanthus } \\
\text { nivalis }\end{array}$ & $\begin{array}{l}\text { Feline } \\
(\text { FCoV) }\end{array}$ & Inhibited FCoV replication & \\
\hline \multicolumn{3}{|c|}{ https://biointerfaceresearch.com/ } & & & 8319 \\
\hline
\end{tabular}




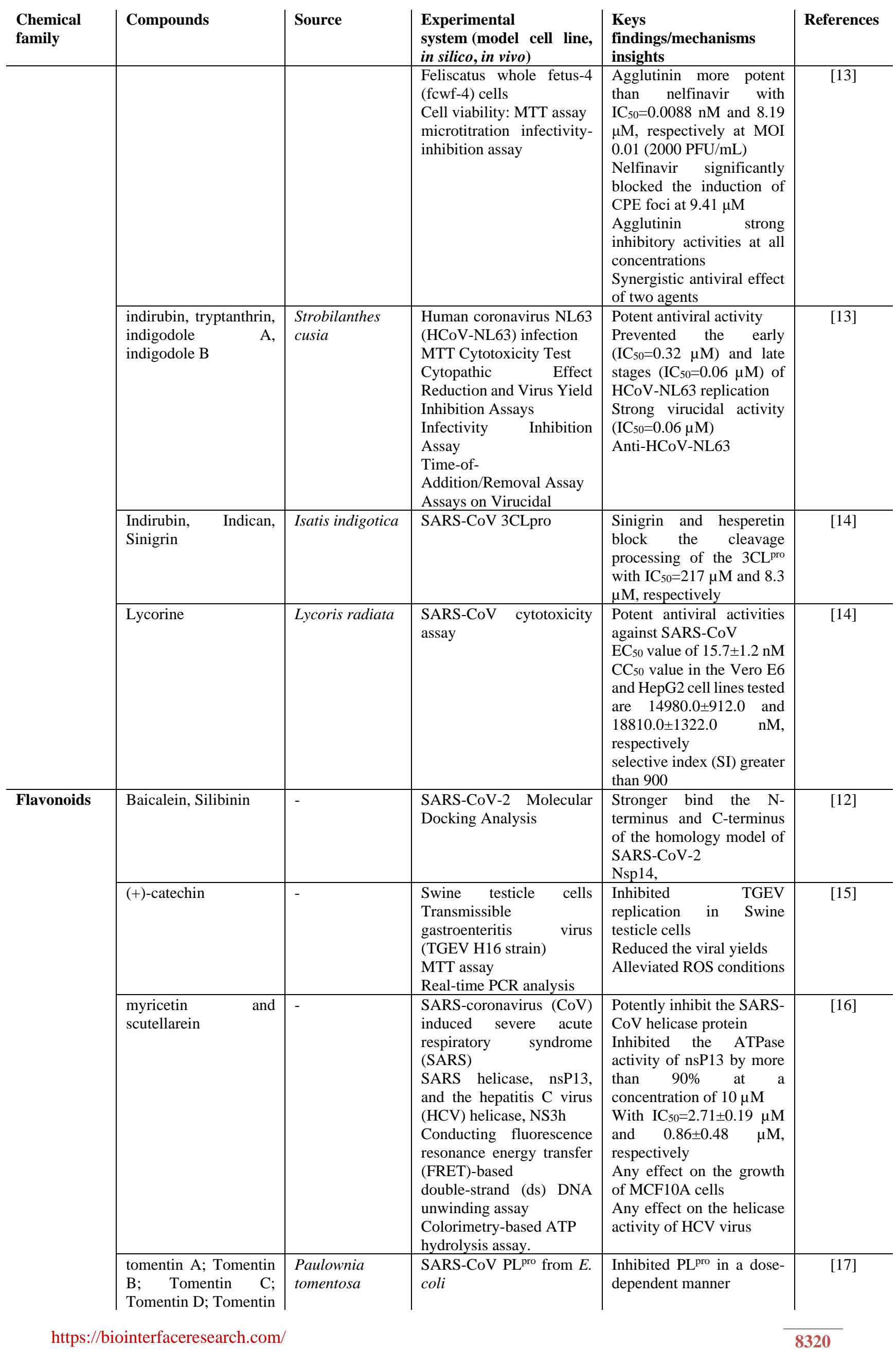




\begin{tabular}{|c|c|c|c|c|c|}
\hline $\begin{array}{l}\text { Chemical } \\
\text { family }\end{array}$ & Compounds & Source & $\begin{array}{l}\text { Experimental } \\
\text { system (model cell line, } \\
\text { in silico, } \text { in vivo) }\end{array}$ & $\begin{array}{l}\text { Keys } \\
\text { findings/mechanisms } \\
\text { insights }\end{array}$ & References \\
\hline & $\begin{array}{ll}\text { E; } & \text { 3'-O- } \\
\text { methyldiplacol; } & 4 \text { '-O- } \\
\text { methyldiplacol; } & \text { 3'-O- } \\
\text { methyldiplacone; 4'-O- } \\
\text { methyldiplacone; } \\
\text { mimulone; diplacone; } \\
\text { 6- geranyl-4',5,7- } \\
\text { trihydroxy-3',5'- } \\
\text { dimethoxyflavanone } \\
\end{array}$ & & $\begin{array}{ll}\text { SARS-CoV } & \text { PLpro } \\
\text { inhibition assay } & \end{array}$ & $\begin{array}{l}\mathrm{IC}_{50} \text { raging between } 5.0 \\
\text { and } 14.4 \mu \mathrm{M} \text {. }\end{array}$ & \\
\hline & ACA, Galangin & Curcuma sp. & $\begin{array}{l}\text { Molecular docking using } \\
\text { the MOE } 2010 \text { program } \\
\text { SARS-CoV-2 marker } \\
\text { protein, RBD-S, PD- } \\
\text { ACE2, and SARS-cov-2 } \\
\text { protease }\end{array}$ & $\begin{array}{l}\text { Highest affinity to bind the } \\
\text { receptors } \\
\text { Exhibited lowest energy } \\
\text { binding with docking score } \\
\text { of }-13.51,-9.61 \text {, and }-9.50 \\
\text { to the respected receptor of } \\
\text { SARS-CoV-2 protease } \\
\text { (6LU7), Spike } \\
\text { glycoprotein-RBD } \\
\text { (6LXT), and PD-ACE2 } \\
(6 \mathrm{VW} 1) \\
\text { Better interaction to the } \\
\text { SARS-CoV-2 protease } \\
\text { compared to lopinavir } \\
\text { Better interaction to Spike- } \\
\text { RBD compared to } \\
\text { nafamostat }\end{array}$ & [18] \\
\hline & $\begin{array}{l}\text { Tangeretin, } \\
\text { Hesperetin, Nobiletin, } \\
\text { Hesperidin, } \\
\text { Naringenin, }\end{array}$ & $\begin{array}{l}\text { Caesalpinia } \\
\text { sappan }\end{array}$ & $\begin{array}{l}\text { Molecular docking using } \\
\text { the MOE } 2010 \text { program } \\
\text { SARS-CoV-2 marker } \\
\text { protein, RBD-S, PD- } \\
\text { ACE2, and SARS-CoV-2 } \\
\text { protease }\end{array}$ & $\begin{array}{l}\text { Highest affinity to bind the } \\
\text { receptors } \\
\text { Exhibited lowest energy } \\
\text { binding with docking score } \\
\text { of }-13.51,-9.61 \text {, and }-9.50 \\
\text { to the respected receptor of } \\
\text { SARS-CoV-2 protease } \\
\text { (6LU7), Spike } \\
\text { glycoprotein-RBD } \\
\text { (6LXT), and PD-ACE2 } \\
\text { (6VW1) } \\
\text { Better interaction to the } \\
\text { SARS-CoV-2 protease } \\
\text { compared to lopinavir } \\
\text { Better interaction to Spike- } \\
\text { RBD compared to } \\
\text { nafamostat }\end{array}$ & [18] \\
\hline & $\begin{array}{l}\text { naringenin, naringin, } \\
\text { hesperetin, hesperidin, } \\
\text { neohesperidin, } \\
\text { nobiletin }\end{array}$ & $\begin{array}{l}\text { Citrus } \\
\text { aurantium } \\
\text { Citrus grandis } \\
\text { Citrus reticulata }\end{array}$ & $\begin{array}{l}\text { LC-MS technique for } \\
\text { analyzed six flavonoids } \\
\text { Molecular docking } \\
\text { Binding affinity of } \\
\text { flavonoids to bind } \\
\text { Angiotensin-Converting } \\
\text { enzyme 2(ACE 2) }\end{array}$ & $\begin{array}{l}\text { Stronger binding affinity } \\
\text { the ACE2. } \\
\text { Naringin had highest } \\
\text { binding activity to the } \\
\text { ACE2 enzyme Docking } \\
\text { energy of }-6.85 \mathrm{kcal} / \mathrm{mol} \\
\text { The docking energy of } \\
\text { naringin, hesperetin and } \\
\text { narigenin binding to ACE2 } \\
\text { were comparable with } \\
\text { chloroquine. }\end{array}$ & [19] \\
\hline & Hesperetin, Daidzein & Isatis indigotica & $\begin{array}{l}\text { SARS-CoV 3CL pro } \\
\text { cell-free assays } \\
\text { cell-based cleavage assays }\end{array}$ & $\begin{array}{l}\text { Sinigrin and hesperetin } \\
\text { blocked the cleavage } \\
\text { processing of the } 3 \mathrm{CL}^{\text {ro }} \\
\text { with } \mathrm{IC}_{50}=217 \mu \mathrm{M} \text { and } 8.3 \\
\mu \mathrm{M} \text { respectively }\end{array}$ & {$[14]$} \\
\hline & $\begin{array}{l}\text { kaempferol, morin, } \\
\text { herbacetin, rhoifolin, } \\
\text { pectolinarin, }\end{array}$ & - & $\begin{array}{l}\text { SARS-CoV 3CL pro } \\
\text { Studied interaction of the } \\
\text { three flavonoids using a } \\
\text { tryptophan-based } \\
\text { fluorescence method } \\
\text { induced-fit docking } \\
\text { analysis }\end{array}$ & $\begin{array}{l}\text { Efficiently blocked the } \\
\text { enzymatic activity of } \\
\text { SARS-CoV 3CL } \\
\text { ICro } 50 \text { of SARS-CoV } 3 \mathrm{CLL}^{\text {pro }} \\
\text { inhibitory activity }=33.17 \text {, } \\
27.45 \text {, and } 37.78 \mu \mathrm{M} \text {, } \\
\text { respectively }\end{array}$ & [20] \\
\hline
\end{tabular}




\begin{tabular}{|c|c|c|c|c|c|}
\hline \multirow[t]{4}{*}{$\begin{array}{l}\text { Chemical } \\
\text { family }\end{array}$} & \multirow[t]{2}{*}{ Compounds } & \multirow[t]{2}{*}{ Source } & $\begin{array}{l}\text { Experimental } \\
\text { system (model cell line, } \\
\text { in silico, in vivo) }\end{array}$ & \multirow[t]{2}{*}{$\begin{array}{l}\text { Keys } \\
\text { findings/mechanisms } \\
\text { insights }\end{array}$} & \multirow[t]{2}{*}{ References } \\
\hline & & & 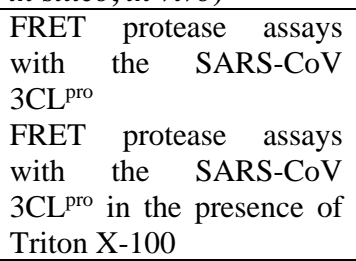 & & \\
\hline & $\begin{array}{l}\text { Quercetin, daidzein, } \\
\text { puerarin, } \\
\text { epigallocatechin, } \\
\text { epigallocatechin } \\
\text { gallate, gallocatechin } \\
\text { gallate, ampelopsin }\end{array}$ & Pichia pastoris & $\begin{array}{l}\text { SARS-CoV } \quad \text { 3C-like } \\
\text { protease (SARS-CoV } \\
\text { 3CL }{ }^{\text {pro }} \text { ) } \\
\text { Molecular docking } \\
\text { Inhibition assay }\end{array}$ & $\begin{array}{l}\text { Good inhibition toward } \\
3 \mathrm{CL}^{\text {pro }} \text { with } \mathrm{IC}_{50} \text { values of } \\
73,73 \text {, and } 47 \mu \mathrm{M} \text {, } \\
\text { respectively } \\
\text { gallocatechin gallate } \\
\text { showed a competitive } \\
\text { inhibition pattern with } \mathrm{K}_{\mathrm{i}} \\
\text { value of } 25 \pm 1.7 \mu \mathrm{M} \\
\text { gallocatechin gallate } \\
\text { displayed a binding energy } \\
\text { of }-14 \mathrm{kcal} \mathrm{mol}^{-1} \text { to the } \\
\text { active site of } 3 \mathrm{CL}^{\text {pro }}\end{array}$ & [21] \\
\hline & $\begin{array}{l}\text { amentoflavone, } \\
\text { bilobetin, ginkgetin, } \\
\text { sciadopitysin }\end{array}$ & Torreyanucifera & $\begin{array}{l}\text { SARS-CoV 3CL pro } \\
\text { Molecular docking study } \\
\text { Enzymatic assays } \\
\text { SARS 3C-like protease } \\
\left(3 \mathrm{CL}^{\text {pro }}\right) \text { inhibition assay }\end{array}$ & $\begin{array}{l}\text { Most potent } 3 \mathrm{CL}^{\text {pro }} \\
\text { inhibitory effect }\left(\mathrm{IC}_{50}=8.3\right. \\
\mu \mathrm{M})\end{array}$ & [22] \\
\hline \multirow[t]{4}{*}{ Terpenoids } & Limonene & Elettaria & $\begin{array}{l}\text { SARS-CoV-2 Protease } \\
\text { Molecular Docking } \\
\text { Analysis using MVD } \\
\text { (molegro virtual docker) } \\
\text { software. }\end{array}$ & $\begin{array}{l}\text { Stronger bond and high } \\
\text { affinity to protease }\end{array}$ & [11] \\
\hline & Thymol & $\begin{array}{l}\text { Mentha } \\
\text { pulegium }\end{array}$ & $\begin{array}{lr}\text { SARS-CoV-2 } & \\
\text { Protease } & \\
\text { Molecular } & \text { Docking } \\
\text { Analysis using } & \text { MVD } \\
\text { (molegro virtual } & \text { docker) } \\
\text { software. } & \end{array}$ & $\begin{array}{l}\text { Stronger bond and high } \\
\text { affinity to protease }\end{array}$ & [11] \\
\hline & $\begin{array}{l}\text { ferruginol, } \\
\text { dehydroabieta-7-one, } \\
\text { sugiol,[8 } \beta \text { - } \\
\text { hydroxyabieta- } \\
9(11), 13 \text {-dien-12- } \\
\text { one)], 6,7- } \\
\text { dehydroroyleanone, } \\
\text { pinusolidic acid, } \alpha \text { - } \\
\text { cadinol }\end{array}$ & $\begin{array}{l}\text { Chamaecyparis } \\
\text { obtuse var } \\
\text { formosana }\end{array}$ & $\begin{array}{l}\text { SARS-CoV-induced } \\
\text { cytopathogenic effect on } \\
\text { Vero E6 cells } \\
\text { Cell-Based Assay } \\
\text { Utilizing CPE on Vero E6 } \\
\text { Cells via SARS-CoV } \\
\text { Infection } \\
\text { cell-based assay } \\
\text { Cytotoxic Effects: MTT } \\
\text { assay } \\
\text { Inhibition of Viral } \\
\text { Replication in SARS- } \\
\text { CoV-Infected Vero E6 } \\
\text { Cells } \\
\text { SARS-CoV 3CL Protease } \\
\text { Inhibition Assay } \\
\text { Computer Modeling of } \\
\text { SARS-CoV 3CL Protease } \\
\text { Inhibition. }\end{array}$ & $\begin{array}{l}\text { Significant levels (++ to } \\
+++) \text { of anti-SARS-CoV } \\
\text { activity at concentrations } \\
\text { between } 3.3 \text { and } 10 \mu \mathrm{M} \text {. } \\
\text { Significant inhibition on } \\
\text { 3CL protease }\end{array}$ & [23] \\
\hline & $\begin{array}{l}\text { diacetoxyabieta- } \\
\text { 6,8,11,13-tetraene, } \\
\text { cedrane-3 } \beta, 12 \text {-diol, } \\
\text { betulonic acid }\end{array}$ & $\begin{array}{l}\text { Juniperus } \\
\text { formosana }\end{array}$ &  & $\begin{array}{l}\text { Significant levels (++ to } \\
+++) \text { of anti-SARS-CoV } \\
\text { activity at concentrations } \\
\text { between } 3.3 \text { and } 10 \mu \mathrm{M} \text {. } \\
\text { Significant inhibition on } \\
\text { 3CL protease }\end{array}$ & [23] \\
\hline
\end{tabular}




\begin{tabular}{|c|c|c|c|c|c|}
\hline $\begin{array}{l}\text { Chemical } \\
\text { family }\end{array}$ & Compounds & Source & $\begin{array}{l}\text { Experimental } \\
\text { system (model cell line, } \\
\text { in silico, in vivo) }\end{array}$ & $\begin{array}{l}\text { Keys } \\
\text { findings/mechanisms } \\
\text { insights }\end{array}$ & References \\
\hline & & & $\begin{array}{l}\text { CoV-Infected Vero E6 } \\
\text { Cells } \\
\text { SARS-CoV 3CL Protease } \\
\text { Inhibition Assay } \\
\text { Computer Modeling of } \\
\text { SARS-CoV 3CL Protease } \\
\text { Inhibition. }\end{array}$ & & \\
\hline & $\begin{array}{l}\text { cryptojaponol, } 7 \beta- \\
\text { hydroxydeoxycryptoja } \\
\text { ponol }\end{array}$ & $\begin{array}{l}\text { Cryptomeria } \\
\text { japonica }\end{array}$ & $\begin{array}{l}\text { SARS-CoV-induced } \\
\text { cytopathogenic effect on } \\
\text { Vero E6 cells } \\
\text { Cell-Based Assay } \\
\text { Utilizing CPE on Vero E6 } \\
\text { Cells via SARS-CoV } \\
\text { Infection } \\
\text { cell-based assay } \\
\text { Cytotoxic Effects: MTT } \\
\text { assay } \\
\text { Inhibition of Viral } \\
\text { Replication in SARS- } \\
\text { CoV-Infected Vero E6 } \\
\text { Cells } \\
\text { SARS-CoV 3CL Protease } \\
\text { Inhibition Assay } \\
\text { Computer Modeling of } \\
\text { SARS-CoV 3CL Protease } \\
\text { Inhibition. }\end{array}$ & $\begin{array}{l}\text { SARS-CoV activity at } \\
\text { concentrations between } \\
3.3 \text { and } 10 \mu \mathrm{M} \text {. } \\
\text { Significant inhibition on } \\
\text { 3CL protease }\end{array}$ & [23] \\
\hline & Betulin & $\begin{array}{l}\text { Strobilanthes } \\
\text { cusia }\end{array}$ & $\begin{array}{l}\text { Human coronavirus NL63 } \\
\text { (HCoV-NL63) infection } \\
\text { MTT Cytotoxicity Test } \\
\text { Cytopathic Effect } \\
\text { Reduction and Virus Yield } \\
\text { Inhibition Assays } \\
\text { Infectivity Inhibition } \\
\text { Assay } \\
\text { Time-of- } \\
\text { Addition/Removal Assay } \\
\text { Assays on Virucidal } \\
\text { Activity }\end{array}$ & $\begin{array}{l}\text { Potent antiviral activity } \\
\text { Prevented the early } \\
\left(\mathrm{IC}_{50}=0.32 \mu \mathrm{M}\right) \text { and late } \\
\text { stages }\left(\mathrm{IC}_{50}=0.06 \mu \mathrm{M}\right) \text { of } \\
\text { HCoV-NL63 replication } \\
\text { Strong virucidal activity } \\
\left(\mathrm{IC}_{50}=0.06 \mu \mathrm{M}\right) \\
\text { Anti-HCoV-NL63 activity } \\
\text { with IC } 50 \text { values of } 1.52 \\
\mu \mathrm{M} \text { and } 0.30 \mu \mathrm{M} \text { in LCC- } \\
\text { MK2 and Calu-3 cells, } \\
\text { respectively }\end{array}$ & [13] \\
\hline & $\begin{array}{l}\text { Betulin, } \\
\text { hydroxyferruginol, } \\
\text { hinokiol, ferruginol, } \\
\text { 18-oxoferruginol, O- } \\
\text { acetyl-18- } \\
\text { hydroxyferruginol, } \\
\text { methyl } \\
\text { dehydroabietate, } \\
\text { isopimaric acid, } \\
\text { kayadiol }\end{array}$ & $\begin{array}{l}\text { Torreya } \\
\text { nucifera }\end{array}$ & $\begin{array}{l}\text { SARS-CoV 3CL pro } \\
\text { Molecular docking study } \\
\text { Enzymatic assays } \\
\text { SARS 3C-like protease } \\
\left(3 \mathrm{CL}^{\text {pro }}\right) \text { inhibition assay }\end{array}$ & $\begin{array}{l}\text { Most potent } 3 \mathrm{CL}^{\text {pro }} \\
\text { inhibitory effect }\left(\mathrm{IC}_{50}=8.3\right. \\
\mu \mathrm{M})\end{array}$ & [22] \\
\hline Tanins & $\begin{array}{l}\text { Phloroglucinol, } \\
\text { triphloretol A, eckol, } \\
\text { dioxinodehydroeckol, } \\
\text { 2-phloroeckol, } \\
\text { phloroeckol, } \\
\text { fucodiphloroethol G, } \\
\text { dieckol, } \\
\text { phlorofucofuroeckol A }\end{array}$ & Ecklonia cava & $\begin{array}{l}\text { SARS-CoV 3CL } \\
\text { SARS-CoV 3CL pro trans- } \\
\text { cleavage assay } \\
\text { SARS-CoV 3CL pro cis- } \\
\text { cleavage assay } \\
\text { Real-time analysis of } \\
\text { ligand interaction with } \\
\text { SARS-CoV 3CL pro by } \\
\text { surface plasmon resonance } \\
\text { (SPR) docking } \\
\text { Molecular } \\
\text { simulation study }\end{array}$ & 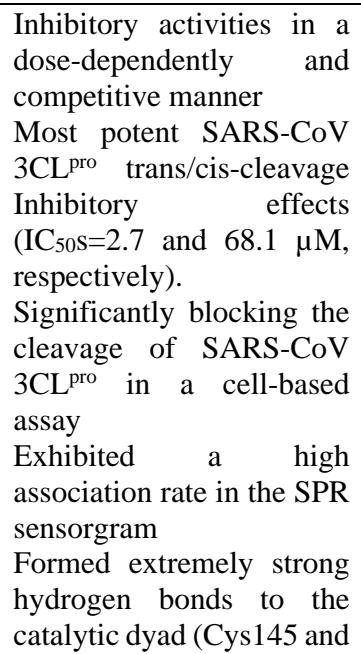 & [24] \\
\hline
\end{tabular}




\begin{tabular}{|c|c|c|c|c|c|}
\hline \multirow[t]{4}{*}{$\begin{array}{l}\text { Chemical } \\
\text { family }\end{array}$} & Compounds & Source & $\begin{array}{l}\text { Experimental } \\
\text { system (model cell line, } \\
\text { in silico, in vivo) }\end{array}$ & $\begin{array}{l}\text { Keys } \\
\text { findings/mechanisms } \\
\text { insights }\end{array}$ & References \\
\hline & & & & $\begin{array}{l}\text { His } 41) \text { of the SARS-CoV } \\
3 \mathrm{CL}^{\text {pro }}\end{array}$ & \\
\hline & $\begin{array}{l}\text { Phloroglucinol, Eckol, } \\
\text { 7-Phloroeckol, } \\
\text { Phlorofucofuroeckol, } \\
\text { Dieckol }\end{array}$ & Ecklonia cava & $\begin{array}{l}\text { Porcine epidemic diarrhea } \\
\text { virus (PEDV) } \\
\text { MTT assay } \\
\text { Antiviral assay } \\
\text { Hemagglutination } \\
\text { inhibition (HI) assay } \\
\text { Real-time PCR analysis } \\
\text { Western blot analysis } \\
\text { Confocal fluorescence } \\
\text { imaging }\end{array}$ & $\begin{array}{l}\text { In the simultaneous- } \\
\text { treatment assay, } \\
\mathrm{IC}_{50}=10.8 \pm 1.4 \mu \mathrm{M} \\
\text { In post-treatment assay, } \\
\mathrm{IC}_{50}=12.2 \pm 2.8 \mu \mathrm{M} \\
\text { Blocked the binding of } \\
\text { viral spike protein to sialic } \\
\text { acids at less than } 36.6 \mu \mathrm{M}\end{array}$ & [25] \\
\hline & $\begin{array}{l}\text { geraniin, } \\
\text { tellimagradin, } \\
\text { punicalin, castalin, } \\
\text { strictinin, granatin A, } \\
\text { pedunculagin, } \\
\text { casuarinin, tercatain, } \\
\text { bicornin }\end{array}$ & - & $\begin{array}{lr}\text { SARS-CoV-2 } & \\
\text { Molecular } & \text { docking } \\
\text { modeling } & \\
\text { Molecular } & \text { Operating } \\
\text { Environment } & \text { (MOE } \\
\text { v2009) software } & \end{array}$ & $\begin{array}{l}\text { Interacted with the } \\
\text { receptor binding site and } \\
\text { catalytic dyad (Cys145 and } \\
\text { His41) of SARS-CoV-2 } \\
\text { Successfully inhibit the } \\
\text { protease enzyme of SARS- } \\
\text { CoV-2 }\end{array}$ & [26] \\
\hline \multirow[t]{4}{*}{ Quinone } & Hypericin, Idarubicin & - & $\begin{array}{ll}\text { SARS-CoV-2 } & \\
\text { Molecular } & \text { Docking } \\
\text { Analysis } & \end{array}$ & $\begin{array}{l}\text { Stronger bind the } \mathrm{N}- \\
\text { terminus and C-terminus } \\
\text { of the homology model of } \\
\text { the SARS-CoV-2 } \\
\text { Nsp14, }\end{array}$ & [12] \\
\hline & $\begin{array}{l}\text { Emodin, Promazine, } \\
\text { Rhein, 1,4-bis-(1- } \\
\text { anthraquinonylamino)- } \\
\text { anthraquinone }\end{array}$ & $\begin{array}{l}\text { Rheum } \\
\text { officinale } \\
\text { and Polygonum } \\
\text { multiflorum, }\end{array}$ & $\begin{array}{l}\text { SARS-CoV S } \\
\text { Biotinylated ELISA } \\
\text { Immunofluorescence } \\
\text { assay (IFA) } \\
\text { 3-(4,5-Dimethylthiazol-2- } \\
\text { yl)-2,5- } \\
\text { diphenyltetrazolium } \\
\text { bromide (MTT) assay }\end{array}$ & $\begin{array}{l}\text { Significantly blocked the } S \\
\text { protein and ACE2 } \\
\text { interaction } \\
\text { Inhibited the infectivity of } \\
\mathrm{S} \text { protein-pseudotyped } \\
\text { retrovirus to Vero E6 cells. } \\
\text { Percent inhibition of } \\
\text { emodin at } 50 \mu \mathrm{M} \text { was } \\
94.12 \pm 5.90 \%\end{array}$ & [27] \\
\hline & Emodin & - & $\begin{array}{l}\text { Coronavirus } \mathrm{HCoV}-\mathrm{OC} 43 \\
\text { Rhabdomyosarcoma cells } \\
\text { Measurement of virus } \\
\text { using real-time PCR } \\
\text { Plaque reduction assay }\end{array}$ & $\begin{array}{l}\text { Inhibited the 3a ion } \\
\text { channel of coronavirus } \\
\text { SARS-CoV and HCoV- } \\
\text { OC43 as well as virus } \\
\text { release from HCoV-OC43 } \\
\mathrm{K} 1 / 2=20 \mu \mathrm{M}\end{array}$ & [28] \\
\hline & Aloeemodin & Isatis indigotica & $\begin{array}{l}\text { SARS-CoV 3CL pro } \\
\text { cell-free assays } \\
\text { cell-based cleavage assays }\end{array}$ & $\begin{array}{l}\text { Sinigrin and hesperetin } \\
\text { blocked the cleavage } \\
\text { processing of the } 3 \mathrm{CL}^{\text {pro }} \\
\text { with } \mathrm{IC}_{50}=217 \mu \mathrm{M} \text { and } 8.3 \\
\mu \mathrm{M} \text {, respectively }\end{array}$ & [14] \\
\hline \multirow[t]{2}{*}{ Coumarin } & Coumarin & $\begin{array}{l}\text { Glycyrrhiza } \\
\text { glabra }\end{array}$ & $\begin{array}{lr}\text { SARS-CoV-2 } & \\
\text { Protease } & \\
\text { Molecular } & \text { Docking } \\
\text { Analysis using } & \text { MVD } \\
\text { (molegro virtual } & \text { docker) } \\
\text { software. } & \\
\end{array}$ & $\begin{array}{l}\text { Stronger bond and high } \\
\text { affinity to protease }\end{array}$ & [11] \\
\hline & $\begin{array}{l}\text { psoralen, bergapten, } \\
\text { xanthotoxin, } \\
\text { isopimpinellin }\end{array}$ & Angelica keiskei & 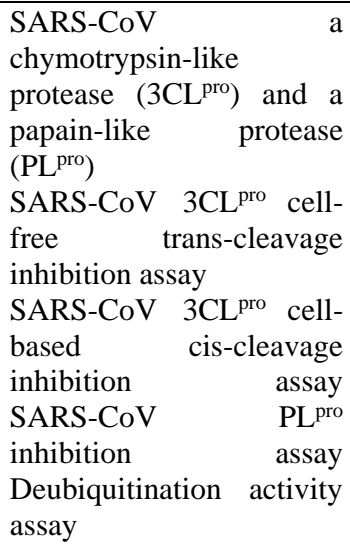 & $\begin{array}{l}\text { Exhibited the most potent } \\
3 \mathrm{CL}^{\text {pro }} \text { and PL }{ }^{\text {pro }} \text { inhibitory } \\
\text { activity with IC } \mathrm{C}_{50} \text { values of } \\
11.4 \text { and } 1.2 \mu \mathrm{M} \text {. } \\
\text { Inhibited cell-free trans- } \\
\text { cleavage of SARS-CoV } \\
3 \mathrm{CL}^{\text {pro }} \text { with IC } 50=11.4 \pm 1.4 \\
\mu \mathrm{M} \\
\text { Inhibited cell-based cis- } \\
\text { cleavage activities of } \\
\text { SARS-CoV 3CL } 3 \text { pro with } \\
\text { IC50=7.1 } \pm 0.8 \mu \mathrm{M} \\
\text { Exhibited the most potent } \\
\text { activity with a selectivity }\end{array}$ & [29] \\
\hline
\end{tabular}




\begin{tabular}{|c|c|c|c|c|c|}
\hline \multirow[t]{2}{*}{$\begin{array}{l}\text { Chemical } \\
\text { family }\end{array}$} & \multirow[t]{2}{*}{ Compounds } & \multirow[t]{2}{*}{ Source } & $\begin{array}{l}\text { Experimental } \\
\text { system (model cell line, } \\
\text { in silico, in vivo) }\end{array}$ & $\begin{array}{l}\text { Keys } \\
\text { findings/mechanisms } \\
\text { insights }\end{array}$ & \multirow[t]{2}{*}{ References } \\
\hline & & & $\begin{array}{l}\text { DeISGylation activity } \\
\text { assay } \\
\text { Chymotrypsin activity } \\
\text { In silico molecular } \\
\text { simulation study } \\
\text { AutoDock version } 3.0 .5 \\
\text { using AutoDock version } \\
3.0 .5\end{array}$ & $\begin{array}{l}\text { index }\left(\mathrm{SI} 1 / 4 \quad \mathrm{CC}_{50} / \mathrm{EC}_{50}\right) \\
\text { value of } 9.2 \text {. } \\
\text { IC }_{50} \text { of Deubiquitination } \\
\text { activity }=2.6 \pm 0.7 \mu \mathrm{M} \\
\text { IC }_{50} \text { of DeISGylation } \\
\text { activity }=5.2 \pm 0.4 \mu \mathrm{M}\end{array}$ & \\
\hline $\begin{array}{l}\text { Steroidal } \\
\text { alkaloids }\end{array}$ & $\begin{array}{l}\text { Verticinone 3-beta-D- } \\
\text { glucoside, Imperialine- } \\
\text { 3- } \beta \text {-D-glucoside, } \\
\text { pseudojervine, } \\
\text { zhebeininoside, } \\
\text { Veratroylzygadenine, } \\
\text { Zhebeinone-3- } \beta \text {-D- } \\
\text { glucoside, } \\
\text { Mulberroside } \\
\text { Hupehenisine, E, } \\
\text { verdineverticinone-3- } \\
\beta-D-\text { glucoside, (E)- } \\
\text { Resveratrol 3,5-O- } \beta- \\
\text { diglucoside, peimisine, } \\
\text { peimisine, 15-O-(2- } \\
\text { Methylbutanoyl)-3-O- } \\
\text { veratroylprotoverine, } \\
\text { 3-Acetylzygadenine, } \\
\text { Polydatin IV, } \\
\text { Piceatannol 3,4'-di- } \beta- \\
\begin{array}{l}\text { D-glucopyranoside, } \\
\text { puqietinone }\end{array}\end{array}$ & $\begin{array}{l}\text { "Agsirga" } \\
\text { species }\end{array}$ & $\begin{array}{l}\text { SARS-CoV-2 } \\
\text { HPLC-Q-Exactive high- } \\
\text { resolution } \\
\text { spectrometry } \\
\text { molecular } \\
\text { technology docking } \\
\text { AutoDock molecular } \\
\text { docking software }\end{array}$ & $\begin{array}{l}\text { blocked the binding of } \\
\text { ACE2 and SARS-CoV-2 } \\
\text { S-protein at the molecular } \\
\text { level }\end{array}$ & [30] \\
\hline \multirow[t]{2}{*}{ Steroids } & Sitosterol & $\begin{array}{l}\text { Strobilanthes } \\
\text { cusia }\end{array}$ & $\begin{array}{l}\text { Human coronavirus NL63 } \\
\text { (HCoV-NL63) infection } \\
\text { MTT Cytotoxicity Test } \\
\text { Cytopathic Effect } \\
\text { Reduction and Virus Yield } \\
\text { Inhibition Assays } \\
\text { Infectivity Inhibition } \\
\text { Assay } \\
\text { Time-of- } \\
\text { Addition/Removal Assay } \\
\text { Assays on Virucidal } \\
\text { Activity }\end{array}$ & $\begin{array}{l}\text { Potent antiviral activity } \\
\text { Prevented the early } \\
\left(\mathrm{IC}_{50}=0.32 \mu \mathrm{M}\right) \text { and late } \\
\text { stages }\left(\mathrm{IC}_{50}=0.06 \mu \mathrm{M}\right) \text { of } \\
\text { HCoV-NL63 replication } \\
\text { Strong virucidal activity } \\
(\text { IC } 50=0.06 \mu \mathrm{M}) \\
\text { Anti-HCoV-NL63 activity } \\
\text { with IC } 50 \text { values of } 1.52 \\
\mu \mathrm{M} \text { and } 0.30 \mu \mathrm{M} \text { in LCC- } \\
\text { MK2 and Calu-3 cells, } \\
\text { respectively }\end{array}$ & [13] \\
\hline & $\begin{array}{l}\text { Glycyrrhizic acid } \\
\text { derivatives, }\end{array}$ & $\begin{array}{l}\text { Glycyrrhiza } \\
\text { radix }\end{array}$ & $\begin{array}{l}\text { SARS-CoV strain FFM1 } \\
\text { Immunocytochemical } \\
\text { Staining of Viral Antigens } \\
\text { and } \\
\text { Visual CPE Assay } \\
\text { Determination of } \\
\text { Cytotoxicity using MTT } \\
\text { assay }\end{array}$ & $\begin{array}{l}\text { Seven derivatives } \\
\text { inhibited SARS-CoV } \\
\text { replication at lower } \\
\text { concentrations compared } \\
\text { to GL } \\
\text { The introduction of } \mathrm{N}- \\
\text { acetylgycosamine into the } \\
\text { glycoside chain of GL (1) } \\
\text { increased the anti SARS- } \\
\text { CoV activity about } 9 \text { times } \\
\text { compared to GL } \\
\text { Compound } 11 \text { more active } \\
\text { against SARS-CoV with } \\
\text { an EC } 50=5 \pm 3 \mu \mathrm{M} \\
\text { High cytotoxicity effect } \\
\text { with CC } 50=15 \pm 3 \mu \mathrm{M} \\
\text { Selectivity index }(\mathrm{SI})=3 \\
\text { The immunocytochemical } \\
\text { staining showed >99\% } \\
\text { suppression of viral } \\
\text { antigen expression }\end{array}$ & [31] \\
\hline
\end{tabular}




\begin{tabular}{|c|c|c|c|c|c|}
\hline $\begin{array}{l}\text { Chemical } \\
\text { family }\end{array}$ & Compounds & Source & $\begin{array}{l}\text { Experimental } \\
\text { system (model cell line, } \\
\text { in silico, in vivo) }\end{array}$ & $\begin{array}{l}\text { Keys } \\
\text { findings/mechanisms } \\
\text { insights }\end{array}$ & References \\
\hline & Beta-sitosterol & Isatis indigotica & $\begin{array}{l}\text { SARS-CoV 3CL } \\
\text { cell-free assays } \\
\text { cell-based cleavage assays }\end{array}$ & $\begin{array}{l}\text { Sinigrin and hesperetin } \\
\text { blocked the cleavage } \\
\text { processing of the } 3 \mathrm{CL}^{\text {pro }} \\
\text { with } \mathrm{IC}_{50}=217 \mu \mathrm{M} \text { and } 8.3 \\
\mu \mathrm{M} \text {, respectively }\end{array}$ & [14] \\
\hline Allyls & DiallylDisulfide & Allium sativum & $\begin{array}{lr}\text { SARS-CoV-2 } & \\
\text { Protease } & \\
\text { Molecular } & \text { Docking } \\
\text { Analysis using } & \text { MVD } \\
\text { (molegro virtual } & \text { docker) } \\
\text { software. } & \end{array}$ & $\begin{array}{l}\text { Stronger bond and high } \\
\text { affinity to protease }\end{array}$ & [11] \\
\hline \multirow[t]{2}{*}{ Stilbenes } & Curcumin & Curcuma longa & $\begin{array}{l}\text { SARS-CoV-2 } \\
\text { Protease } \\
\text { Molecular } \quad \text { Docking } \\
\text { Analysis using } \text { MVD } \\
\text { (molegro virtual docker) } \\
\text { software. }\end{array}$ & $\begin{array}{l}\text { Stronger bond and high } \\
\text { affinity with protease }\end{array}$ & [11] \\
\hline & Curcumin, DMC & Citrus sp. & $\begin{array}{l}\text { Molecular docking using } \\
\text { the MOE } 2010 \text { program } \\
\text { SARS-CoV-2 marker } \\
\text { protein, RBD-S, PD- } \\
\text { ACE2, and SARS-CoV-2 } \\
\text { protease }\end{array}$ & $\begin{array}{l}\text { Highest affinity to bind the } \\
\text { receptors } \\
\text { Exhibited lowest energy } \\
\text { binding with docking score } \\
\text { of }-13.51,-9.61 \text {, and }-9.50 \\
\text { to the respected receptor of } \\
\text { SARS-CoV-2 protease } \\
\text { (6LU7), Spike } \\
\text { glycoprotein-RBD } \\
\text { (6LXT), and PD-ACE2 } \\
\text { (6VW1) } \\
\text { Better interaction to the } \\
\text { SARS-CoV-2 protease } \\
\text { compared to lopinavir } \\
\text { Better interaction to Spike- } \\
\text { RBD compared to } \\
\text { nafamostat }\end{array}$ & {$[18]$} \\
\hline $\begin{array}{l}\text { Phenylpropan } \\
\text { oids }\end{array}$ & Verbascoside & $\begin{array}{l}\text { Stachys } \\
\text { schtschegleevi }\end{array}$ & $\begin{array}{l}\text { SARS-CoV-2 } \\
\text { Protease } \\
\text { Molecular Docking } \\
\text { Analysis using MVD } \\
\text { (molegro virtual dockers) } \\
\text { software }\end{array}$ & $\begin{array}{l}\text { Stronger bond and high } \\
\text { affinity to protease }\end{array}$ & [11] \\
\hline Glucosides & Glucuronic acid & \begin{tabular}{|l|} 
Astraglus \\
gossypinus
\end{tabular} & $\begin{array}{l}\text { SARS-CoV-2 } \\
\text { Protease } \\
\text { Molecular Docking } \\
\text { Analysis using MVD } \\
\text { (molegro virtual dockers) } \\
\text { software } \\
\end{array}$ & $\begin{array}{l}\text { Stronger bond and high } \\
\text { affinity with protease }\end{array}$ & [11] \\
\hline Lignoids & hinokinin, savinin & - & $\begin{array}{l}\text { SARS-CoV-induced } \\
\text { cytopathogenic effect on } \\
\text { Vero E6 cells } \\
\text { Cell-Based Assay } \\
\text { Utilizing CPE on Vero E6 } \\
\text { Cells via SARS-CoV } \\
\text { Infection } \\
\text { cell-based assay } \\
\text { Cytotoxic Effects: MTT } \\
\text { assay } \\
\text { Inhibition of Viral } \\
\text { Replication in SARS- } \\
\text { CoV-Infected Vero E6 } \\
\text { Cells } \\
\text { SARS-CoV 3CL Protease } \\
\text { Inhibition Assay } \\
\text { Computer Modeling of } \\
\text { SARS-CoV 3CL Protease } \\
\text { Inhibition. }\end{array}$ & $\begin{array}{l}\text { Significant levels (++ to } \\
+++) \text { of anti-SARS-CoV } \\
\text { activity at concentrations } \\
\text { between } 3.3 \text { and } 10 \mu \mathrm{M} \text {. } \\
\text { Significant inhibition on } \\
\text { 3CL protease }\end{array}$ & [23] \\
\hline
\end{tabular}




\begin{tabular}{|c|c|c|c|c|c|}
\hline $\begin{array}{l}\text { Chemical } \\
\text { family }\end{array}$ & Compounds & Source & $\begin{array}{l}\text { Experimental } \\
\text { system (model cell line, } \\
\text { in silico, in vivo) }\end{array}$ & $\begin{array}{l}\text { Keys } \\
\text { findings/mechanisms } \\
\text { insights }\end{array}$ & References \\
\hline \multirow[t]{2}{*}{ Tanshinones } & $\begin{array}{l}\text { tanshinone IIA, } \\
\text { tanshinone IIB, methyl } \\
\text { tanshinonate, } \\
\text { cryptotanshinone, } \\
\text { tanshinone } \\
\text { dihydrotanshinone } \\
\text { rosmariquinone }\end{array}$ & $\begin{array}{l}\text { Salvia } \\
\text { miltiorrhiza }\end{array}$ & $\begin{array}{l}\text { SARS-CoV 3CL }{ }^{\text {pro }} \text { and } \\
\text { PL pro viral cysteine } \\
\text { proteases. } \\
\text { SARS-CoV } \\
\text { inhibition assay } \\
\text { SARS-CoV } \\
\text { PL proinhibition assay } \\
\text { Kinetics of SARS-3CL pro } \\
\text { activation, } \\
\text { Analysis of SARS-CoV } \\
\text { 3CL pro and PL }{ }^{\text {pro }} \text { inhibition } \\
\text { progress curves }\end{array}$ & $\begin{array}{l}\text { Tanshinone I (5) exhibited } \\
\text { the most potent nanomolar } \\
\text { level inhibitory activity } \\
\text { toward deubiquitinating } \\
\left(\mathrm{IC}_{50}=0.7 \mu \mathrm{M}\right) \\
\text { Good inhibitors of both } \\
\text { cysteine proteases } \\
\text { Slight activity }\end{array}$ & [32] \\
\hline & $\begin{array}{l}\text { phloroglucinol, } \\
\text { triphloretol A, eckol, } \\
\text { dioxinodehydroeckol, } \\
\text { 2-phloroeckol, } \\
\text { phloroeckol, } \\
\text { fucodiphloroethol G, } \\
\text { dieckol, } \\
\text { phlorofucofuroeckol A }\end{array}$ & $\begin{array}{l}\text { Salvia } \\
\text { miltiorrhiza }\end{array}$ & $\begin{array}{l}\text { SARS-CoV 3CL pro and } \\
\text { PLpro } \\
\text { SARS-CoV viral proteases } \\
\text { inhibition using the FRET } \\
\text { method } \\
\text { SARS-CoV PL pro } \\
\text { deubiquitination assay } \\
\text { SARS-CoV PL pro deIS } \\
\text { Gylation assay }\end{array}$ & $\begin{array}{l}\text { Potent inhibitor of PL } \text { Pro }^{\text {po }} \\
\text { with an } \mathrm{IC}_{50} \text { value of } 3.7 \\
\mu \mathrm{M} \\
\text { inhibited } \\
3 \mathrm{CL}^{\text {pro }} \text { with } \\
\mathrm{IC}_{50}=103.6 \pm 17.4 \mu \mathrm{M} \text { an } \\
\text { Strongly inhibited the } \\
\text { cleavage of both ubiquitin } \\
\text { and ISG15 (IC } 50=7.6 \text { and } \\
8.5 \mu \mathrm{M} \text {, respectively) }\end{array}$ & [33] \\
\hline $\begin{array}{l}\text { Alkylated } \\
\text { chalcones }\end{array}$ & $\begin{array}{ll}\begin{array}{l}\text { isobavachalcone, } \\
\text { hydroxyderricin, }\end{array} & 4- \\
\text { xanthoangelol, } & \\
\text { xanthoangelol } & \mathrm{F}, \\
\text { xanthoangelol } & \mathrm{D}, \\
\text { xanthoangelol } & \mathrm{E}, \\
\text { xanthoangelol } & \mathrm{B}, \\
\text { xanthoangelol } & \mathrm{G}, \\
\text { xanthokeistal A } & \end{array}$ & Angelica keiskei & 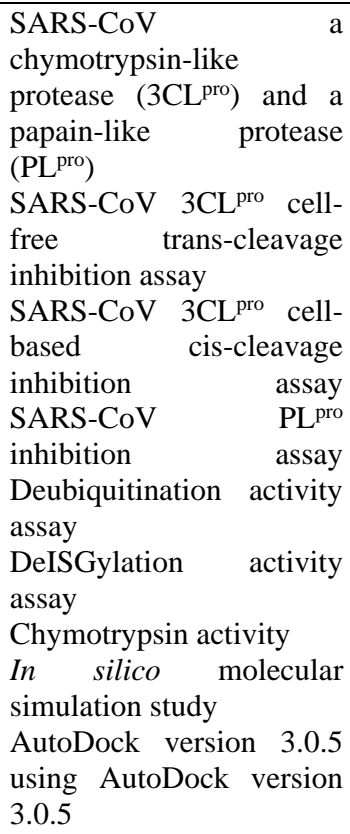 & $\begin{array}{l}\text { Exhibited the most potent } \\
3 \mathrm{CL}^{\text {pro }} \text { and PL Proinhibitory } \\
\text { activity with } \mathrm{IC}_{50} \text { values of } \\
11.4 \text { and } 1.2 \mu \mathrm{M} \text {. } \\
\text { Inhibited cell-free trans- } \\
\text { cleavage of SARS-CoV } \\
3 \mathrm{CL}^{\text {pro }} \text { with } \mathrm{IC}_{50}=11.4 \pm 1.4 \\
\mu \mathrm{M} \\
\text { Inhibited cell-based cis- } \\
\text { cleavage activities of } \\
\text { SARS-CoV } 3 \mathrm{CL}^{\text {pro }} \text { with } \\
\text { IC50=7.1 } \pm 0.8 \mu \mathrm{M} \\
\text { Exhibited the most potent } \\
\text { activity with a selectivity } \\
\text { index (SI } 1 / 4 \text { CC50/EC50) } \\
\text { value of } 9.2 . \\
\text { IC } 50 \text { of Deubiquitination } \\
\text { activity }=2.6 \pm 0.7 \mu \mathrm{M} \\
\text { IC } 50 \text { of DeISGylation } \\
\text { activity }=5.2 \pm 0.4 \mu \mathrm{M}\end{array}$ & [29] \\
\hline
\end{tabular}

2.1.1. Mechanism insights of natural alkaloids anti-SARS-CoV-2.

Some researchers have reported an important antiviral activity of alkaloids such as Capsaicin, Bromocriptine, Celsentri, Delavirdine, Emend, Golvatinib, Maraviroc, Olysio, Saquinavir, Sovaprevir, Tanespimycin, Agglutinin, nelfinavir, indirubin, tryptanthrin, indigodole A, indigodole B, Indirubin, Indican, Sinigrin, and Lycorine (Figure 1 and Table 1). Among them, Liu et al. [12] demonstrated, in silico, that Saquinavir and Bromocriptine could bind to the N-terminus and C-terminus of the homology model of SARS-CoV-2 Nsp14 which is important for replication and transcription of SARS and other coronaviruses, meaning that these compounds may be useful in the treatment of early stages of virus cycle. 


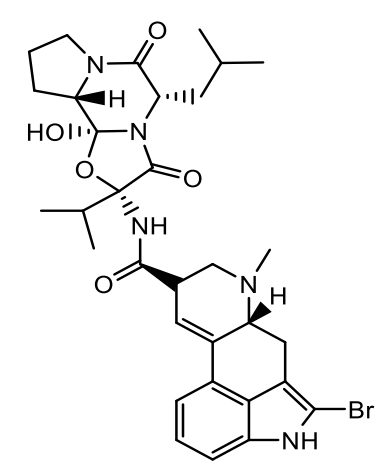

1: Bromocriptine<smiles>CN1CCN(C2CCN(C(=O)Nc3cc(Oc4ccc(NC(=O)C5(C(=O)Nc6ccc(F)cc6)CC5)c(F)c4)ccn3)CC2)CC1</smiles>

4: Golvatinib<smiles>O[C@H]1O[C@H](Oc2c[nH]c3ccccc23)[C@H](O)[C@@H](O)[C@@H]1O</smiles>

7: Indican<smiles></smiles>

9: Lycorine



2.: Celsentri

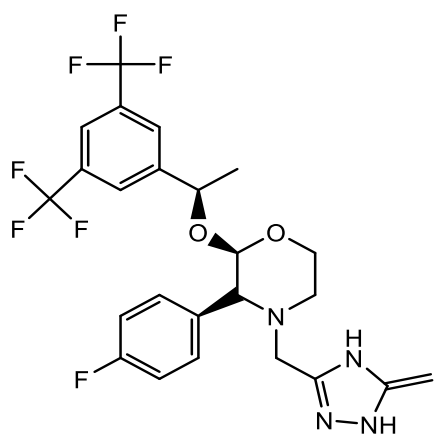

5: Emend

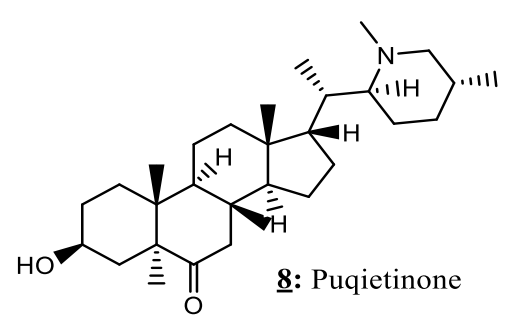<smiles>OC[C@H]1O[C@@H](Oc2cc(O)cc(/C=C/c3ccc(O)cc3)c2)[C@H](O)[C@@H](O)[C@@H]1O</smiles>

10: Polydatin<smiles>CC(C)/C=C/CCCCC(=O)NCc1ccc(O)c(O)c1</smiles>

․: Capsaicin<smiles>CC(C)Nc1cccnc1N1CCN(C(=O)c2cc3cc(NS(C)(=O)=O)ccc3[nH]2)CC1</smiles>

6: Delavirdine

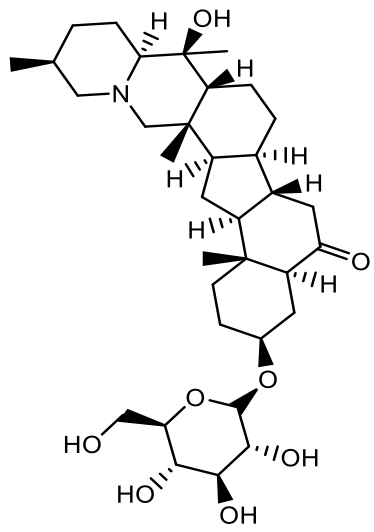

11: Imperialine-3- beta -D-glucoside

Figure 1. Chemical structures of natural alkaloids isolated from medicinal plants with anti-SARS-CoV-2 activities (these structures were drawn by ChemDraw).

In another study carried out in vitro, Tsai et al. [13] evaluated, in the first step, the antiviral activity of tryptanthrin against HCoV-NL63 using the CPE reduction assay. The results showed that at $40 \mu \mathrm{M}$, tryptanthrin exhibits an important antiviral effect with a significant reduction in HCoV-NL63-induced CPE in LLC-MK2 cells 36 and $48 \mathrm{~h}$ postinfection. In the same study, the infectivity assay with immunofluorescent staining demonstrated that this alkaloid compound exhibits a strong inhibitory activity in the early and late stages of HCoV-NL63 replication. 


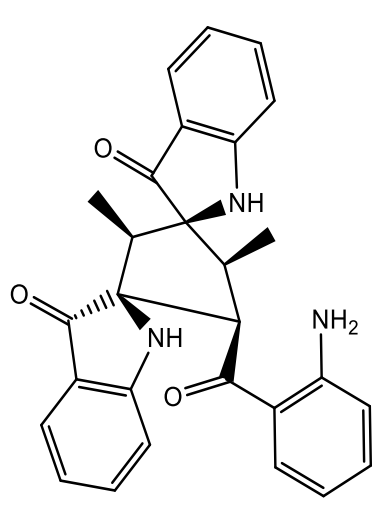

12: Indigodole A

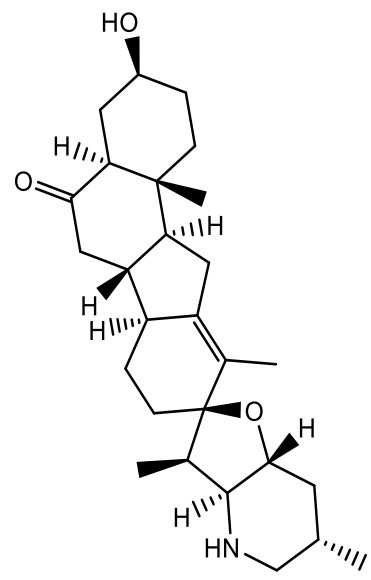

16: Peimisine<smiles>O=C1c2ccccc2-n2c1nc1ccccc1c2=O</smiles>

13: Tryptanthrin

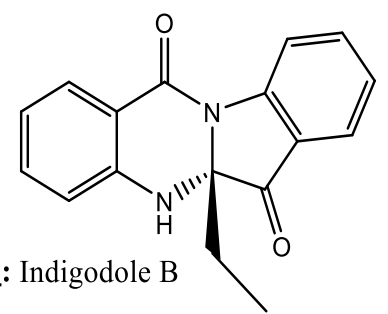<smiles>Cc1c(O)cccc1C(=O)N[C@@H](CSc1ccccc1)[C@H](O)CN1C[C@H]2CCCC[C@H]2C[C@H]1C(=O)NC(C)(C)C</smiles>

17: Nelfinavir<smiles>C=c1[nH]c2ccccc2c1=c1[nH]c2ccccc2c1=C</smiles>

15: Indirubin<smiles>OC[C@H]1O[C@@H](Oc2ccc3cc(-c4cc(O)cc(O[C@H]5O[C@H](CO)[C@@H](O)[C@H](O)[C@H]5O)c4)oc3c2)[C@H](O)[C@@H](O)[C@@H]1O</smiles>

18: Mulberroside E

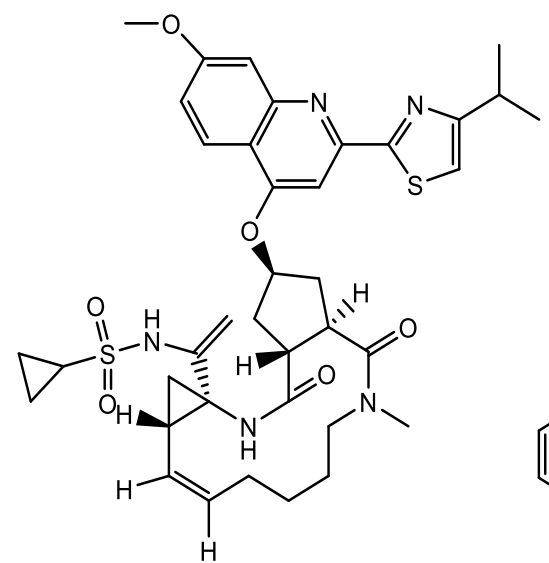

19: Olysio<smiles></smiles>

20: Saquinavir

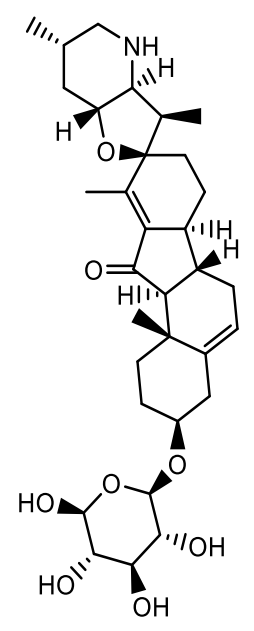

21: Pseudojervine

Figure 1. Continued.

However, tryptanthrin was less potent in impeding the early $\left(\mathrm{IC}_{50}=0.32 \mu \mathrm{M}\right)$ than the late-stage $\left(\mathrm{IC}_{50}=0.06 \mu \mathrm{M}\right)$; and considerably decreased the production of extracellular virions in these two stages. More interesting, this study indicated that tryptanthrin significantly attacked the viral enzymes such as RNA-dependent RNA polymerase and PLP2 during the late stages of HCoV-NL63 replication, indicating that the viral RNA genome synthesis and progeny virus production were moderated. Thus, tryptanthrin demonstrated important virucidal activity against $\mathrm{HCoV}-\mathrm{NL} 63\left(\mathrm{IC}_{50}=0.06 \mu \mathrm{M}\right)$. Tryptanthrin could be used against human coronaviruses 
as an inhibitor targeting the viral replication cycle. Another alkaloid compound, namely sinigrin, exhibits a good antiviral effect. Indeed, Lin et al. [14] studied its anti-SARS coronavirus $3 \mathrm{C}$-like protease effect. According to this study, the use of the cell-based assay revealed that sinigrin $\left(\mathrm{IC}_{50}=217 \mu \mathrm{M}\right)$ significantly blocks the cleavage processing of the viral protease $3 \mathrm{CL}^{\text {pro }}$. In addition, sinigrin $\left(\mathrm{CC}_{50}>10 \mathrm{mM}\right)$ was not toxic to Vero cells; this compound may be considered as a potential alternative to develop an inhibitor of SARS-CoV 3CL ${ }^{\text {pro }}$ [14]. In addition, using cytotoxicity assay, the authors demonstrated an interesting anti-SARS-CoV effect of lycorine with an $\mathrm{EC}_{50}$ value of $15.7 \pm 1.2 \mathrm{nM}$. The results suggested that this alkaloid compound is a candidate for new anti-SARS-CoV drug development.<smiles>C=CC/C(=N\OS(=C)(=C)OC)S[C@@H]1O[C@H](CO)[C@@H](O)[C@H](O)[C@H]1O</smiles>

22: Sinigrin



24: Tanespimycin

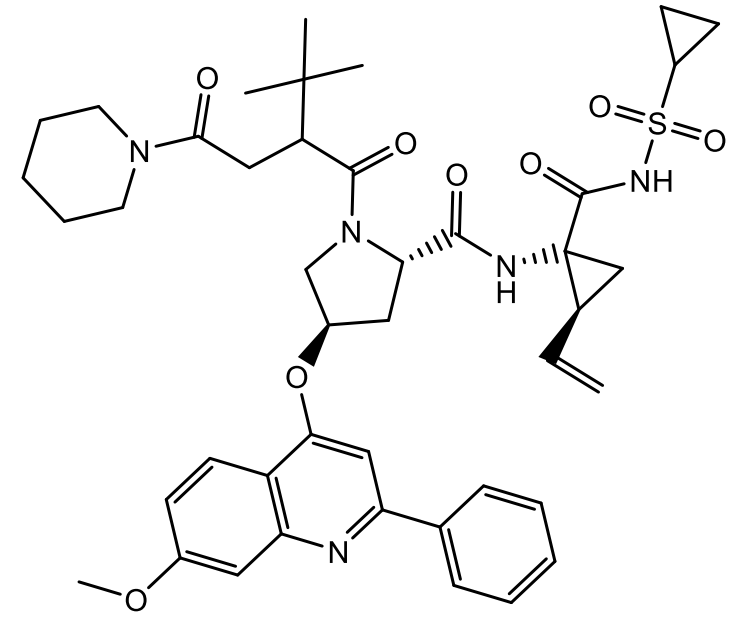

23: Sovaprevir

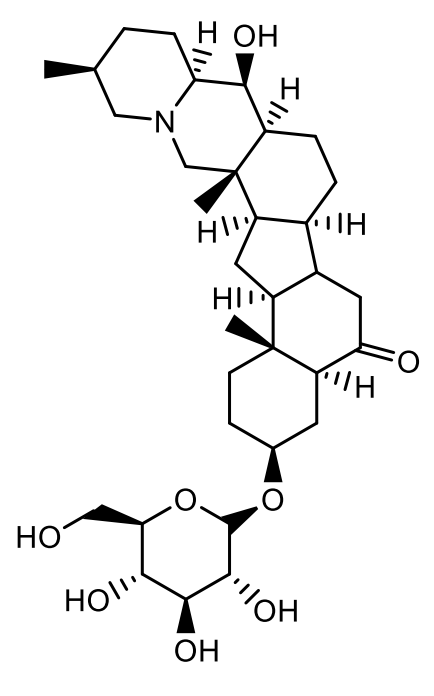

25: Verticinone 3-beta-D-glucoside

Figure 1. Continued.



26: Veratroylzygadenine 
<smiles>[R]c1c(/C(C)=C/C)oc2cc(O)cc(O)c2c1=O</smiles><smiles>C[C@@H]1OC(O[C@@H]2[C@@H](Oc3cc(O)c4c(c3)O[CH]CC4=O)O[C@@H](CO)[C@H]2O)[C@H](O)[C@@H](O)[C@H]1O</smiles>

3: Hesperidin<smiles>O=c1cc(-c2ccc(O)c(-c3c(O)cc(O)c4c(=O)cc(-c5ccc(O)cc5)oc34)c2)oc2cc(O)cc(O)c12</smiles>

4: Amentoflavone

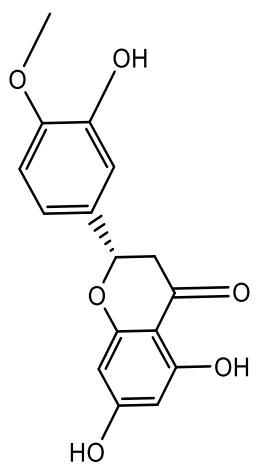

5: Hesperetin<smiles>O=C(O[C@H]1Cc2c(O)cc(O)cc2O[C@H]1c1cc(O)c(O)c(O)c1)c1cc(O)c(O)c(O)c1</smiles>

7: Epigallocatechin gallate<smiles>O=C(O[C@H]1Cc2c(O)cc(O)cc2O[C@H]1c1cc(O)c(O)c(O)c1)c1cc(O)c(O)c(O)c1</smiles>

8: Gallocatechin gallate<smiles>COc1ccccc1O</smiles><smiles>O</smiles><smiles>CC(C)[C@@H]1CC(=O)c2c(O)cc(O[C@@H]3O[C@H](CO)[C@@H](O)[C@H](O)[C@H]3O[C@]3(C)O[C@H](C)[C@@H](O)[C@H](O)[C@H]3O)cc2O1</smiles>

6: Naringin

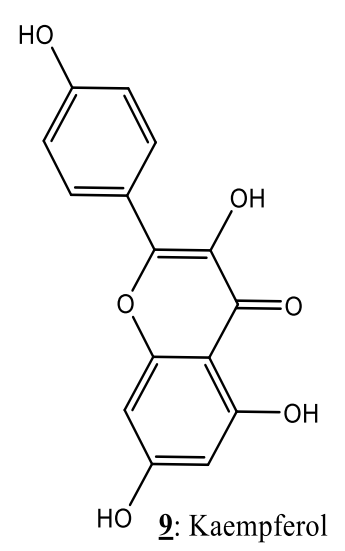<smiles>Oc1cc(O)c2c(c1)O[C@H](c1ccc(O)c(O)c1)[C@H](O)C2</smiles>

10: $(+)$-catechin<smiles>Oc1cc(O)c2c(c1)O[C@H](c1cc(O)c(O)c(O)c1)[C@H](O)C2</smiles>

11: Epigallocatechin<smiles>O=c1c(O)c(-c2cc(O)c(O)c(O)c2)oc2cc(O)cc(O)c12</smiles>

12: Myricetin

Figure 2. Chemical structures of natural flavonoids isolated from medicinal plants with anti-SARS-CoV-2 activities (these structures were drawn by ChemDraw).

\subsubsection{Mechanism insights of flavonoids anti-SARS-CoV-2.}

Other secondary metabolites namely flavonoids confirmed the anti-SARS effects such as baicalein, silibinin, myricetin, and scutellarein, (+)-catechin tomentin A; Tomentin B; Tomentin C; Tomentin D; Tomentin E; 3'-O-methyldiplacol; 4'-O-methyldiplacol; 3'-Omethyldiplacone; 4'-O-methyldiplacone; mimulone; diplacone; 6- geranyl-4',5,7-trihydroxy3',5'-dimethoxyflavanone, Tangeretin, Hesperetin, Nobiletin, Hesperidin, Naringenin, ACA, Galangin, naringenin, naringin, hesperetin, hesperidin, neohesperidin, nobiletin, kaempferol, 
morin, herbacetin, rhoifolin, pectolinarin, daidzein, quercetin, daidzein, puerarin, epigallocatechin, epigallocatechin gallate, gallocatechin gallate, ampelopsin, amentoflavone, bilobetin, ginkgetin, and sciadopitysin (Figure 2 and Table 1). Among these compounds, hesperidin was described as a potent inhibitor of SARS-CoV-2.<smiles>COc1cc([C@H]2Oc3cc(O)c(CC=C(C)CCC=C(C)C)c(O)c3C(=O)[C@H]2O)ccc1O</smiles>

13: 3'-O-methyldiplacol<smiles>COc1cc([C@@H]2CC(=O)c3c(cc(O)c(C/C=C(\C)CCC=C(C)C)c3O)O2)ccc1O</smiles>

15: 3'-O-methyldiplacone<smiles>COc1ccc([C@H]2Oc3cc(O)c(C/C=C(\C)CCC=C(C)C)c(O)c3C(=O)[C@H]2O)cc1O</smiles>

14: 4'-O-methyldiplacol<smiles>COc1ccc([C@@H]2CC(=O)c3c(cc(O)c(C/C=C(\C)CCC=C(C)C)c3O)O2)cc1O</smiles>

16: 4'-O-methyldiplacone

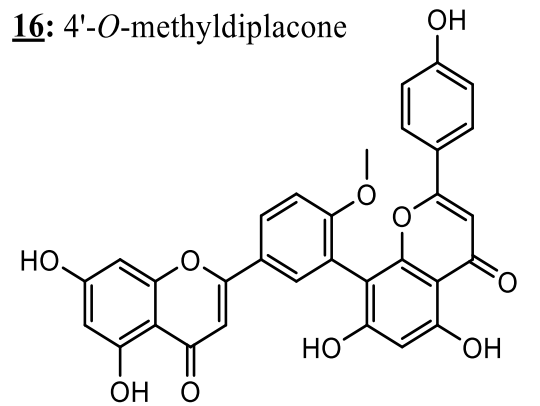

18: Bilobetin

17: Diplacone<smiles>O=c1c(O)c(-c2ccc(O)cc2O)oc2cc(O)cc(O)c12</smiles>

19: Morin

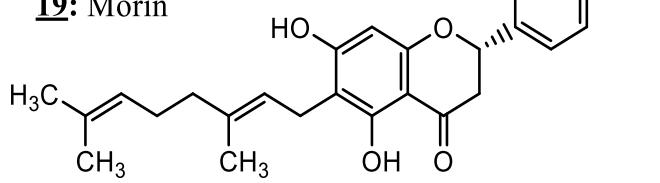<smiles>O=c1c(-c2ccc(O)cc2)coc2cc(O)ccc12</smiles>

20: Daidzein<smiles>COc1cc(O)c2c(=O)cc(-c3ccc(OC)c(-c4c(O)cc(O)c5c(=O)cc(-c6ccccc6)oc45)c3)oc2c1</smiles>

22: Ginkgetin

21: Mimulone<smiles>O=C1C(O)=C(c2ccc(O)cc2)OC2C1=C(O)C=C(O)C2O</smiles>

23: Herbacetin<smiles>O=c1c(O)c(-c2ccccc2)oc2cc(O)cc(O)c12</smiles>

24: Galangin<smiles>O=c1cc(-c2ccccc2)oc2cc(O)c(O)c(O)c12</smiles>

25: Baicalein

Figure 2. Continued. 
Indeed, Utomo et al. [18] revealed, in silico, the anti-SARS-Cov-2 potential of hesperidin through its binding to RBDS, PD-ACE2, and SARS-CoV-2 protease. The results showed that hesperidin has the lowest docking score for all three protein receptors representing the highest affinity to bind the receptors tested. More importantly, this flavonoid compound has better interaction with the SARS-CoV-2 protease and to Spike-RBD compared to lopinavir and nafamostat [18]. These results suggest that hesperidin would be effective to block virus infection and replication.<smiles>COc1ccc(-c2cc(=O)c3c(OC)c(OC)c(OC)c(OC)c3o2)cc1OC</smiles>

26: Nobiletin<smiles>CC[C@H]1O[C@@H](c2c(O)ccc3c(=O)c(-c4ccc(O)cc4)coc23)[C@H](O)[C@@H](O)[C@@H]1O</smiles>

28: Puerarin<smiles>COc1ccc(-c2cc(=O)c3c(OC)c(OC)c(OC)c(OC)c3o2)cc1</smiles>

27: Tangeretin

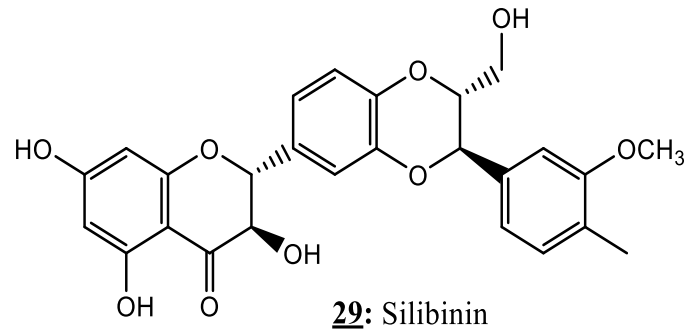

29: Silibinin<smiles>CC(C)(O)CCCC1(C)CCc2c(cc3c(c2O)C(=O)C[C@@H](c2ccc(O)c(O)c2)O3)O1</smiles><smiles>COc1ccc([C@H]2CC(=O)c3c(cc4c(c3O)CCC(C)(CCCC(C)(C)O)O4)O2)cc1O</smiles><smiles>COc1cc([C@H]2CC(=O)c3c(cc4c(c3O)CCC(C)(CCCC(C)(C)O)O4)O2)cc(OC)c1OC</smiles><smiles>COc1cc([C@H]2CC(=O)c3c(cc4c(c3O)CCC(C)(CCCC(C)(C)O)O4)O2)cc(OC)c1O</smiles><smiles>COc1cc([C@H]2Oc3cc4c(c(O)c3C(=O)[C@@H]2O)CCC(C)(CCCC(C)(C)O)O4)ccc1O</smiles>

Figure 2. Continued. 
In another study, herbacetin, rhoifolin, and pectolinarin (flavonoids)were reported as antiviral molecules against coronaviruses. The in silico results indicated that herbacetin, rhoifolin, and pectolinarin block the enzymatic activity of SARS-CoV 3CL ${ }^{\text {pro }}$ [35]. In addition, the confirmation of their interaction was performed using a tryptophan-based fluorescence assay; the in silico results demonstrated that S1, S2, and S30 sites are involved in binding with flavonoids, meaning that herbacetin, rhoifolin, and pectolinarin may be suggested to be inhibitors of the responsible enzyme for cleavage of the remaining 11 locations causing a release of a total of 16 nonstructural proteins (nsp) in both SARS- and MERS-CoV. Another study evaluated the antiviral effect of quercetin, epigallocatechin gallate, and gallocatechin gallate [21]. Indeed, these three flavonoid products exhibited a good inhibition of $3 \mathrm{CL}^{\text {pro }}$ with IC50 values of 73,73 , and $47 \mu \mathrm{M}$, for quercetin, epigallocatechin gallate, and gallocatechin gallate, respectively. Notably, gallocatechin gallate demonstrated a competitive inhibition pattern with $\mathrm{K}_{i}=25 \pm 1.7 \mu \mathrm{M}$. In silico, gallocatechin gallate showed numerous hydrophobic and H-bonds interaction with amino acid residues in the active site pocket of $3 \mathrm{CL}^{\text {pro }}$. In another work, the SARS-CoV 3CL pro was the target of amentoflavone [22]. The results of fluorogenic methods showed that amentoflavone inhibits SARS-CoV 3CL ${ }^{\text {pro }}$ with an $\mathrm{IC}_{50}$ value of $8.3 \mu \mathrm{M}$. The characterization of the inhibitory mechanism of amentoflavone against SARS-CoV $3 \mathrm{CL}^{\text {pro }}$ activity was investigated. The results indicate that this compound exhibits non-competitive inhibition characteristics toward $3 \mathrm{CL}^{\text {pro }}$. According to this study, an elucidation, performed in silico, of the interaction of SARS-CoV $3 \mathrm{CL}^{\text {pro }}$ with this compound supports the inferences drawn from the enzymatic assay, revealing its important inhibitory effect on SARS-CoV $3 \mathrm{CL}^{\text {pro }}$. Thus, these results suggest amentoflavone, such as a natural therapeutic drug against SARS-CoV infection.

\subsubsection{Mechanism insights of natural steroids anti-SARS-CoV-2.}

The research is also interested in the antiviral activity of steroids such as glycyrrhizic acid derivatives, sitosterol, beta-sitosterol (Figure 3 and Table 1). Among these compounds, the glycyrrhizic acid derivatives demonstrated, in vitro, an important anti-SARS-CoV compared to glycyrrhizic acid [31]. The results of this study indicate that seven derivatives inhibited SARS-CoV replication at lower concentrations ( $\mathrm{EC}_{50}$ values varied between $5 \pm 3$ to $139 \pm 20 \mu \mathrm{M})$ compared to glycyrrhizic acid $\left(\mathrm{EC}_{50}=365 \pm 12 \mu \mathrm{M}\right)$.
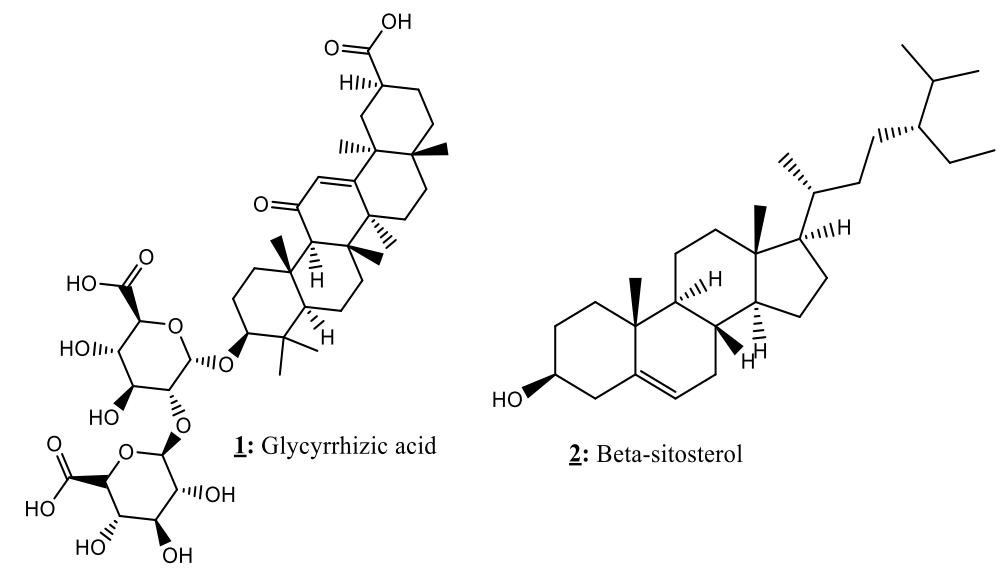

Figure 3. Chemical structures of natural steroids isolated from medicinal plants with anti-SARS-CoV-2 activities (these structures were drawn by ChemDraw).

Indeed, the anti-SARS-CoV activity of the compound resulting from the integration of $\mathrm{N}$-acetylgycosamine into the glycoside chain of glycyrrhizic acid is nine times higher compared 
to glycyrrhizic acid [31]. This derivative compound inhibited SARS-CoV replication at an EC50 of $40 \mu \mathrm{M}$. More importantly, the $\mathrm{CC}_{50}$ was superior to $3000 \mu \mathrm{M}$, and the resulting selectivity index (SI) is >75; thus, no CPE was detectable at a $500 \mu \mathrm{M}$ of this compound, and the immunocytochemical staining indicated that the suppression of viral antigen expression was superior to $99 \%$. Since the coronaviruses are known by their highly glycosylated, particularly in the $S$ proteins which have been shown to be important for viral entry into cells by binding to the ACE2 receptor, the authors suppose that the addition of $\mathrm{N}$-acetylglucosamine residues into the carbohydrate part of the basic structure of glycyrrhizic acid plays an important role in its interaction with $S$ proteins, meaning that viral entry might be inhibited by these binding [31].

\subsubsection{Mechanism insights of natural tannins anti-SARS-CoV-2.}

Several tannins molecules have been tested against SARS-CoV. Such as phloroglucinol, triphloretol A, eckol, dioxinodehydroeckol, 2-phloroeckol, 7 phloroeckol, fucodiphloroethol G, dieckol, phlorofucofuroeckol A, phloroglucinol, eckol, 7-phloroeckol, phlorofucofuroeckol, geraniin, tellimagradin, punicalin, castalin, strictinin, granatin A, pedunculagin, casuarinin, tercatain, and bicornin (Figure 4 and Table 1). In this context, Khalifa et al. [26] analyzed, in silico, the biological activity of hydrosoluble tannins as natural anti-SARS-CoV-2 through the binding with the main protease of this virus [26].

Among the hydrosoluble tannins tested, pedunculagin, tercatain, and punicalin were found to have a stronger bond and high affinity with the receptor binding site and catalytic dyad (Cys145 and His41) of SARS-CoV-2 main protease, indicating their fruitful inhibition of the SARS-CoV-2 protease enzyme. These results anticipated that tannins might be more useful candidates for COVID-19 drug therapy. In another investigation of the antiviral effect of tannin compounds, Park et al. [24] targeted in their research SARS-CoV 3CL pro which plays an important role in viral replication. Indeed, the results of the effect of nine phlorotannins 1-9 on the cell-free SARS-CoV 3CL ${ }^{\text {pro }}$ trans-cleavage assay demonstrated that among the products tested, the dieckol displayed a good inhibitory effect against SARS-CoV 3CL ${ }^{\text {pro }}$ cell-free cleavage with an $\mathrm{IC}_{50}$ value of $2.7 \mu \mathrm{M}$. The results of the kinetic mechanism investigation of the compound inhibitor and SARS-CoV 3CL prointeractionindicated that dieckol had competitive inhibition profiles with $K_{\mathrm{i}}$ value of $2.4 \mu \mathrm{M}$. In addition, the authors determined the kinetic binding parameters, the association rate constant, and the dissociation rate constant using surface plasmon resonance [24]. Diekcol increased the SPR sensorgram in a significant and dose-dependent manner. The dissociation constant $K_{\mathrm{D}}\left(k_{\mathrm{off}} / k_{\mathrm{on}}\right)$ was calculated by globally fitting the kinetic data at various dieckol concentrations $(12.5,25$, and $50 \mu \mathrm{M})$ to the Langmuir binding model $\left(K_{D}=10.3 \mu \mathrm{M}\right)$. The $K_{D}$ for the dieckol interaction with $\mathrm{k}_{\mathrm{on}}=73.5 \mu \mathrm{M}^{-1} \mathrm{~S}^{-1}$ and $\mathrm{k}_{\text {off }}=0.000843 \mathrm{~S}^{-1}$, which quantitatively revealed a higher association rate than that of positive control hesperetin $\left(\mathrm{K}_{\mathrm{D}}=24.5 \mu \mathrm{M}\right)$. To explain the inhibition mechanism of dieckol as an important potent inhibitor of SARS-CoV $3 \mathrm{CL}^{\text {pro }}$, a docking experiment was performed. The results indicated that dieckol bound to the $\mathrm{S} 1$ site of SARS-CoV 3CL pro through $\mathrm{H}$-bonds, and formed strong hydrogen bonds to the catalytic dyad (Cys145 and His41) of SARS-CoV 3CL ${ }^{\text {pro. }}$. In silico experiments, support the results obtained with the enzymatic assay that revealed the important inhibitory action of dieckol on SARS-CoV 3CL ${ }^{\text {pro }}$ [24]. 


<smiles></smiles>

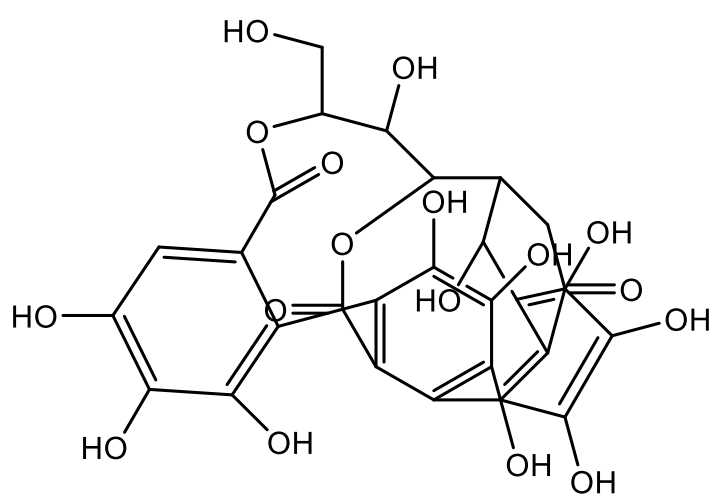

3: Castalin

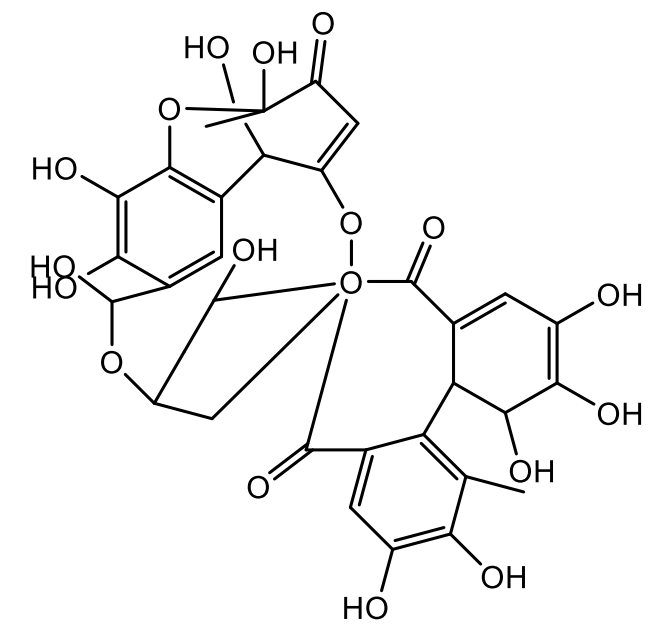

5: Granatin A

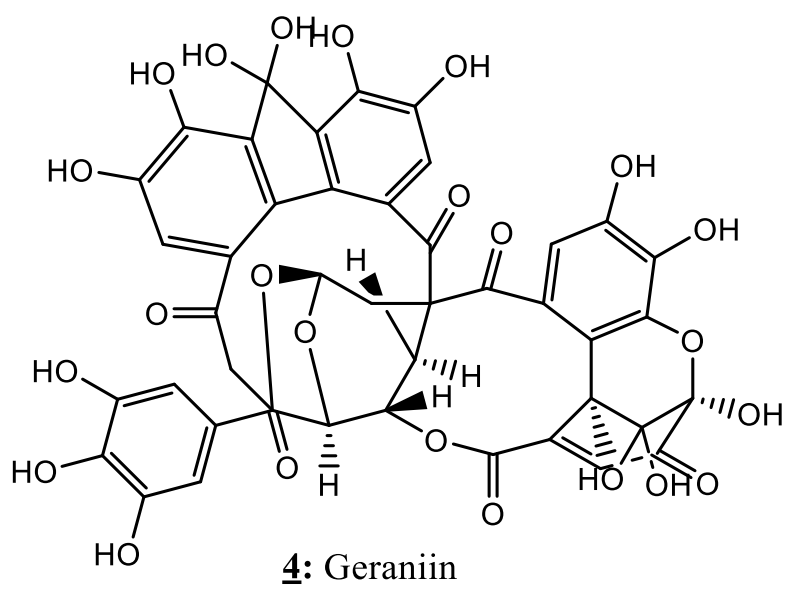

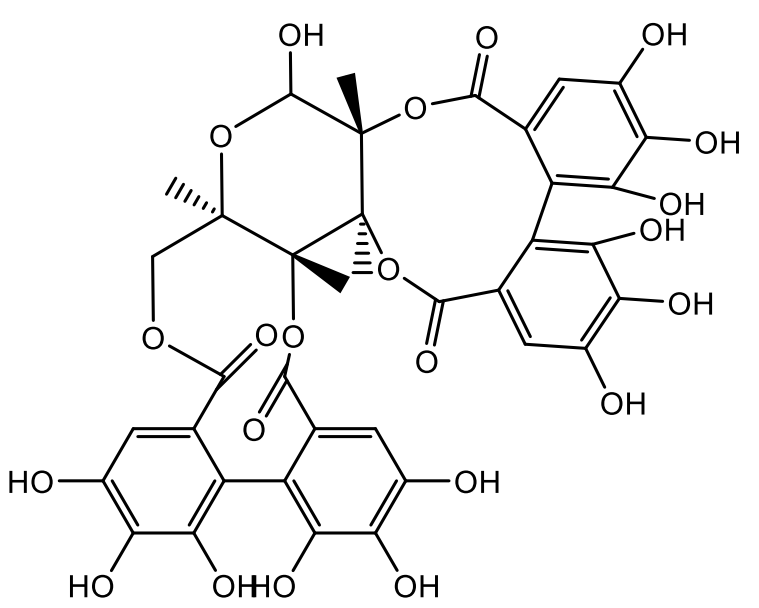

6: Pedunculagin

Figure 4. Chemical structures of natural tannins isolated from medicinal plants with anti-SARS-CoV-2 activities (these structures were drawn by ChemDraw). 




7: Strictinin<smiles>CC1CC(O)C(O)C(C)C1c1c(C(=O)OC[C@@H]2CC(OC(=O)c3cc(O)c(O)c(O)c3)C(OC(=O)c3cc(O)c(O)c(O)c3)C(OC(=O)c3cc(O)c(O)c(O)c3)C2OC(=O)C2CC(O)C(O)C(C)C2C)cc(O)c(O)c1O</smiles>

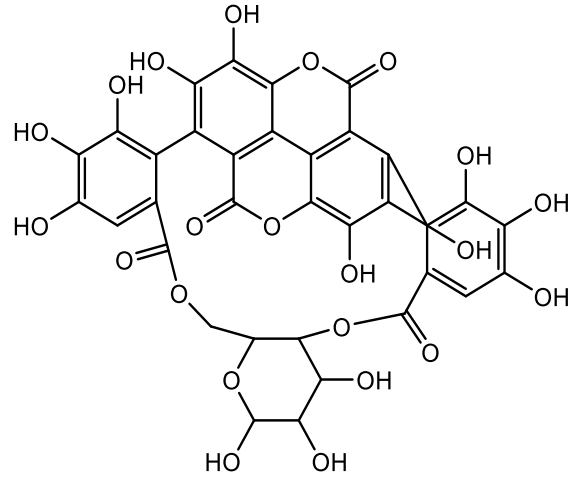

8: Punicalin

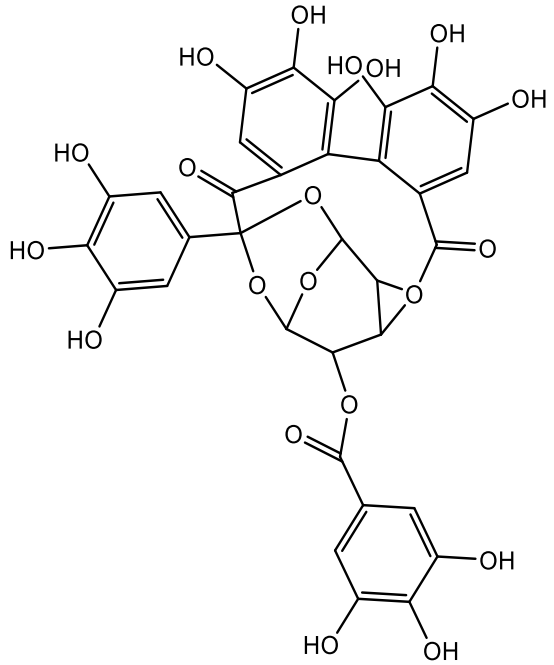

10: Tercatain

9: Tellimagrandin

Figure 4. Continued.

\subsubsection{Mechanism insights of natural quinone anti-SARS-CoV-2.}

The quinone is one of the secondary metabolites studied for their antiviral activity. The hypericin, idarubicin, emodin, promazine, rhein, 1,4-bis-(1-anthraquinonylamino)anthraquinone, emodin, and aloe-emodin are the most tested quinones (Figure 5 and Table 1). Among them, emodin has been confirmed as an anti-SARS-CoV compound [27]. According to this study, the results of the biotinylated ELISA assay showed that emodin blocked the binding of S protein to ACE2 in a dose-dependent manner with an $\mathrm{IC}_{50}$ value of $200 \mu \mathrm{M}$. The inhibitory potential of emodin on the SARS-CoV S protein and Vero E6 cell interaction was also evaluated using IFA. Neither cytotoxic effect, nor cellular morphological change has been observed in emodin-treated cells. Treatment of Vero E6 cells with emodin/biotinylated S protein decreased the cell-associated fluorescence, indicating that this quinone compound is able to block the S protein and Vero E6 cell interaction. Additionally, the inhibitory potential of emodin was evaluated by the S protein-pseudotyped retrovirus infectivity [27]. The results showed that emodin inhibited the $S$ protein-pseudotyped retrovirus infectivity in a dosedependent manner, and at $50 \mu \mathrm{M}$ (without toxic effect) of emodin, the percent of inhibition was 
94.12\%. The finding of this study suggested that emodin was a novel anti-SARS-CoV compound and might be considered as a potential drug to treat the SARS infection [27].

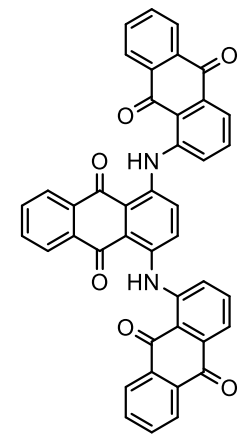

1: 1,4-bis-(1-anthraquinonylamino)-anthraquinone<smiles>Cc1cc(=O)c2c(O)c3c(O)cc(O)c4c5c(O)cc(O)c6c(O)c7c(=O)cc(C)c8c1c2c(c34)c(c65)c78</smiles>

2:: Hypericin<smiles>O=C(O)c1cc(O)c2c(c1)C(=O)c1cccc(O)c1C2=O</smiles><smiles>O=C1c2cc(CO)cc(O)c2C(=O)c2cccc(O)c21</smiles><smiles>O=C1c2cc(O)cc(O)c2C(=O)c2cc(O)cc(O)c21</smiles><smiles>CN(C)CCCN1c2ccccc2Sc2ccccc21</smiles>

6: Promazine<smiles>CC(=O)[C@]1(O)Cc2c(O)c3c(c(O)c2[C@@H](OC2C[C@H](C)[C@H](O)[C@H](N)C2)C1)C(=O)c1ccccc1C3=O</smiles>

7: Idarubicin

Figure 5. Chemical structures of natural quinones isolated from medicinal plants with anti-SARS-CoV-2 activities (these structures were drawn by ChemDraw).

In another work, Schwarz et al. [28] demonstrated that emodin inhibits HCoV-OC 43 release from infected RD cells with similar effectiveness of $K_{1 / 2} \approx 20 \mu \mathrm{M}$ for inhibition of SNE3a protein of SARS-CoV and $\mathrm{HCoV-OC43.This} \mathrm{inhibition} \mathrm{of} \mathrm{3a} \mathrm{ion} \mathrm{channel} \mathrm{could} \mathrm{contribute}$ to the reduction of virus release from the SARS-CoV-infected host. Therefore, reduced virus release from infected cells may provide the immune system sufficient time to improve the response against the infection [28].

2.1.6. Mechanism insights of natural stilbenesanti-SARS-CoV-2.

Curcumin compound, belonging to the stilbene's groups, has been reported as antiSARS-CoV (Figure 6 and Table 1). Mohammed and Shaghaghi, [11] evaluated the bioinformatics study of SARS-CoV-2 inhibition by a secondary metabolite of medicinal plants. The results showed that curcumin has a stronger bond and high affinity with protease [11].<smiles>COc1cc(/C=C/C(=O)CC(=O)/C=C/c2ccc(O)c(OC)c2)ccc1O</smiles>

Figure 6. Natural chemical structures of stilbene isolated from medicinal plants with promising anti-SARS-

CoV-2 activity (these structures were drawn by ChemDraw). 
Finally, due to the high effectiveness function of plant compounds, the authors arrived at the conclusion that the coumarin compound may be considered as an effective anti-protease drug to treat COVID-19. Concerning the products belonging to other compound groups such as terpenoids, coumarin, steroidal alkaloids, allyls, phenylpropanoids, glucosides, lignoids, tanshinones, and alkylated chalcones, a detailed list of their anti-SARS activities is presented in Table 1.

\subsection{Synthetic pharmacophores as possible drugs against SARS-CoV-2.}

The search for new synthetic molecules as therapeutic drugs requires time for biological screening in vitro and in vitro. With the COVID-19 pandemic, the screening for therapeutic treatments, particularly targeted therapy using active molecules, could not be carried out routinely. Indeed, many research groups have started urgently to identify synthetic molecules with anti-SARS-CoV-2 properties (Table 2).

Table 2. Synthetic compounds with possible anti-SARS-CoV-2 effects.

\begin{tabular}{|c|c|c|c|}
\hline Synthetic drugs & $\begin{array}{l}\text { Experimental } \\
\text { system (model cell line, in } \\
\text { silico, } \text { in vivo) }\end{array}$ & Keys findings/mechanism insights & Authors \\
\hline $9 \mathbf{a}$ & Structure-guided design & $\begin{array}{l}\mathrm{IC}_{50}=0.6 \mu \mathrm{M} \\
\text { Inhibition of MERS coronavirus 3CL protease. }\end{array}$ & [36] \\
\hline $10 a$ & Structure-guided design & $\begin{array}{l}\text { IC }_{50}=0.4 \mu \mathrm{M} \\
\text { Inhibition of MERS coronavirus 3CL protease. }\end{array}$ & [36] \\
\hline $9 \mathrm{~b}$ & Structure-guided design & $\begin{array}{l}\mathrm{IC}_{50}=0.7 \mu \mathrm{M} \\
\text { Inhibition of MERS coronavirus 3CL protease. }\end{array}$ & [36] \\
\hline 10b & Structure-guided design & $\begin{array}{l}\mathrm{IC}_{50}=0.6 \mu \mathrm{M} \\
\text { Inhibition of MERS coronavirus } 3 \mathrm{CL} \text { protease. }\end{array}$ & [36] \\
\hline $9 \mathrm{c}$ & Structure-guided design & $\begin{array}{l}\mathrm{IC}_{50}=0.8 \mu \mathrm{M} \\
\text { Inhibition of MERS coronavirus 3CL protease. }\end{array}$ & [36] \\
\hline 10c & Structure-guided design & $\begin{array}{l}\mathrm{IC}_{50}=0.7 \mu \mathrm{M} \\
\text { Inhibition of MERS coronavirus 3CL protease. }\end{array}$ & [36] \\
\hline 9d & Structure-guided design & $\begin{array}{l}\mathrm{IC}_{50}=0.7 \mu \mathrm{M} \\
\text { Inhibition of MERS coronavirus } 3 \mathrm{CL} \text { protease. }\end{array}$ & [36] \\
\hline 10d & Structure-guided design. & $\begin{array}{l}\mathrm{IC}_{50}=0.9 \mu \mathrm{M} \\
\text { Inhibition of MERS coronavirus } 3 \mathrm{CL} \text { protease. }\end{array}$ & [36] \\
\hline $9 \mathrm{e}$ & Structure-guided design & $\begin{array}{l}\mathrm{IC}_{50}=6.1 \mu \mathrm{M} \\
\text { Inhibition of MERS coronavirus 3CL protease. }\end{array}$ & {$[36]$} \\
\hline 10e & Structure-guided design & $\begin{array}{l}\mathrm{IC}_{50}=7.5 \mu \mathrm{M} \\
\text { Inhibition of MERS coronavirus } 3 \mathrm{CL} \text { protease. }\end{array}$ & [36] \\
\hline 9f & Structure-guided design & $\begin{array}{l}\mathrm{IC}_{50}=0.6 \mu \mathrm{M} \\
\text { Inhibition of MERS coronavirus 3CL protease. }\end{array}$ & [36] \\
\hline 10f & Structure-guided design & $\begin{array}{l}\mathrm{IC}_{50}=0.5 \mu \mathrm{M} \\
\text { Inhibition of MERS coronavirus 3CL protease. }\end{array}$ & [36] \\
\hline $10 a$ & Structure-guided design & $\begin{array}{l}\mathrm{EC}_{50}=0.5 \mu \mathrm{M} \\
\text { Inhibition of MERS coronavirus 3CL protease. }\end{array}$ & [36] \\
\hline 10c & Structure-guided design & $\begin{array}{l}\mathrm{EC}_{50}=0.8 \mu \mathrm{M} \\
\text { Inhibition of MERS coronavirus 3CL protease. }\end{array}$ & [36] \\
\hline $\begin{array}{l}\text { SP-4 (residues } \\
\text { 192-203) }\end{array}$ & $\begin{array}{lr}\text { Expression } & \text { and } \\
\text { purification } & \text { of } \\
\text { recombinant SARS-CoV S } \\
\text { protein } \\
\text { Biotinylated enzyme- } \\
\text { linked immunosorbent } \\
\text { assay (ELISA) }\end{array}$ & $\begin{array}{l}\text { Significantly blocked the interaction between } \mathrm{S} \text { protein } \\
\text { and ACE2. } \\
\mathrm{IC}_{50}=4.30 \pm 2.18 \mathrm{nmol} \text {. }\end{array}$ & [37] \\
\hline $\begin{array}{c}\text { SP-8 (residues } \\
483-494)\end{array}$ & $\begin{array}{lr}\text { Expression } & \text { and } \\
\text { purification } & \text { of } \\
\text { recombinant SARS-CoV S } \\
\text { protein } \\
\text { Biotinylated enzyme- } \\
\text { linked immunosorbent } \\
\text { assay (ELISA) }\end{array}$ & $\begin{array}{l}\text { Significantly blocked the interaction between } \mathrm{S} \text { protein } \\
\text { and ACE2. } \\
\mathrm{IC}_{50}=6.99 \pm 0.71 \mathrm{nmol} \text {. }\end{array}$ & [37] \\
\hline $\begin{array}{l}\text { SP-10 (residues } \\
668-679)\end{array}$ & $\begin{array}{l}\text { Expression } \\
\text { purification }\end{array}$ & $\begin{array}{l}\text { Significantly blocked the interaction between } \mathrm{S} \text { protein } \\
\text { and ACE2. }\end{array}$ & [37] \\
\hline
\end{tabular}




\begin{tabular}{|c|c|c|c|}
\hline Synthetic drugs & $\begin{array}{l}\text { Experimental } \\
\text { system (model cell line, in } \\
\text { silico, in vivo) }\end{array}$ & Keys findings/mechanism insights & Authors \\
\hline & $\begin{array}{l}\text { recombinant SARS-CoV S } \\
\text { protein } \\
\text { Biotinylated enzyme- } \\
\text { linked immunosorbent } \\
\text { assay (ELISA) }\end{array}$ & $\begin{array}{l}\text { Blocked both binding of the } \mathrm{S} \text { protein and infectivity of } \\
\mathrm{S} \text { protein-pseudotyped retrovirus to Vero E6 cells. } \\
\text { IC }_{50}=1.88 \pm 0.52 \mathrm{nmol} \text {. }\end{array}$ & \\
\hline Compound 1 & $\begin{array}{ll}\text { Computation } & \text { tool } \\
\text { Autodock 3.0.5 } & \end{array}$ & $\begin{array}{l}\text { Inhibitory activity against recombinant } 3 \text {-like } \\
\text { protease. } \\
\mathrm{IC}_{50}=58.35 \pm 1.41 \mu \mathrm{M} \text {. }\end{array}$ & [38] \\
\hline Compound 2 & $\begin{array}{l}\text { Computation } \\
\text { Autodock 3.0.5 }\end{array}$ & $\begin{array}{l}\text { Inhibitory activity against recombinant } 3 \text { C-like } \\
\text { protease. } \\
\text { IC }_{50}=62.79 \pm 3.19 \mu \mathrm{M} \text {. }\end{array}$ & [38] \\
\hline Compound 3 & $\begin{array}{l}\text { Computation } \\
\text { Autodock 3.0.5 }\end{array}$ & $\begin{array}{l}\text { Inhibitory activity against recombinant 3C-like } \\
\text { protease. } \\
\mathrm{IC}_{50}=101.38 \pm 3.27 \mu \mathrm{M} \text {. }\end{array}$ & [38] \\
\hline Compound 4 & $\begin{array}{l}\text { Computation } \\
\text { Autodock 3.0.5. }\end{array}$ & $\begin{array}{l}\text { Inhibitory activity against recombinant } 3 \text {-like } \\
\text { protease. } \\
\mathrm{IC}_{50}=77.09 \pm 1.94 \mu \mathrm{M} \text {. }\end{array}$ & [38] \\
\hline Compound 5 & $\begin{array}{l}\text { Computation } \\
\text { Autodock 3.0.5 }\end{array}$ & $\begin{array}{l}\text { Inhibitory activity against recombinant 3C-like } \\
\text { protease. } \\
\mathrm{IC}_{50}=90.72 \pm 5.54 \mu \mathrm{M} \text {. }\end{array}$ & [38] \\
\hline Compound 6 & $\begin{array}{l}\text { Computation } \\
\text { Autodock 3.0.5 }\end{array}$ & $\begin{array}{l}\mathrm{IC}_{50}=38.57 \pm 2.41 \mu \mathrm{M} . \\
\text { Competitive inhibition of } 3 \mathrm{C} \text {-like } \quad \text { protease } \\
\left(K_{i}=9.11 \pm 1.61 \mu \mathrm{M}\right) .\end{array}$ & [38] \\
\hline Compound 7 & $\begin{array}{l}\text { Computation } \\
\text { Autodock 3.0.5 }\end{array}$ & $\begin{array}{l}\mathrm{IC}_{50}=41.39 \pm 1.17 \mu \mathrm{M} . \\
\text { Competitive inhibition of } 3 \mathrm{C} \text {-like protease } \\
\left(K_{i}=9.93 \pm 0.44 \mu \mathrm{M}\right) .\end{array}$ & [38] \\
\hline $\mathrm{cmp} 3$ & $\begin{array}{l}\text { SARS-CoV-2 M } \text { M }^{\text {pro }} \\
\text { Molecular docking study }\end{array}$ & $\begin{array}{l}\text { Exhibited favorable electrostatic energy }(\Delta \text { Gelec }=- \\
21.38 \mathrm{kcal} / \mathrm{mol})\end{array}$ & [39] \\
\hline cmp12 & $\begin{array}{l}\text { SARS-CoV-2 M } \mathrm{M}^{\text {pro }} \\
\text { Molecular docking study }\end{array}$ & $\begin{array}{l}\text { Total binding free energy }(\Delta \mathrm{Gtol})=-45.22 \mathrm{kcal} / \mathrm{mol}) \\
\text { ligand RMSD values after } 20 \mathrm{~ns}=0.91 \AA \\
\text { Exhibited favorable electrostatic energy }(\Delta \mathrm{Gelec}=- \\
26.16 \mathrm{kcal} / \mathrm{mol})\end{array}$ & [39] \\
\hline cmp14 & $\begin{array}{l}\text { SARS-CoV-2 M } \text { M }^{\text {pro }} \\
\text { Molecular docking study }\end{array}$ & $\begin{array}{l}\text { Total binding free energy }(\Delta \mathrm{Gtol})=-44.91 \mathrm{kcal} / \mathrm{mol} \\
\text { Ligand RMSD values after } 20 \mathrm{~ns}=1.18 \AA \\
\text { Exhibited favorable electrostatic energy }(\Delta \mathrm{Gelec}=- \\
33.56 \\
\mathrm{kcal} / \mathrm{mol})\end{array}$ & [39] \\
\hline cmp17 & $\begin{array}{l}\text { SARS-CoV-2 Mpro } \\
\text { Molecular docking study }\end{array}$ & $\begin{array}{l}\text { Total binding free energies }(\Delta \mathrm{Gtol})=-41.72 \mathrm{kcal} / \mathrm{mol} \\
\text { Ligand RMSD values after } 20 \mathrm{~ns}=0.84 \AA \\
\text { Exhibited favorable electrostatic energy }(\Delta \mathrm{Gelec}=- \\
36.65 \mathrm{kcal} / \mathrm{mol})\end{array}$ & [39] \\
\hline cmp18 & $\begin{array}{l}\text { SARS-CoV-2 M } \text { Mro }^{\text {par }} \\
\text { Molecular docking study }\end{array}$ & $\begin{array}{l}\text { Total binding free energies }(\Delta \mathrm{Gtol})=-44.55 \mathrm{kcal} / \mathrm{mol} \\
\text { Ligand RMSD values after } 20 \mathrm{~ns}=1.03 \AA \\
\text { Exhibited favorable electrostatic energy }(\Delta \mathrm{Gelec}=-5.39 \\
\mathrm{kcal} / \mathrm{mol})\end{array}$ & [39] \\
\hline cmp2 & $\begin{array}{l}\text { SARS-CoV-2 Nsp12 } \\
\text { RdRp } \\
\text { Molecular docking study }\end{array}$ & $\begin{array}{l}\text { Exhibited favorable electrostatic energy ( } \Delta \mathrm{Gtol}=-41.74 \\
\mathrm{kcal} / \mathrm{mol}) \\
\text { Formed three H-bonds with motif C (Ser759), motifD } \\
\text { (Lys798) and motif E (Ser814) }\end{array}$ & [39] \\
\hline cmp17a & $\begin{array}{l}\text { SARS-CoV-2 Nsp12 } \\
\text { RdRp } \\
\text { Molecular docking study }\end{array}$ & $\begin{array}{l}\text { Exhibited favorable electrostatic energy ( } \Delta \text { Gtol=- } \\
34.37 \mathrm{kcal} / \mathrm{mol} \text { ) } \\
\text { Formed five H-bonds with Arg624 (motif A),Thr680 } \\
\text { and Ser682 (motif B), Ser756 (motif C) and Lys798 } \\
\text { (motif D) }\end{array}$ & [39] \\
\hline cmp21 & $\begin{array}{l}\text { SARS-CoV-2 Nsp12 } \\
\text { RdRp } \\
\text { Molecular docking study }\end{array}$ & $\begin{array}{l}\text { Exhibited favorable electrostatic energy }(\Delta \mathrm{Gtol}=-24.9 \\
\mathrm{kcal} / \mathrm{mol}) \\
\text { Formed four H-bonds with motif A (Asp623), motif F } \\
\text { (Arg553 and Arg555), and motif C (Ser759) }\end{array}$ & [39] \\
\hline $\mathrm{cmp} 1$ & $\begin{array}{l}\text { SARS-CoV-2 Nsp13 } \\
\text { helicase } \\
\text { Molecular docking study }\end{array}$ & Estimated favourable $\Delta$ Gtol(-37.29kcal $/ \mathrm{mol})$ & [39] \\
\hline cmp3a & $\begin{array}{l}\text { SARS-CoV-2 Nsp13 } \\
\text { helicase } \\
\text { Molecular docking study }\end{array}$ & Estimated favorable $\Delta$ Gtol $(-40.08 \mathrm{kcal} / \mathrm{mol})$ & [39] \\
\hline cmp11 & $\begin{array}{l}\text { SARS-CoV-2 Nsp13 } \\
\text { helicase } \\
\text { Molecular docking study }\end{array}$ & Estimated favorable $\Delta$ Gtol $(-49.73 \mathrm{kcal} / \mathrm{mol})$ & [39] \\
\hline \multicolumn{3}{|c|}{ https://biointerfaceresearch.com/ } & 8340 \\
\hline
\end{tabular}




\begin{tabular}{|c|c|c|c|}
\hline Synthetic drugs & $\begin{array}{l}\text { Experimental } \\
\text { system (model cell line, in } \\
\text { silico, in vivo) }\end{array}$ & Keys findings/mechanism insights & Authors \\
\hline cmp15 & $\begin{array}{l}\text { SARS-CoV-2 Nsp13 } \\
\text { helicase } \\
\text { Molecular docking study }\end{array}$ & Estimated favorable $\Delta \mathrm{Gtol}(-30.56 \mathrm{kcal} / \mathrm{mol})$ & [39] \\
\hline $\begin{array}{l}\text { A novel series of } \\
\text { fused } \quad 1,2,3- \\
\text { triazoles } \\
\text { derivatives }\end{array}$ & $\begin{array}{l}\text { HEL cells } \\
\text { In silico } \text { studies. }\end{array}$ & $\begin{array}{l}\text { Inhibition of } 3 \mathrm{CL} \text { protease. } \\
\text { Promising antiviral properties for compounds } 14 \mathrm{~d}, 14 \mathrm{n} \text {, } \\
14 \mathrm{q}, 18 \mathrm{f} \text {, and } 18 \mathrm{i} \text { against human coronavirus } 229 \mathrm{E} \text {. }\end{array}$ & [40] \\
\hline 1 & Molecular docking study & Inhibitory activity against SARS-CoV 3CL pro. & [41] \\
\hline 2 & Molecular docking study & $\begin{array}{l}\mathrm{IC}_{50}=10 \mu \mathrm{M} . \\
\text { Inhibitory activity against SARS-CoV 3CL }\end{array}$ & [41] \\
\hline 3 & Molecular docking study & $\begin{array}{l}\mathrm{IC}_{50}=0.60 \mu \mathrm{M} . \\
\text { Inhibitory activity against SARS-CoV } 3 \mathrm{CL}^{\text {pro }} \text {. }\end{array}$ & [41] \\
\hline 4 & Molecular docking study & $\begin{array}{l}\mathrm{IC}_{50}=9.1 \mu \mathrm{M} . \\
K_{i}=0.66 \mu \mathrm{M} . \\
\text { Inhibitory activity against SARS-CoV } 3 \mathrm{CL}^{\text {pro }} \text {. }\end{array}$ & [41] \\
\hline 5 & Molecular docking study & $\begin{array}{l}K_{\text {inact }} / K_{i}=1900 \mathrm{M}^{-1} \mathrm{~s}^{-1} . \\
\text { Inhibitory activity against SARS-CoV } 3 \mathrm{CL}^{\text {pro }} \text {. }\end{array}$ & [41] \\
\hline 6 & Molecular docking study & $\begin{array}{l}\mathrm{IC}_{50}=0.065 \mu \mathrm{M} \text {. } \\
\text { Inhibitory activity against SARS-CoV } 3 \mathrm{CL}^{\text {pro }} \text {. }\end{array}$ & [41] \\
\hline 7 & Molecular docking study & $\begin{array}{l}K_{i}=2.2 \mu \mathrm{M} . \\
\text { Inhibitory activity against SARS-CoV } 3 \mathrm{CL}^{\text {pro }} \text {. }\end{array}$ & [41] \\
\hline 8 & Molecular docking study & $\begin{array}{l}\mathrm{IC}_{50}=1.7 \mu \mathrm{M} . \\
K_{i}=0.0041 \mu \mathrm{M} . \\
\text { Inhibitory activity against SARS-CoV 3CL }{ }^{\text {pro }} \text {. }\end{array}$ & [41] \\
\hline 9 & Molecular docking study & $\begin{array}{l}K_{i}=0.0031 \mu \mathrm{M} . \\
\text { Inhibitory activity against SARS-CoV } 3 \mathrm{CL}^{\text {pro }} \text {. }\end{array}$ & [41] \\
\hline 10 & Molecular docking study & $\begin{array}{l}K_{i}=3.2 \mu \mathrm{M} . \\
\text { Inhibitory activity against SARS-CoV 3CL pro. }\end{array}$ & [41] \\
\hline 11 & Molecular docking study & $\begin{array}{l}\mathrm{IC}_{50}=323 \mu \mathrm{M} \text {. } \\
\text { Inhibitory activity against SARS-CoV } 3 \mathrm{CL}^{\text {pro }} \text {. }\end{array}$ & [41] \\
\hline 12 & Molecular docking study & $\begin{array}{l}K_{i}=0.065 \mu \mathrm{M} . \\
\text { Inhibitory activity against SARS-CoV 3CL pro. }\end{array}$ & [41] \\
\hline 13 & Molecular docking study & $\begin{array}{l}\mathrm{IC}_{50}=0.37 \mu \mathrm{M} \text {. } \\
\text { Inhibitory activity against SARS-CoV } 3 \mathrm{CL}^{\text {pro }} \text {. }\end{array}$ & {$[41]$} \\
\hline 14 & Molecular docking study & $\begin{array}{l}K_{i}=0.0075 \mu \mathrm{M} . \\
\text { Inhibitory activity against SARS-CoV 3CL pro. }\end{array}$ & {$[41]$} \\
\hline 15 & Molecular docking study & $\begin{array}{l}\mathrm{IC}_{50}=6.1 \mu \mathrm{M} \text {. } \\
\text { Inhibitory activity against SARS-CoV } 3 \mathrm{CL}^{\text {pro }} \text {. }\end{array}$ & [41] \\
\hline 16 & Molecular docking study & $\begin{array}{l}\mathrm{IC}_{50}=6.8 \mu \mathrm{M} . \\
\text { Inhibitory activity against SARS-CoV 3CL pro. }\end{array}$ & [41] \\
\hline 17 & Molecular docking study & $\begin{array}{l}\mathrm{IC}_{50}=17.2 \mu \mathrm{M} . \\
\text { Inhibitory activity against SARS-CoV } 3 \mathrm{CL}^{\text {pro. }} \text {. }\end{array}$ & [41] \\
\hline $25 a$ & Molecular docking study & $\begin{array}{l}K_{i}=5.90 \mu \mathrm{M} . \\
\text { Inhibitory activity against SARS-CoV 3CL pro. }\end{array}$ & [41] \\
\hline $25 b$ & Molecular docking study & $\begin{array}{l}K_{i}=23.0 \mu \mathrm{M} . \\
\text { Inhibitory activity against SARS-CoV 3CL pro. }\end{array}$ & [41] \\
\hline $25 c$ & Molecular docking study & $\begin{array}{l}K_{i}=0.46 \mu \mathrm{M} . \\
\text { IC } 50=21.0 \mu \mathrm{M} . \\
\text { Inhibitory activity against SARS-CoV } 3 \mathrm{CL}^{\text {pro }} \text {. }\end{array}$ & {$[41]$} \\
\hline 25d & Molecular docking study & $\begin{array}{l}K_{i}=1.60 \mu \mathrm{M} . \\
\text { Inhibitory activity against SARS-CoV 3CL pro. }\end{array}$ & {$[41]$} \\
\hline $25 \mathrm{e}$ & Molecular docking study & $\begin{array}{l}K_{i}=1.71 \mu \mathrm{M} . \\
\text { Inhibitory activity against SARS-CoV 3CL pro. }\end{array}$ & {$[41]$} \\
\hline $25 f$ & Molecular docking study & $\begin{array}{l}K_{i}=29.0 \mu \mathrm{M} . \\
\text { Inhibitory activity against SARS-CoV 3CL pro. }\end{array}$ & [41] \\
\hline $25 g$ & Molecular docking study & $\begin{array}{l}K_{i}=9.40 \mu \mathrm{M} . \\
\text { Inhibitory activity against SARS-CoV } 3 \mathrm{CL}^{\text {pro }} \text {. }\end{array}$ & [41] \\
\hline $25 \mathrm{~h}$ & Molecular docking study & $\begin{array}{l}K_{i}=1.20 \mu \mathrm{M} . \\
\text { Inhibitory activity against SARS-CoV } 3 \mathrm{CL}^{\text {pro }} \text {. }\end{array}$ & [41] \\
\hline $26 a$ & Molecular docking study & $\begin{array}{l}K_{i}=3.20 \mu \mathrm{M} . \\
\text { Inhibitory activity against SARS-CoV 3CL pro. }\end{array}$ & {$[41]$} \\
\hline $26 \mathbf{b}$ & Molecular docking study & $\begin{array}{l}K_{i}=0.42 \mu \mathrm{M} . \\
\mathrm{IC}_{50}=43.0 \mu \mathrm{M} . \\
\text { Inhibitory activity against SARS-CoV 3CL pro. }\end{array}$ & {$[41]$} \\
\hline
\end{tabular}




\begin{tabular}{|c|c|c|c|}
\hline Synthetic drugs & $\begin{array}{l}\text { Experimental } \\
\text { system (model cell line, in } \\
\text { silico, in vivo) }\end{array}$ & Keys findings/mechanism insights & Authors \\
\hline $26 c$ & Molecular docking study & $\begin{array}{l}K_{i}=0.61 \mu \mathrm{M} . \\
\text { Inhibitory activity against SARS-CoV 3CL pro. }\end{array}$ & [41] \\
\hline 26d & Molecular docking study & $\begin{array}{l}K_{i}=7.4 \mu \mathrm{M} . \\
\text { Inhibitory activity against SARS-CoV 3CL pro. }\end{array}$ & [41] \\
\hline $26 e$ & Molecular docking study & $\begin{array}{l}K_{i}=0.69 \mu \mathrm{M} . \\
\text { Inhibitory activity against SARS-CoV } 3 \mathrm{CL}^{\text {pro }} \text {. }\end{array}$ & {$[41]$} \\
\hline $26 f$ & Molecular docking study & $\begin{array}{l}K_{i}=0.70 \mu \mathrm{M} . \\
\text { Inhibitory activity against SARS-CoV 3CL pro. }\end{array}$ & [41] \\
\hline $26 \mathrm{~g}$ & Molecular docking study & $\begin{array}{l}K_{i}=1.30 \mu \mathrm{M} . \\
\text { Inhibitory activity against SARS-CoV 3CL pro. }\end{array}$ & [41] \\
\hline $26 \mathrm{~h}$ & Molecular docking study & $\begin{array}{l}K_{i}=0.56 \mu \mathrm{M} . \\
\mathrm{IC}_{50}=24.0 \mu \mathrm{M} . \\
\text { Inhibitory activity against SARS-CoV } 3 \mathrm{CL}^{\text {pro }} \text {. }\end{array}$ & [41] \\
\hline $26 \mathbf{i}$ & Molecular docking study & $\begin{array}{l}K_{i}=1.56 \mu \mathrm{M} . \\
\text { Inhibitory activity against SARS-CoV 3CL pro. }\end{array}$ & [41] \\
\hline $26 \mathbf{j}$ & Molecular docking study & $\begin{array}{l}K_{i}=8.4 \mu \mathrm{M} . \\
\text { Inhibitory activity against SARS-CoV 3CL }{ }^{\text {pro }} \text {. }\end{array}$ & [41] \\
\hline $26 \mathbf{k}$ & Molecular docking study & $\begin{array}{l}K_{i}=0.84 \mu \mathrm{M} . \\
\text { Inhibitory activity against SARS-CoV 3CL pro. }\end{array}$ & [41] \\
\hline 261 & Molecular docking study & $\begin{array}{l}K_{i}=3.20 \mu \mathrm{M} . \\
\text { Inhibitory activity against SARS-CoV 3CL pro. }\end{array}$ & {$[41]$} \\
\hline $26 \mathrm{~m}$ & Molecular docking study & $\begin{array}{l}K_{i}=0.39 \mu \mathrm{M} . \\
\text { IC } 50=10.0 \mu \mathrm{M} . \\
\text { Good inhibitory activity against } 3 \mathrm{CL}^{\mathrm{pro}} \text {. }\end{array}$ & [41] \\
\hline $26 n$ & Molecular docking study & $\begin{array}{l}K_{i}=0.33 \mu \mathrm{M} . \\
\text { IC }_{50}=14.0 \mu \mathrm{M} . \\
\text { Good inhibitory activity against } 3 \mathrm{CL}^{\mathrm{pro}} \text {. }\end{array}$ & [41] \\
\hline $27 \mathbf{a}$ & Molecular docking study & $\begin{array}{l}K_{i}=0.66 \mu \mathrm{M} . \\
\text { Inhibitory activity against SARS-CoV 3CL pro. }\end{array}$ & [41] \\
\hline $27 \mathbf{b}$ & Molecular docking study & $\begin{array}{l}K_{i}=37.0 \mu \mathrm{M} . \\
\text { Inhibitory activity against SARS-CoV 3CL pro. }\end{array}$ & {$[41]$} \\
\hline $27 \mathrm{c}$ & Molecular docking study & $\begin{array}{l}K_{i}=52.0 \mu \mathrm{M} . \\
\text { Inhibitory activity against SARS-CoV 3CL pro. }\end{array}$ & [41] \\
\hline 27d & Molecular docking study & $\begin{array}{l}K_{i}=2.50 \mu \mathrm{M} . \\
\text { Inhibitory activity against SARS-CoV 3CL } \mathrm{CL}^{\text {pro }} \text {. }\end{array}$ & [41] \\
\hline 1 & Molecular docking study & $\begin{array}{l}\text { IC } 50=0.5 \mu \mathrm{M} . \\
\text { Inhibitory activity against SARS-CoV } 3 \mathrm{CL}^{\text {pro }} \text {. }\end{array}$ & {$[42]$} \\
\hline 2 & Molecular docking study & $\begin{array}{l}\mathrm{IC}_{50}=5 \mu \mathrm{M} . \\
\text { Inhibitory activity against SARS-CoV } 3 \mathrm{CL}^{\text {pro }} \text {. }\end{array}$ & {$[42]$} \\
\hline 3 & Molecular docking study & $\begin{array}{l}\text { IC } 50=11.1 \mu \mathrm{M} \text {. } \\
\text { Inhibitory activity against SARS-CoV 3CL pro. }\end{array}$ & [42] \\
\hline 4 & Molecular docking study & $\begin{array}{l}\mathrm{IC}_{50}=30 \mathrm{nM} \text {. } \\
\text { Inhibitory activity against SARS-CoV 3CL pro. }\end{array}$ & [42] \\
\hline 5 & Molecular docking study & $\begin{array}{l}\mathrm{IC}_{50}=13 \mu \mathrm{M} \text {. } \\
\text { Inhibitory activity against SARS-CoV } 3 \mathrm{CL}^{\text {pro }} \text {. }\end{array}$ & {$[42]$} \\
\hline 6 & Molecular docking study & $\begin{array}{l}\mathrm{IC}_{50}=1.5 \mu \mathrm{M} \text {. } \\
\text { Inhibitory activity against SARS-CoV } 3 \mathrm{CL}^{\text {pro }} \text {. }\end{array}$ & {$[42]$} \\
\hline 7 & Molecular docking study & $\begin{array}{l}\mathrm{IC}_{50}=6.2 \mu \mathrm{M} . \\
\text { Inhibitory activity against SARS-CoV } 3 \mathrm{CL}^{\text {pro. }} \text {. }\end{array}$ & {$[42]$} \\
\hline 9a & Molecular docking study & Inactive. & {$[42]$} \\
\hline $9 \mathbf{b}$ & Molecular docking study & Inactive. & [42] \\
\hline 9c & Molecular docking study & Inactive. & [42] \\
\hline $10 \mathbf{a}$ & Molecular docking study & Inactive. & {$[42]$} \\
\hline $10 \mathrm{~b}$ & Molecular docking study & Inactive. & [42] \\
\hline $10 \mathrm{c}$ & Molecular docking study & $\begin{array}{l}\mathrm{IC}_{50}=11 \mu \mathrm{M} . \\
\text { Inhibitory activity against SARS-CoV } 3 \mathrm{CL}^{\text {pro }} \text {. }\end{array}$ & {$[42]$} \\
\hline 12 & Molecular docking study & $\mathrm{IC}_{50}>20 \mu \mathrm{M}$ & [42] \\
\hline 13a & Molecular docking study & $\begin{array}{l}\mathrm{IC}_{50}=7.72 \mu \mathrm{M} . \\
\text { Inhibitory activity against SARS-CoV } 3 \mathrm{CL}^{\text {pro }} \text {. }\end{array}$ & [42] \\
\hline 13b & Molecular docking study & $\begin{array}{l}\mathrm{IC}_{50}=25.3 \mu \mathrm{M} . \\
\text { Inhibitory activity against SARS-CoV } 3 \mathrm{CL}^{\text {pro }} \text {. }\end{array}$ & {$[42]$} \\
\hline $13 \mathrm{c}$ & Molecular docking study & $\begin{array}{l}\mathrm{IC}_{50}=6.9 \mu \mathrm{M} \text {. } \\
\text { Inhibitory activity against SARS-CoV } 3 \mathrm{CL}^{\text {pro }} \text {. }\end{array}$ & {$[42]$} \\
\hline
\end{tabular}




\begin{tabular}{|c|c|c|c|}
\hline Synthetic drugs & $\begin{array}{l}\text { Experimental } \\
\text { system (model cell line, in } \\
\text { silico, } \text { in vivo) }\end{array}$ & Keys findings/mechanism insights & Authors \\
\hline 13d & Molecular docking study & $\begin{array}{l}\mathrm{IC}_{50}=4.1 \mu \mathrm{M} \text {. } \\
\text { Inhibitory activity against SARS-CoV } 3 \mathrm{CL}^{\text {pro }} \text {. }\end{array}$ & [42] \\
\hline $13 \mathbf{e}$ & Molecular docking study & $\begin{array}{l}\mathrm{IC}_{50}=22.5 \mu \mathrm{M} \text {. } \\
\text { Inhibitory activity against SARS-CoV } 3 \mathrm{CL}^{\text {pro }} \text {. }\end{array}$ & [42] \\
\hline 13f & Molecular docking study & $\begin{array}{l}\text { IC } 50=9.1 \mu \mathrm{M} . \\
\text { Inhibitory activity against SARS-CoV } 3 \mathrm{CL}^{\text {pro. }} \text {. }\end{array}$ & [42] \\
\hline $13 \mathrm{~g}$ & Molecular docking study & $\begin{array}{l}\mathrm{IC}_{50}=3.8 \mu \mathrm{M} \text {. } \\
\text { Inhibitory activity against SARS-CoV } 3 \mathrm{CL}^{\text {pro }} \text {. }\end{array}$ & [42] \\
\hline 13h & Molecular docking study & $\begin{array}{l}\mathrm{IC}_{50}=100 \mu \mathrm{M} \text {. } \\
\text { Inhibitory activity against SARS-CoV } 3 \mathrm{CL}^{\text {pro }} \text {. }\end{array}$ & [42] \\
\hline $\mathbf{1 3 i}$ & Molecular docking study & Inactive. & {$[42]$} \\
\hline 13j & Molecular docking study & $\begin{array}{l}\mathrm{IC}_{50}=100 \mu \mathrm{M} . \\
\text { Inhibitory activity against SARS-CoV 3CL }\end{array}$ & {$[42]$} \\
\hline 13k & Molecular docking study & $\begin{array}{l}\mathrm{IC}_{50}=26 \mu \mathrm{M} . \\
\text { Inhibitory activity against SARS-CoV 3CL pro. }\end{array}$ & [42] \\
\hline 131 & Molecular docking study & Inactive. & [42] \\
\hline 16a & Molecular docking study & $\begin{array}{l}\mathrm{IC}_{50}=2.9 \mu \mathrm{M} . \\
\text { Inhibitory activity against SARS-CoV 3CL }\end{array}$ & [42] \\
\hline 16b & Molecular docking study & $\begin{array}{l}\mathrm{IC}_{50}=3.6 \mu \mathrm{M} \text {. } \\
\text { Inhibitory activity against SARS-CoV 3CL }{ }^{\text {pro }} \text {. }\end{array}$ & {$[42]$} \\
\hline $16 \mathrm{c}$ & Molecular docking study & $\begin{array}{l}\mathrm{IC}_{50}=13.3 \mu \mathrm{M} \text {. } \\
\text { Inhibitory activity against SARS-CoV } 3 \mathrm{CL}^{\text {pro }} \text {. }\end{array}$ & [42] \\
\hline 16d & Molecular docking study & $\begin{array}{l}\mathrm{IC}_{50}=3.4 \mu \mathrm{M} \text {. } \\
\text { Inhibitory activity against SARS-CoV } 3 \mathrm{CL}^{\text {pro }} \text {. }\end{array}$ & [42] \\
\hline $16 \mathrm{e}$ & Molecular docking study & $\begin{array}{l}\mathrm{IC}_{50}=4.1 \mu \mathrm{M} \text {. } \\
\text { Inhibitory activity against SARS-CoV } 3 \mathrm{CL}^{\text {pro }} \text {. }\end{array}$ & {$[42]$} \\
\hline $16 f$ & Molecular docking study & $\begin{array}{l}\mathrm{IC}_{50}=8.1 \mu \mathrm{M} . \\
\text { Inhibitory activity against SARS-CoV 3CL pro. }\end{array}$ & [42] \\
\hline $16 \mathrm{~g}$ & Molecular docking study & $\begin{array}{l}\mathrm{IC}_{50}=22.1 \mu \mathrm{M} . \\
\text { Inhibitory activity against SARS-CoV } 3 \mathrm{CL}^{\text {pro }} \text {. }\end{array}$ & [42] \\
\hline $16 \mathrm{~h}$ & Molecular docking study & $\begin{array}{l}\mathrm{IC}_{50}=100 \mu \mathrm{M} \text {. } \\
\text { Inhibitory activity against SARS-CoV } 3 \mathrm{CL}^{\text {pro }} \text {. }\end{array}$ & [42] \\
\hline $16 \mathbf{i}$ & Molecular docking study & $\begin{array}{l}\mathrm{IC}_{50}=10.3 \mu \mathrm{M} \text {. } \\
\text { Inhibitory activity against SARS-CoV } 3 \mathrm{CL}^{\text {pro }} \text {. }\end{array}$ & {$[42]$} \\
\hline $16 j$ & Molecular docking study & $\begin{array}{l}\mathrm{IC}_{50}=2.1 \mu \mathrm{M} . \\
\text { Inhibitory activity against SARS-CoV } 3 \mathrm{CL}^{\text {pro }} \text {. }\end{array}$ & {$[42]$} \\
\hline $16 k$ & Molecular docking study & $\begin{array}{l}\mathrm{IC}_{50}=1.5 \mu \mathrm{M} . \\
\text { Inhibitory activity against SARS-CoV } 3 \mathrm{CL}^{\text {pro. }} \text {. }\end{array}$ & [42] \\
\hline $17 \mathbf{a}$ & Molecular docking study & $\begin{array}{l}\mathrm{IC}_{50}=0.051 \mu \mathrm{M} . \\
\text { Inhibitory activity against SARS-CoV } 3 \mathrm{CL}^{\text {pro }} \text {. }\end{array}$ & [42] \\
\hline $17 \mathbf{b}$ & Molecular docking study & $\begin{array}{l}\mathrm{IC}_{50}=0.97 \mu \mathrm{M} \text {. } \\
\text { Inhibitory activity against SARS-CoV } 3 \mathrm{CL}^{\text {pro }} \text {. }\end{array}$ & [42] \\
\hline $17 \mathrm{c}$ & Molecular docking study & $\begin{array}{l}\mathrm{IC}_{50}=0.70 \mu \mathrm{M} \text {. } \\
\text { Inhibitory activity against SARS-CoV } 3 \mathrm{CL}^{\text {pro }} \text {. }\end{array}$ & {$[42]$} \\
\hline 17d & Molecular docking study & $\begin{array}{l}\mathrm{IC}_{50}=2.0 \mu \mathrm{M} . \\
\text { Inhibitory activity against SARS-CoV } 3 \mathrm{CL}^{\text {pro }} \text {. }\end{array}$ & [42] \\
\hline $17 \mathrm{e}$ & Molecular docking study & $\begin{array}{l}\mathrm{IC}_{50}=12.5 \mu \mathrm{M} . \\
\text { Inhibitory activity against SARS-CoV 3CL pro. }\end{array}$ & [42] \\
\hline 1 & $\begin{array}{l}\text { Normal human fibroblast } \\
\text { cells (HS27) } \\
\text { In silico studies }\end{array}$ & $\begin{array}{l}\text { Activity against } \mathrm{HCV}\left(\mathrm{EC}_{50}=0.8 \mu \mathrm{M}\right) \text {. } \\
\text { Activity against } \mathrm{SCV}\left(\mathrm{IC}_{50}>50 \mu \mathrm{M} \text { for ATPase activity, }\right. \\
\mathrm{IC}_{50}=11 \mu \mathrm{M} \text { for helicase activity). }\end{array}$ & {$[43]$} \\
\hline 3 & $\begin{array}{l}\text { Normal human fibroblast } \\
\text { cells (HS27) } \\
\text { In silico studies }\end{array}$ & $\begin{array}{l}\text { Activity against } \mathrm{HCV}\left(\mathrm{EC}_{50}=5 \mu \mathrm{M}\right) \text {. } \\
\text { Activity against } \mathrm{SCV}\left(\mathrm{IC}_{50}>50 \mu \mathrm{M} \text { for ATPase activity, }\right. \\
\mathrm{IC}_{50}>50 \mu \mathrm{M} \text { for helicase activity). }\end{array}$ & [43] \\
\hline 4 & $\begin{array}{l}\text { Normal human fibroblast } \\
\text { cells (HS27) } \\
\text { In silico studies } \\
\end{array}$ & $\begin{array}{l}\text { Activity against } \mathrm{HCV}\left(\mathrm{EC}_{50}=3 \mu \mathrm{M}\right) \text {. } \\
\text { Activity against } \mathrm{SCV}\left(\mathrm{IC}_{50}>50 \mu \mathrm{M} \text { for ATPase activity, }\right. \\
\mathrm{IC}_{50}>50 \mu \mathrm{M} \text { for helicase activity). }\end{array}$ & [43] \\
\hline 1a & Vero 76 cells & $\begin{array}{l}\text { Reduced cytopathic effect induced by human SARS } \\
\text { CoV. } \\
\text { EC }_{50}=0.018 \mu \mathrm{M} \text {. }\end{array}$ & {$[44]$} \\
\hline $1 \mathrm{c}$ & Vero 76 cells & $\begin{array}{l}\text { Reduced cytopathic effect induced by human SARS } \\
\text { CoV. } \\
\text { EC }_{50}<0.005 \mu \mathrm{M} \text {. }\end{array}$ & [44] \\
\hline 1e & Vero 76 cells & $\begin{array}{l}\text { Reduced cytopathic effect induced by human SARS } \\
\text { CoV. }\end{array}$ & [44] \\
\hline
\end{tabular}




\begin{tabular}{l|l|l|c} 
Synthetic drugs & $\begin{array}{l}\text { Experimental } \\
\text { system (model cell line, in } \\
\text { silico, in vivo) }\end{array}$ & Keys findings/mechanism insights & Authors \\
\hline $\mathbf{4 a}$ & Vero 76 cells & $\mathrm{EC}_{50}<0.005 \mu \mathrm{M}$. & [44] \\
& & $\begin{array}{l}\text { Reduced cytopathic effect induced by human SARS } \\
\text { CoV. } \\
\text { EC } 50=0.34 \mu \mathrm{M} .\end{array}$ & $\begin{array}{l}\text { Reduced cytopathic effect induced by human SARS } \\
\text { CoV. } \\
\text { EC } 50=0.039 \mu \mathrm{M} .\end{array}$ \\
& Vero 76 cells &
\end{tabular}

Researchers have greatly exploited the behavior of other coronaviruses (SARS-CoV and MERS) to be able to mimic the molecular action on pharmacodynamic targets, which are certainly similar. Indeed, as being the result of Darwinian adaptive mutations, SARS-CoV-2 uses the same molecular scenario in its parasitic behavior, which made it possible to test some molecules against the targets of other coronaviruses, which will certainly have pharmacodynamic actions and possibly therapeutic effects on SARS-CoV-2. In our research approach, a bibliometric study was carried out using the various databases in order to identify, index, and organize the studies that have been recently carried out on molecules that specifically attack SARS-CoV-2 or the molecular targets of other coronaviruses. Table 2 presents the research work on the properties of synthetic molecules that we have schematized by ChemDraw.

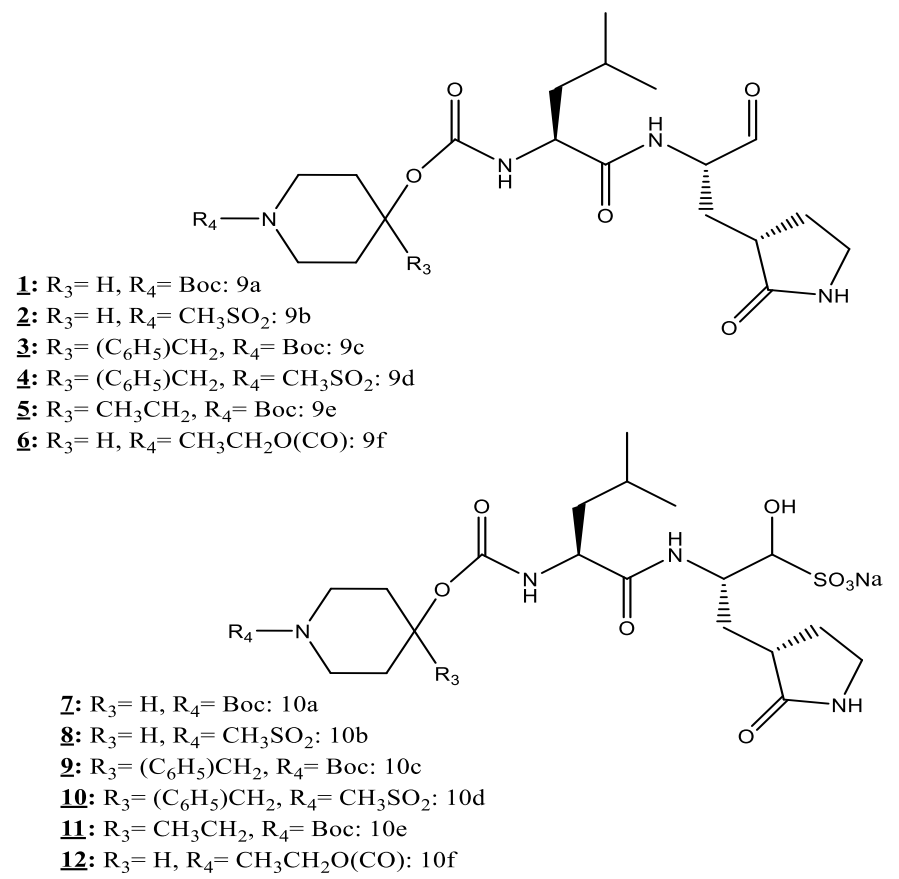

Figure 7. Structures of guided design inhibitor of SARS-CoV-2 (this structure was drawn by ChemDraw).

The CL3 protease protein is a molecule expressed by the virus to proteolyze nonfunctional viral proteins into functional function units. The inhibition of this protease is an important pharmacological target for blocking the assembly of the virus after its impossible and/or difficult replication. In this way, several studies have already confirmed the inhibitory action of certain synthetic molecules against CL3p (Table 2). Using an in-silico model, Galasiti Kankanamalage et al. [36] tested the action of fourteen synthetic molecules (Figure 7) on the 3CL protease of MERS coronavirus. The molecule 10a has been shown to be the most active in inhibiting this protein with an inhibition value of $\mathrm{IC}_{50}=0.6 \mu \mathrm{M}$. The two molecules $10 \mathrm{f}$ and 
$10 \mathrm{a}$ also revealed a strong inhibition ( $\left.\mathrm{IC}_{50}=0.5 \mu \mathrm{M}\right)$, followed by $9 \mathrm{f}, 10 \mathrm{~b}$ and $9 \mathrm{a}\left(\mathrm{IC}_{50}=0.6 \mu \mathrm{M}\right)$, then by $9 \mathrm{~b}, 10 \mathrm{c}$ and $9 \mathrm{~d}\left(\mathrm{IC}_{50}=0.5 \mu \mathrm{M}\right)[36]$.



1: Compound 1<smiles>COc1cc(/C=N/NC(=O)/C(=C/c2ccccc2)NC(=O)c2ccccc2)cc(OC)c1O</smiles>

3: Compound 3<smiles>COc1cc(C2C(C(=O)c3ccc(OCC(C)C)cc3C)=C(O)C(=O)N2CCN(C)C)ccc1O</smiles>

2: Compound 2<smiles>Cc1nc(C)c(C(=O)C2=C(O)C(=O)N(CCCN3CCOCC3)C2c2cccc([N+](=O)[O-])c2)s1</smiles><smiles>O=C(CSc1ncnc2c1sc1nc(N3CCOCC3)c3c(c12)CCCC3)NCc1ccco1</smiles>

5: Compound 5<smiles>C/C(=C(/NC(=O)c1ccc(C)cc1)C(=O)NCCCN(C)C)c1ccc(-c2cccc([N+](=O)O)c2)o1</smiles>

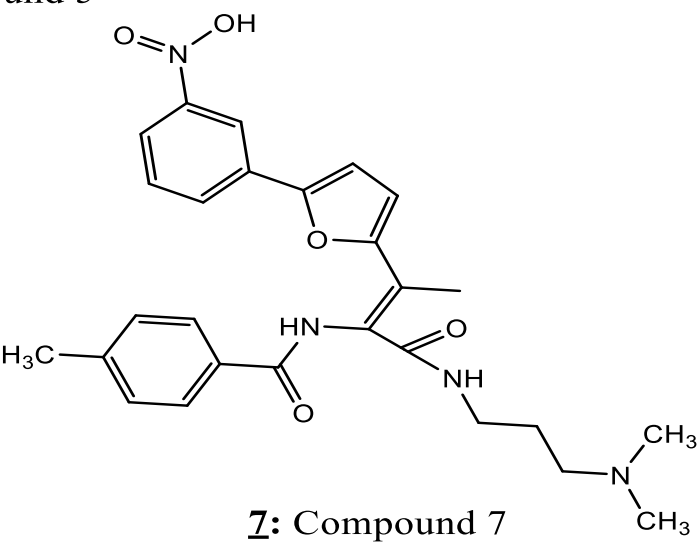

Figure 8. Chemical structure of the novel $3 \mathrm{CL}^{\text {pro }}$ inhibitors studied (these structures were drawn by ChemDraw).

In another work, the inhibitory action of seven synthetic molecules (Figure 8) was tested against CL3p [38]. Molecule 6 showed very strong inhibition with a low concentration $\left(\mathrm{IC}_{50}=38.57 \pm 2.41 \mu \mathrm{M}\right)$ followed by molecule $7\left(\mathrm{IC}_{50}=41.39 \pm 1.17 \mu \mathrm{M}\right)$. 
<smiles></smiles>

<smiles></smiles><smiles>CCCC[C@H](NC(=O)OCc1ccccc1)C(=O)N[C@@H](C[C@@H]1CCNC1=O)C(=O)c1nc2ccccc2s1</smiles><smiles>CC(C)[C@H](NC(=O)OCc1ccccc1)C(=O)N[C@@H](C[C@H]1CCNC1=O)C(=O)c1nc2ccccc2s1</smiles><smiles>CCC(C)C(NC(=O)OCc1ccccc1)[C@@H](C(=O)N[C@@H](C[C@@H]1CCNC1=O)C(=O)c1nc2ccccc2s1)C(C)CC</smiles>

5: $25 \mathrm{e}$

6: $25 f$<smiles>[Z16][R5]</smiles><smiles>O=C(N[C@@H](Cc1ccccc1)C(=O)N[C@@H](C[C@@H]1CCNC1=O)C(=O)c1nc2ccccc2s1)OCc1ccccc1</smiles>

Figure 9. Structure of synthetic dipeptide-type SARS-CoV 3CL protease inhibitors (these structures were drawn by ChemDraw).

The authors have shown that the inhibitory action of these two molecules is a competitive action. However, molecules 1, 2, and 4 showed moderate inhibitory effects against CL3p with inhibitory concentrations of $\mathrm{IC}_{50}=58.35 \pm 1.41, \quad \mathrm{IC}_{50}=62.79 \pm 3.19$, and $\mathrm{IC}_{50}=77.09 \pm 1.94 \mu \mathrm{M}$, respectively. Other molecules showed the lowest inhibitory effects. A previous study highlighted the anti-SARS-CoV effects of 26 synthetic molecules (Figure 8) by studying, in silico, their interactions with the CL3 protease [41]. These molecules have shown a different inhibitory action to each other and give hope for their use as therapeutic drugs against COVID-19. Indeed, the results of this study allowed the identification of certain molecules with an important inhibitory action against CL3p. 
<smiles>[R16][Y6]#[R16]</smiles><smiles>[R6][Y6]#[W]</smiles>

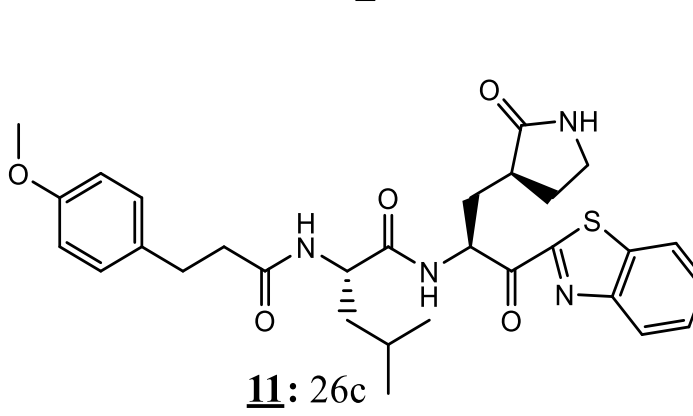<smiles>[R12][Z10](=O)C[C@H](CC(C)C)NC(=O)[C@H](C[C@@H]1CCNC1=O)C(=O)c1nc2ccccc2s1</smiles><smiles></smiles>

13: $26 \mathrm{e}$<smiles>[R16]C[Y5]#[Y5]</smiles><smiles>CC(C)C[C@H](NC(=O)COc1ccccc1)C(=O)N[C@@H](C[C@@H]1CCNC1=O)C(=O)c1nc2ccccc2s1</smiles><smiles></smiles><smiles>CC(C)C[C@H](NC(=O)COc1ccc(O)cc1)C(=O)N[C@@H](C[C@@H]1CCNC1=O)C(=O)c1nc2ccccc2s1</smiles><smiles>CC(C)C[C@H](NC(=O)COc1cccc(N(C)C)c1)C(=O)N[C@@H](C[C@@H]1CCNC1=O)C(=O)c1nc2ccccc2s1</smiles><smiles></smiles>

Figure 9. Continued.

The $25 \mathrm{c}$ molecule inhibited the CL3 protease at a low concentration $\left(\mathrm{IC}_{50}=21.0 \mu \mathrm{M}\right.$ ) and a high degree of affinity $\left(\mathrm{K}_{\mathrm{i}}=0.46 \mu \mathrm{M}\right)$. The $26 \mathrm{~m}$ molecule also showed significant inhibition ( $\mathrm{IC}_{50}=10.0 \mu \mathrm{M}$ ) with a degree of a strong bond with CL3p $\left(\mathrm{K}_{\mathrm{i}}=0.39 \mu \mathrm{M}\right)$ [41].

In addition, the molecule $26 \mathrm{n}$ showed similar significant effects $\left(\mathrm{K}_{\mathrm{i}}=0.33 \mu \mathrm{M}\right.$ and $\mathrm{IC}_{50}=14.0 \mu \mathrm{M}$ ). The other molecules (Figure 9) also showed inhibitory effects against CL3p 
but in a moderate way. These molecules deserve further investigations that could allow for highlighting anti-CL3p drugs for COVID-19 treatment [41].<smiles>[Z12][R17](=O)C[C@H](NC(=O)CNc1cccc(OC)c1)C(=O)N[C@@H](C[C@@H]1CCNC1=O)C(=O)c1nc2ccccc2s1</smiles><smiles></smiles><smiles></smiles><smiles>[Z16]#[Z16][CH]C(C)C[C@H](NC(=O)OCc1ccccc1)C(=O)N[C@H](C[C@@H]1CCNC1=O)C(=O)c1ncc(-c2ccc(C)cc2)s1</smiles><smiles>COc1ccc(-c2cnc(C(=O)N[C@@H](C[C@@H]3CCNC3=O)C(=O)N[C@@H](CC(C)C)C(=O)NC(=O)OCc3ccccc3)s2)cc1</smiles><smiles></smiles>

Figure 9. Continued.

Mirza and Froeyen, [39] have tested, in silico, the effect of 12 compounds (Figure 10) on SARS-CoV-2 protein targets Nsp12 RNA-dependent-RNA-polymerase, Nsp13 helicase, and $\mathrm{M}^{\text {pro }}$ protease (Table 2). All molecules presented important interactions with $\mathrm{M}$ protease. Indeed, the molecule cmp3, cmp12, cmp14, cmp17, andcmp18 (Figure 10) interacted positively to $\mathrm{M}^{\text {pro }}$ with electrostatic energy of $\Delta \mathrm{Gelec}=-21.38 \mathrm{kcal} / \mathrm{mol}, \Delta \mathrm{Gelec}=-26.16$ $\mathrm{kcal} / \mathrm{mol}, \Delta \mathrm{Gelec}=-33.56 \mathrm{kcal} / \mathrm{mol}, \Delta \mathrm{Gelec}=-36.65 \mathrm{kcal} / \mathrm{mol}$, and $\Delta \mathrm{Gelec}=-5.39 \mathrm{kcal} / \mathrm{mol}$, respectively [39]. Non-structural proteins (nsps) such as RNA-dependent RNA polymerase (nsp 12) is essential for SARS-CoV-2 genome replication. Some synthetic molecules such as cmp2, cmp17a, and cmp21 (Figure 9) showed their capacity to block this target [39]. The molecule cmp2 showed important inhibition of Nsp12 RdRp by electrostatic energy $(\Delta \mathrm{Gtol}=-$ $41.74 \mathrm{kcal} / \mathrm{mol}$ ). Molecular interactions showed that this compound forms three H-bonds with motif C (Ser759), motifD (Lys798), and motif E (Ser814)[39]. However, cmp17a, also acted as electrostatic energy $(\Delta \mathrm{Gtol}=-34.37 \mathrm{kcal} / \mathrm{mol})$, interacted with five H-bonds with $\operatorname{Arg} 624$ (motif A), Thr680 and Ser682 (motif B), Ser756 (motif C) and Lys798 (motif D). Moreover, such bounds (A (Asp623), motif F (Arg553 and Arg555), and motif C (Ser759)) were established between cmp21Nsp12 RdRp [39]. 

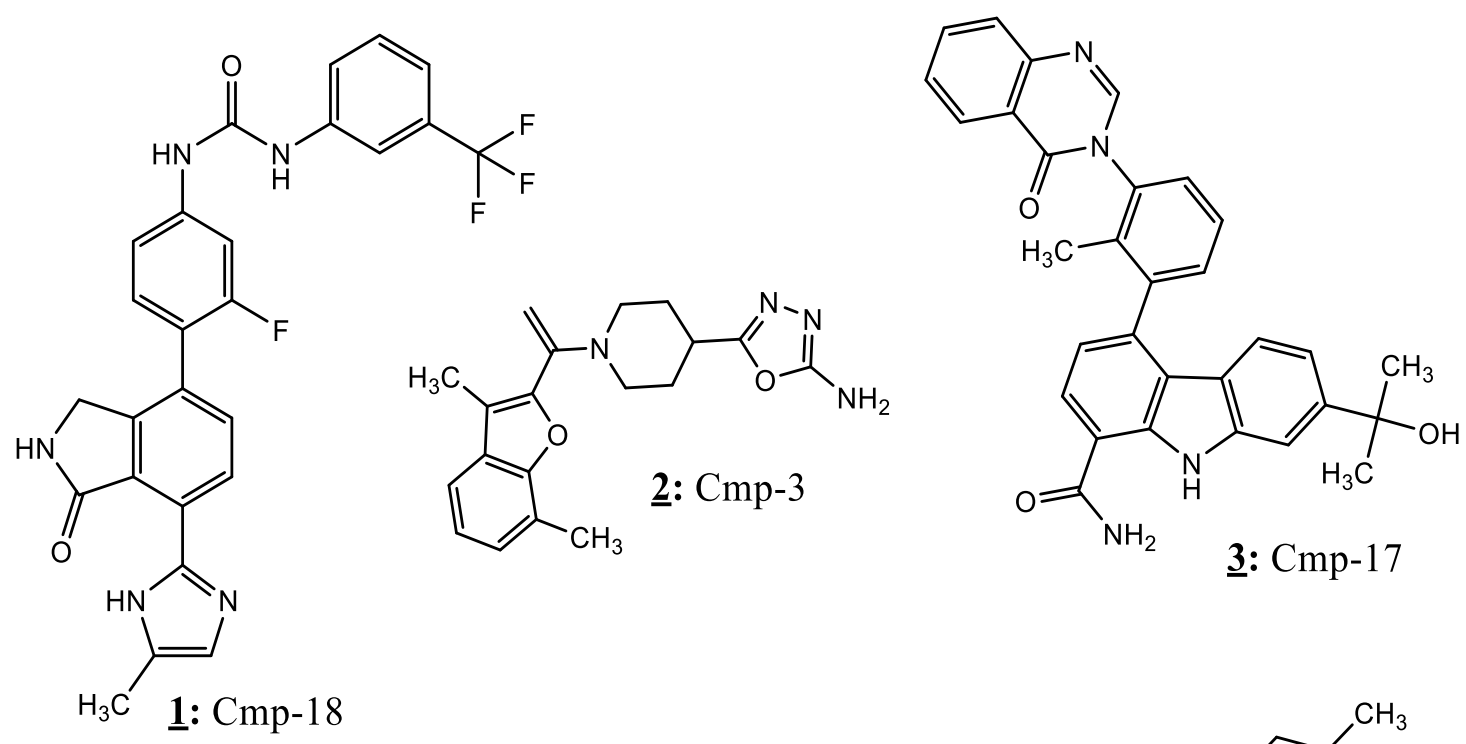

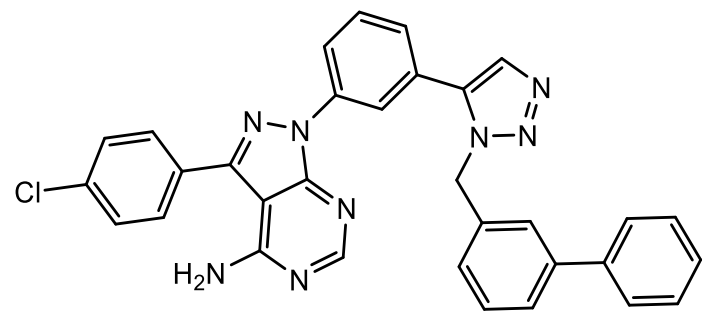

4: Cmp-14<smiles>Cc1ccc(NC(=O)CSC2=NN=C3C2C(=O)Cc2ccnn23)cc1</smiles>

5: Cmp-12<smiles>CC1(C)NC(=O)c2ccc(-c3cnn(-c4cncc(-n5cc(-c6ccc7c(c6)C(C)(C)NC7=O)cn5)c4)c3)cc21</smiles>

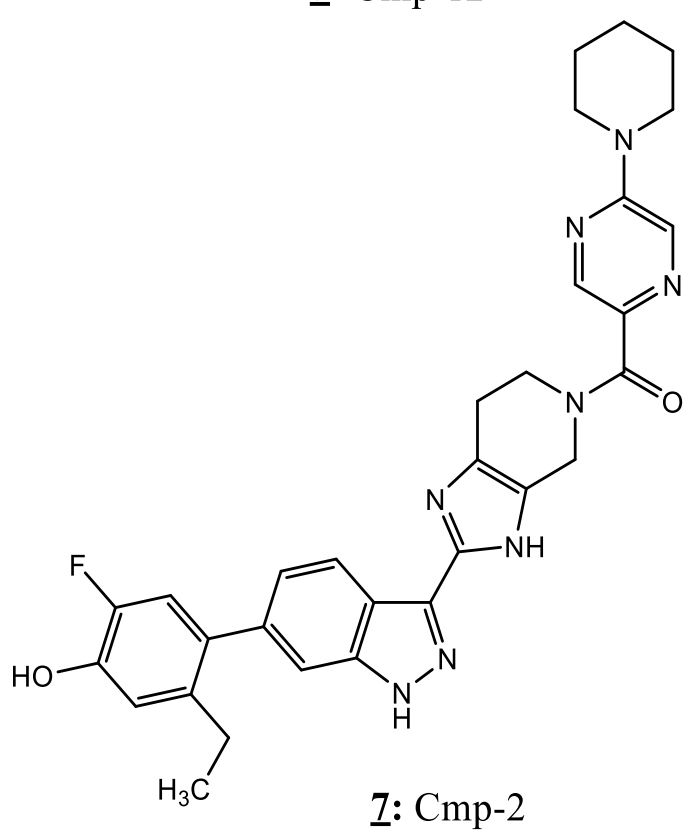

Figure 10. Chemical structures of synthetic inhibitors of against protease, Nsp12 and Nsp13 helicase of SRASCoV-2 (these structures were drawn by ChemDraw).

ACE2, a membrane receptor expressed in several human cells, is behind the penetration of SARS-CoV-2 into the host cell. Since the binding of SARS-CoV S protein to ACE2 is the first step in infection with this virus, this protein constitutes a major pharmacological target for inhibiting the penetration SARS-CoV-2. Consequently, several molecules have been tested, in silico, against this receptor. Ho et al. [37] analyzed the inhibitory powers of 14 synthesized peptides derived from $\mathrm{S}$ protein on the interaction of this protein and ACE2. By the ELISA test, they found that SP-10 (residues 668-679), SP-8 (residues 483-494), and SP-4 (residues 192-203) significantly inhibited the interaction in a dose-dependent manner with IC50 values 
of $1.88 \pm 0.52,6.99 \pm 0.71$, and $4.30 \pm 2.18 \mathrm{nmol}$, respectively, with the definition of a novel region of receptor binding by a peptide-scanning method.



8: Cmp-21<smiles>Fc1ccccc1F</smiles><smiles>C=CC(=C)n1cc(-c2nc3sc(-c4cn(-c5ccccc5)nc4-c4ccccc4)nc3s2)c(-c2ccccc2)n1</smiles><smiles>Cc1ccc(S(=O)(=O)Nc2ccc(N=Nc3cc(C(=O)Nc4ccccc4)c(O)c4ccccc34)c(C)c2)cc1</smiles>

10: Cmp-11<smiles>O=C(NN1C(=O)c2cc3c(cc2C1=O)-c1cc2c(cc1C3)C(=O)N(NC(=O)c1ccncc1)C2=O)c1ccncc1</smiles>

11: Cmp-1<smiles>O=c1oc(=O)c2cc3c(=O)n(-c4ccc(Cc5ccc(-n6c(=O)c7cc8c(=O)oc(=O)c8cc7c6=O)cc5)cc4)c(=O)c3cc12</smiles>

12: Cmp-15

Figure 10. Continued.

In addition, they mentioned that SP-10 was a potent inhibitor of $\mathrm{S}$ protein binding to Vero E6 cells. Furthermore, Yang et al. [44] evaluated SARS-CoV-induced anti-CPE activity of the tylophorine compounds (1a, 1c, 1e, 4a, and 4b) (Figure 11) in Vero 76 cells and, consequently, these small molecules decreased the CPE induced by the virus, with EC 50 values between 5 and $340 \mathrm{nM}$ [44].

\subsection{Old antiviral drugs against SARS-CoV-2.}

In order to inhibit or delay a viral infection, the use of antivirals can be considered as an effective treatment. These molecules can limit the multiplication of viral particles by disrupting the viral replication cycle. Indeed, several studies have evaluated the mechanisms by which synthetic drugs act against different human coronaviruses (HCoV) [45-47]. In 2011, a Korean research team, using normal human fibroblast cells (HS27), showed that 5hydroxychromone derivatives with two arylmethyloxy substituents have antiviral activity 
against SARS-associated coronavirus [48]. Among the molecules tested, 3-iodobenzyloxysubstituted derivative $5 \mathrm{e}$ exhibited the most important activity ( $\mathrm{IC}_{50}=11 \mu \mathrm{M}$ for helicase activity and $4 \mu \mathrm{M}$ for ATPase activity) (Table 3).

1: $\mathrm{R}_{1}=\mathrm{R}_{2}=\mathrm{OCH}_{3}, \mathrm{R}_{3}=\mathrm{R}_{4}=\mathrm{H}, \mathrm{n}=1: \mathbf{1 a} \& \mathbf{1}^{\prime}$

2: $\mathrm{R}_{1}=\mathrm{R}_{2}=\mathrm{R}_{3}=\mathrm{OCH}_{3}, \mathrm{R}_{4}=\mathrm{H}, \mathrm{n}=1: \mathbf{1 b}$

ㅇ: $\mathrm{R}_{1}=\mathrm{R}_{2}=\mathrm{OCH}_{3}, \mathrm{R}_{3}=\mathrm{R}_{4}=\mathrm{H}, \mathrm{n}=2: \mathbf{1 c}$

4: $\mathrm{R}_{1}=\mathrm{R}_{3}=\mathrm{R}_{4}=\mathrm{H}, \mathrm{R}_{2}=\mathrm{OCH}_{3}, \mathrm{n}=1: \mathbf{1 d}$

5: $\mathrm{R}_{1}=\mathrm{R}_{3}=\mathrm{H}, \mathrm{R}_{2}=\mathrm{OCH}_{3}, \mathrm{R}_{4}=\mathrm{OH}, \mathrm{n}=1: \mathbf{1 e}$

ㅇ: $\mathrm{R}_{1}=\mathrm{R}_{3}=\mathrm{H}, \mathrm{R}_{2}=\mathrm{OCH}_{3}, \mathrm{R}_{4}=\mathrm{OAc}, \mathrm{n}=1: \mathbf{1 f}$

7: $\mathrm{R}_{1}=\mathrm{H}, \mathrm{R}_{3}=\mathrm{OCH}_{3}, \mathrm{R}_{2}=\mathrm{R}_{4}=\mathrm{OH}, \mathrm{n}=1: \mathbf{1 g}$

ㅇ: $\mathrm{R}_{1}=\mathrm{R}_{3}=\mathrm{H}, \mathrm{R}_{2}=\mathrm{R}_{4}=\mathrm{OH}, \mathrm{n}=1: \mathbf{1 h}$

9: $\mathrm{R}_{1}=\mathrm{R}_{2}=\mathrm{R}_{3}=\mathrm{OCH}_{3}, \mathrm{R}_{4}=\mathrm{H}, \mathrm{n}=2: \mathbf{1 i}$<smiles>[R]c1cc2c3c(c4cc(OC)c(C)cc4c2c([R3])c1[R])CN1C[CH]CC1C([R])C3</smiles>

10: $\mathrm{R}_{1}=\mathrm{R}_{3}=\mathrm{R}_{4}=\mathrm{H}, \mathrm{R}_{2}=\mathrm{OCH}_{3}, \mathrm{n}=2: \mathbf{1 j}$

11: $\mathrm{R}_{1}=\mathrm{OCH}_{3}, \mathrm{R}_{2}=\mathrm{H}, \mathrm{n}=1: \mathbf{2 a}$

12: $\mathrm{R}_{1}=\mathrm{R}_{2}=\mathrm{OCH}_{3}, \mathrm{n}=1: \mathbf{2 b}$

13: $\mathrm{R}_{1}=\mathrm{OCH}_{3}, \mathrm{R}_{2}=\mathrm{H}, \mathrm{n}=2$ : $2 \mathrm{c}$

14: $\mathrm{R}_{1}=\mathrm{R}_{2}=\mathrm{H}, \mathrm{n}=1: \mathbf{2 d}$<smiles>[R]c1cc2c3c(c4cc(OC)c([O-])cc4c2c([R2])c1[O-])C(=O)N1CCCCC1C3</smiles><smiles></smiles>

15: $\mathrm{R}_{1}=\mathrm{OCH}_{3}, \mathrm{R}_{2}=\mathrm{H}, \mathrm{n}=1: \mathbf{3 a}$

16: $\mathrm{R}_{1}=\mathrm{R}_{2}=\mathrm{OCH}_{3}, \mathrm{n}=1: \mathbf{3 b}$

17: $\mathrm{R}_{1}=\mathrm{OCH}_{3}, \mathrm{R}_{2}=\mathrm{H}, \mathrm{n}=2: 3 \mathrm{c}$<smiles>COc1cc2c3c(c4cc(OC)c(OC)cc4c2cc1OC)CN1CCCC1C3</smiles>

19: $n=2: 4 b$

Figure 11. Structures of phenanthroindolizines and phenanthroquinolizidines as inhibitors of coronavirus.

Table 3. Old antiviral drugs with possible anti-SARS-CoV-2 effects.

\begin{tabular}{l|l|l|l} 
Antiviral & $\begin{array}{l}\text { Experimental } \\
\text { system (model cell line, in } \\
\text { silico, in vivo) }\end{array}$ & Keys findings/mechanisms insights & Authors \\
\hline Sofosbuvir & $\begin{array}{l}\text { Construction of model for } \\
\text { Wuhan SARS-CoV-2 RdRp } \\
\text { from sequence analysis, } \\
\text { modeling and docking. }\end{array}$ & $\begin{array}{l}\text { Effectiveness of molecules tested as } \\
\text { potent drugs against the newly } \\
\text { emerged HCoV disease. }\end{array}$ & [49] \\
\hline IDX-184 & $\begin{array}{l}\text { Construction of model for } \\
\text { Wuhan SARS-CoV-2 RdRp } \\
\text { from sequence analysis, } \\
\text { modeling and docking. }\end{array}$ & $\begin{array}{l}\text { Effectiveness of molecules tested as } \\
\text { potent drugs against the newly } \\
\text { emerged HCoV disease. }\end{array}$ & [49] \\
\hline Ribavirin & $\begin{array}{l}\text { Construction of model for } \\
\text { Wuhan SARS-CoV-2 RdRp } \\
\text { from sequence analysis, } \\
\text { modeling and docking. }\end{array}$ & $\begin{array}{l}\text { Effectiveness of molecules tested as } \\
\text { potent drugs against the newly } \\
\text { emerged HCoV disease. }\end{array}$ & [49] \\
\hline Remidisvir & $\begin{array}{l}\text { Construction of model for } \\
\text { Wuhan SARS-CoV-2 RdRp }\end{array}$ & $\begin{array}{l}\text { Effectiveness of molecules tested as } \\
\text { potent drugs against the newly } \\
\text { emerged HCoV disease. }\end{array}$ & [49]
\end{tabular}




\begin{tabular}{|c|c|c|c|}
\hline Antiviral & $\begin{array}{l}\text { Experimental } \\
\text { system (model cell line, in } \\
\text { silico, in vivo) }\end{array}$ & Keys findings/mechanisms insights & Authors \\
\hline & $\begin{array}{l}\text { from sequence analysis, } \\
\text { modeling and docking. }\end{array}$ & & \\
\hline Pemirolast & $\begin{array}{l}\text { Molecular } \\
\text { (Autodock Tools) }\end{array}$ & $\begin{array}{l}\text { Limiting the binding of the SARS- } \\
\text { CoV-2 S-protein with the ACE2 } \\
\text { receptor. }\end{array}$ & {$[50]$} \\
\hline Isoniazid pyruvate & $\begin{array}{l}\text { Molecular } \\
\text { (Autodock Tools) }\end{array}$ & $\begin{array}{l}\text { Limiting the binding of the SARS- } \\
\text { CoV-2 S-protein with the ACE2 } \\
\text { receptor. }\end{array}$ & {$[50]$} \\
\hline Nitrofurantoin & $\begin{array}{ll}\text { Molecular } & \text { docking } \\
\text { (Autodock Tools) } & \end{array}$ & $\begin{array}{l}\text { Limiting the binding of the SARS- } \\
\text { CoV-2 S-protein with the ACE2 } \\
\text { receptor. }\end{array}$ & {$[50]$} \\
\hline Eriodictyol & $\begin{array}{ll}\text { Molecular } & \text { docking } \\
\text { (Autodock Tools) } & \end{array}$ & $\begin{array}{l}\text { Limiting the binding of the SARS- } \\
\text { CoV-2 S-protein with the ACE } 2 \\
\text { receptor. }\end{array}$ & {$[50]$} \\
\hline Cepharanthine & $\begin{array}{ll}\begin{array}{l}\text { Molecular } \\
\text { (Autodock Tools) }\end{array} & \text { docking } \\
\end{array}$ & $\begin{array}{l}\text { Limiting SARS-CoV-2 virus-host } \\
\text { interactions. }\end{array}$ & {$[50]$} \\
\hline Ergoloid & $\begin{array}{ll}\begin{array}{l}\text { Molecular } \\
\text { (Autodock Tools) }\end{array} & \text { docking } \\
\end{array}$ & $\begin{array}{l}\text { Limiting SARS-CoV-2's virus-host } \\
\text { interactions. }\end{array}$ & {$[50]$} \\
\hline Hypericin & $\begin{array}{ll}\text { Molecular } & \text { docking } \\
\text { (Autodock Tools) }\end{array}$ & $\begin{array}{l}\text { Limiting SARS-CoV-2's virus-host } \\
\text { interactions. }\end{array}$ & {$[50]$} \\
\hline Saquinavir & $\begin{array}{ll}\begin{array}{l}\text { Molecular } \\
\text { (Vina1.1.2) }\end{array} & \text { docking } \\
\end{array}$ & $\begin{array}{l}\text { Can bind to the NSP12-NSP7 } \\
\text { interface as interfacial blocker. }\end{array}$ & [51] \\
\hline Tipranavir & $\begin{array}{l}\text { Molecular } \\
\text { (Vina1.1.2). }\end{array}$ & $\begin{array}{l}\text { Can bind to the NSP12-NSP7 } \\
\text { interface as interfacial blocker. }\end{array}$ & [51] \\
\hline Lonafarnib & $\begin{array}{l}\text { Molecular } \\
\text { (Vina1.1.2). }\end{array}$ & $\begin{array}{l}\text { Can bind to the interface active } \\
\text { pockets between the SARS-CoV-2 } \\
\text { NSP12 and NSP7. }\end{array}$ & {$[51]$} \\
\hline Tegobuvir & $\begin{array}{l}\text { Molecular } \\
\text { (Vina1.1.2). }\end{array}$ & $\begin{array}{l}\text { Can bind to both of the interface } \\
\text { active pockets of the SARS-CoV-2 } \\
\text { NSP12-NSP7 and NSP12-NSP8. }\end{array}$ & [51] \\
\hline Olysio & $\begin{array}{l}\text { Molecular } \quad \text { docking } \\
\text { (Vina1.1.2). }\end{array}$ & $\begin{array}{l}\text { Can bind to the interface active } \\
\text { pockets of the SARS-CoV-2 NSP12- } \\
\text { NSP8. }\end{array}$ & [51] \\
\hline Filibuvir & $\begin{array}{l}\text { Molecular } \\
\text { (Vina1.1.2). }\end{array}$ & $\begin{array}{l}\text { Can bind to the interface active } \\
\text { pockets of the SARS-CoV-2 NSP12- } \\
\text { NSP8 }\end{array}$ & [51] \\
\hline Cepharanthine & $\begin{array}{l}\text { Molecular } \quad \text { docking } \\
\text { (Vina1.1.2) }\end{array}$ & $\begin{array}{l}\text { Can bind to the interface active } \\
\text { pockets of the SARS-CoV-2 NSP12- } \\
\text { NSP8. }\end{array}$ & [51] \\
\hline Trypsin & $\begin{array}{l}\text { 293T ACE2 and Vero E6 } \\
\text { cells }\end{array}$ & $\begin{array}{l}\text { Inhibition of cathepsin L (an } \\
\text { endosomal protease sensitive to } \mathrm{pH}) \\
\text { prevents SARS coronavirus entry. }\end{array}$ & {$[52]$} \\
\hline Peptide drugs & $\begin{array}{l}\text { An autodock vina based } \\
\text { docking simulation. }\end{array}$ & $\begin{array}{l}\text { Inhibition of SARS-CoV-2 main } \\
\text { protease. }\end{array}$ & [45] \\
\hline Hexachlorophene & $\begin{array}{l}\text { Mouse astrocytoma DBT and } \\
\text { fibroblast } 17 \mathrm{Cl}-1 \text { cells. }\end{array}$ & $\begin{array}{l}\text { Robust anti-coronavirus activities (a } \\
\left.\text { reduction of } 8 \log _{10}\right) \text { with an } \mathrm{IC}_{50}=1.2 \\
\mu \mathrm{M} \text {. }\end{array}$ & [46] \\
\hline Nitazoxanide & $\begin{array}{l}\text { Mouse astrocytoma DBT and } \\
\text { fibroblast } 17 \mathrm{Cl}-1 \text { cells. }\end{array}$ & $\begin{array}{l}\text { Robust anti-coronavirus activities }(\mathrm{a} \\
\left.\text { reduction } 6 \log _{10}\right) \text { with an } \mathrm{IC}_{50}=1 \mu \mathrm{M} \text {. }\end{array}$ & [46] \\
\hline Homoharringtonine & $\begin{array}{l}\text { Mouse astrocytoma DBT and } \\
\text { fibroblast } 17 \mathrm{Cl}-1 \text { cells. }\end{array}$ & $\begin{array}{l}\text { Robust anti-coronavirus activities (a } \\
\left.\text { reduction of } 8 \log _{10}\right) \text { with an } \\
\mathrm{IC}_{50}=12 \mathrm{nM} \text {. }\end{array}$ & [46] \\
\hline 6-Mercaptopurine & $\begin{array}{l}\text { Molecular docking } \\
\text { Modeling } 1.7 \text { software). }\end{array}$ & $\begin{array}{l}\text { Inhibition of MERS-CoV papain-like } \\
\text { protease. } \\
\text { Inhibition constant } \mathrm{K}_{\mathrm{is}}=14.3 \pm 1.6 \mu \mathrm{M} \text {. } \\
\text { IC }_{50} \text { of } 25.8-26.9 \mu \mathrm{M} \text {. }\end{array}$ & [47] \\
\hline 6-Thioguanine & $\begin{array}{l}\text { Molecular docking } \\
\text { Modeling } 1.7 \text { software). }\end{array}$ & $\begin{array}{l}\text { Inhibition of MERS-CoV papain-like } \\
\text { protease. } \\
\text { Inhibition constant } \mathrm{K}_{\mathrm{is}}=9.1 \pm 1.2 \mu \mathrm{M} \text {. } \\
\mathrm{IC}_{50} \text { of } 12.4-24.4 \mu \mathrm{M} \text {. }\end{array}$ & [47] \\
\hline N-ethylmaleimide & $\begin{array}{l}\text { Molecular docking } \\
\text { Modeling } 1.7 \text { software). }\end{array}$ & $\begin{array}{l}\text { Inhibition of MERS-CoV papain-like } \\
\text { protease. } \\
\text { IC50 of } 45.0 \mu \mathrm{M} \text {. }\end{array}$ & [47] \\
\hline
\end{tabular}




\begin{tabular}{|c|c|c|c|}
\hline Antiviral & $\begin{array}{l}\text { Experimental } \\
\text { system (model cell line, in } \\
\text { silico, in vivo) }\end{array}$ & Keys findings/mechanisms insights & Authors \\
\hline Mycophenolic acid & $\begin{array}{l}\text { Molecular docking } \\
\text { Modeling } 1.7 \text { software). }\end{array}$ & $\begin{array}{l}\text { Unable to inhibit SARS-CoV PLpro } \\
\text { even at a concentration of } 1 \mathrm{mM} \text {; } \\
\text { nevertheless, it shows a dose- } \\
\text { dependent inhibitory effect on the } \\
\text { E168R mutant of SARS-CoV PL }{ }^{\text {pro }} \text {. } \\
\text { Inhibition constant } \\
\mathrm{K}_{\text {is }}=263.7 \pm 13.8 \mu \mathrm{M} \text {. } \\
\mathrm{IC}_{50} \text { of } 222.5-247.6 \mu \mathrm{M} \text {. }\end{array}$ & [47] \\
\hline $\begin{array}{l}\text { 2,6-bis-(3-chloro-benzyloxy)-5- } \\
\text { hydroxy- chromen-4-one (5b) }\end{array}$ & $\begin{array}{l}\text { Normal human fibroblast } \\
\text { cells (HS27). }\end{array}$ & $\begin{array}{l}\text { IC }_{50}=10 \mu \mathrm{M} \text { for ATPase activity. } \\
\text { IC }{ }_{50}=40 \mu \mathrm{M} \text { for helicase activity. } \\
\text { Inhibitory activity against SARS- } \\
\text { associated coronavirus. }\end{array}$ & [43] \\
\hline $\begin{array}{l}\text { 6-(3-chloro-benzyloxy)-2-(4- } \\
\text { chloro- benzyloxy)-5-hydroxy- } \\
\text { chromen-4-one }(\mathbf{5 c})\end{array}$ & $\begin{array}{l}\text { Normal human fibroblast } \\
\text { cells (HS27). }\end{array}$ & $\begin{array}{l}\mathrm{IC}_{50}=28 \mu \mathrm{M} \text { for ATPase activity. } \\
\mathrm{IC}_{50}=53 \mu \mathrm{M} \text { for helicase activity. } \\
\text { Inhibition activity against SARS- } \\
\text { associated coronavirus. }\end{array}$ & [43] \\
\hline $\begin{array}{l}\text { 6-(3-chloro-benzyloxy)-2-(3,5- } \\
\text { dichloro- benzyloxy)-5-hydroxy- } \\
\text { chromen-4-one }(\mathbf{5 d}) \text {. }\end{array}$ & $\begin{array}{l}\text { Normal human fibroblast } \\
\text { cells (HS27). }\end{array}$ & $\begin{array}{l}\text { IC }_{50}>50 \mu \mathrm{M} \text { for ATPase activity. } \\
\text { IC } 50>50 \mu \mathrm{M} \text { for helicase activity. } \\
\text { Inhibition activity against SARS- } \\
\text { associated coronavirus. }\end{array}$ & [43] \\
\hline $\begin{array}{l}\text { 6-(3-chloro-benzyloxy)-5-hydroxy- } \\
\text { 2-(3-iodo- benzyloxy)-chromen-4- } \\
\text { one (5e). }\end{array}$ & $\begin{array}{l}\text { Normal human fibroblast } \\
\text { cells (HS27). }\end{array}$ & $\begin{array}{l}\text { The most potent inhibition activity } \\
\text { against } \\
\text { coronavirus. } \\
\text { IC } \mathrm{C}_{50}=4 \mu \mathrm{M} \text { for ATPase activity. } \\
\text { IC }_{50}=11 \mu \mathrm{M} \text { for helicase activity. }\end{array}$ & [43] \\
\hline $\begin{array}{l}\text { 6-(3-chloro-benzyloxy)-5-hydroxy- } \\
\text { 2-(4-iodo- benzyloxy)-chromen-4- } \\
\text { one (5f). }\end{array}$ & $\begin{array}{l}\text { Normal human fibroblast } \\
\text { cells (HS27). }\end{array}$ & $\begin{array}{l}\mathrm{IC}_{50}=23 \mu \mathrm{M} \text { for ATPase activity. } \\
\mathrm{IC}_{50}=31 \mu \mathrm{M} \text { for helicase activity. } \\
\text { Inhibition activity against SARS- } \\
\text { associated coronavirus. }\end{array}$ & [43] \\
\hline Remdesivir (RDV) & $\begin{array}{l}\text { Vero CCL81 cells } \\
\text { MERS CoV EMC } 2012 \text { and } \\
\text { MERS-nLUC } \\
\text { human lung epithelial cell } \\
\text { line, Calu-3 2B4 } \\
\text { MERS-CoV pathogenesis in } \\
\text { Ces } 1 c^{-/} \text {and } h D P P 4 \text { mice. }\end{array}$ & $\begin{array}{l}\text { RDV (WT } \mathrm{EC}_{50}=0.12 \mu \mathrm{M} \text {; MERS- } \\
\text { nLUCEC } 50=0.09 \mu \mathrm{M} \text { ) in the human } \\
\text { lung epithelial cell line, Calu-3 } \\
\text { Significantly diminished MERS- } \\
\text { CoV-induced weight loss in mice } \\
\text { infected with } 5 \mathrm{E}+04 \\
\text { Significantly reduced ATS lung } \\
\text { injury scores } \\
\text { Reduced virus lung titers the most (>3 } \\
\text { log reduction, } \\
\text { vehicle median }=1.4 \mathrm{E}+05 \text { pfu/lobe, } \\
\text { RDV median }=50 \mathrm{pfu} / \mathrm{lobe})\end{array}$ & [53] \\
\hline Lopinavir (LPV) & $\begin{array}{l}\text { Vero CCL81 cells } \\
\text { MERS CoV EMC } 2012 \text { and } \\
\text { MERS-nLUC } \\
\text { human lung epithelial cell } \\
\text { line, Calu-3 2B4 } \\
\text { MERS-CoV pathogenesis in } \\
\text { Ces } 1 c^{-/} \text {and } h D P P 4 \text { mice. }\end{array}$ & $\begin{array}{l}\mathrm{EC}_{50 \text { values }}=11.6 \mu \mathrm{M} \text { with } \mathrm{CC}_{50} \\
\text { values }>50 \mu \mathrm{M} \\
\text { SI was }>4.3 \text { inhibition of MERS- } \\
\text { CoV }\end{array}$ & [53] \\
\hline Interferon beta (IFNb) & $\begin{array}{l}\text { Vero CCL81 cells } \\
\text { MERS CoV EMC } 2012 \text { and } \\
\text { MERS-nLUC } \\
\text { human lung epithelial cell } \\
\text { line, Calu-3 2B4 } \\
\text { MERS-CoV pathogenesis in } \\
\text { Ces } 1 c^{-/-} \text {and } h D P P 4 \text { mice. }\end{array}$ & $\begin{array}{l}\mathrm{EC}_{50}=175 \text { international units } \\
(\mathrm{IU}) / \mathrm{mL} \text { ) } \\
\mathrm{CC}_{50} \text { values }>2800 \mathrm{IU} / \mathrm{mL} \text { and an SI } \\
>16 \text { inhibition of MERS-CoV } \\
\text { Significantly induced sustained } \\
\text { expression of interferon gamma- } \\
\text { induced protein } 10 \text { (IP-10, CXCL-10) } \\
\text { in the serum of both strains of mice } \\
\text { Induced dose dependent expression } \\
\text { of interferon stimulated gene (ISG), } \\
\begin{array}{l}\text { Mx1, in peripheral blood } \\
\text { mononuclear cells (PBMCs) in } \\
\text { Ces } 1 c^{-/-m i c e}\end{array}\end{array}$ & [53] \\
\hline Ritonavir (RTV) & $\begin{array}{l}\text { Vero CCL81 cells } \\
\text { MERS CoV EMC } 2012 \text { and } \\
\text { MERS-nLUC } \\
\text { human lung epithelial cell } \\
\text { line, Calu-3 2B4 }\end{array}$ & $\begin{array}{l}\mathrm{EC}_{50} \text { values }=24.9 \mu \mathrm{M} \text { with } \mathrm{CC}_{50} \\
\text { values }>50 \mu \mathrm{M} \\
\text { SI for RTV was }>2 \text {, inhibition of } \\
\text { MERS-CoV }\end{array}$ & [53] \\
\hline
\end{tabular}




\begin{tabular}{|c|c|c|c|}
\hline Antiviral & $\begin{array}{l}\text { Experimental } \\
\text { system (model cell line, in } \\
\text { silico, in vivo) }\end{array}$ & Keys findings/mechanisms insights & Authors \\
\hline & $\begin{array}{l}\text { MERS-CoV pathogenesis in } \\
\text { Ces } 1 c^{-/} \text {and } h D P P 4 \text { mice. }\end{array}$ & & \\
\hline Remdesivir & $\begin{array}{l}\text { SARS-CoV-2 } \\
\text { Vero E6 cells (ATCC-1586) } \\
\text { CCK8 assay } \\
\text { RT-PCR (qRT-PCR) } \\
\text { Virus nucleoprotein (NP) } \\
\text { expression through } \\
\text { Immunofluorescence } \\
\text { microscopy }\end{array}$ & $\begin{array}{l}\mathrm{EC}_{50}=0.77 \mu \mathrm{M} ; \mathrm{CC}_{50}>100 \mu \mathrm{M} ; \mathrm{SI}> \\
129.87\end{array}$ & {$[54]$} \\
\hline Ribavirin & $\begin{array}{l}\text { SARS-CoV-2 } \\
\text { Vero E6 cells (ATCC-1586) } \\
\text { CCK8 assay } \\
\text { RT-PCR (qRT-PCR) } \\
\text { Virus nucleoprotein (NP) } \\
\text { expression through } \\
\text { Immunofluorescence } \\
\text { microscopy }\end{array}$ & $\begin{array}{l}\mathrm{EC}_{50}=109.50 \mu \mathrm{M}, \mathrm{CC}_{50}>400 \mu \mathrm{M}, \\
\text { selectivity index }(\mathrm{SI})>3.65\end{array}$ & {$[54]$} \\
\hline Penciclovir & $\begin{array}{l}\text { SARS-CoV-2 } \\
\text { Vero E6 cells (ATCC-1586) } \\
\text { CCK8 assay } \\
\text { RT-PCR (qRT-PCR) } \\
\text { Virus nucleoprotein (NP) } \\
\text { expression through } \\
\text { Immunofluorescence } \\
\text { microscopy }\end{array}$ & $\begin{array}{l}\mathrm{EC}_{50}=95.96 \mu \mathrm{M}, \mathrm{CC}_{50}>400 \mu \mathrm{M}, \mathrm{SI}> \\
4.17\end{array}$ & [54] \\
\hline Favipiravir & $\begin{array}{l}\text { SARS-CoV-2 } \\
\text { Vero E6 cells (ATCC-1586) } \\
\text { CCK8 assay } \\
\text { RT-PCR (qRT-PCR) } \\
\text { Virus nucleoprotein (NP) } \\
\text { expression through } \\
\text { Immunofluorescence } \\
\text { microscopy }\end{array}$ & $\begin{array}{l}\mathrm{EC}_{50}=61.88 \mu \mathrm{M}, \mathrm{CC}_{50}>400 \mu \mathrm{M}, \mathrm{SI}> \\
6.46\end{array}$ & [54] \\
\hline Nafamostat & $\begin{array}{l}\text { SARS-CoV-2 } \\
\text { Vero E6 cells (ATCC-1586) } \\
\text { CCK8 assay } \\
\text { RT-PCR (qRT-PCR) } \\
\text { Virus nucleoprotein (NP) } \\
\text { expression through } \\
\text { Immunofluorescence } \\
\text { microscopy }\end{array}$ & $\begin{array}{l}\mathrm{EC}_{50}=22.50 \mu \mathrm{M}, \mathrm{CC}_{50}>100 \mu \mathrm{M}, \mathrm{SI}> \\
4.44\end{array}$ & [54] \\
\hline Nitazoxanide & $\begin{array}{l}\text { SARS-CoV-2 } \\
\text { Vero E6 cells (ATCC-1586) } \\
\text { CCK8 assay } \\
\text { RT-PCR (qRT-PCR) } \\
\text { Virus nucleoprotein (NP) } \\
\text { expression through } \\
\begin{array}{l}\text { Immunofluorescence } \\
\text { microscopy }\end{array}\end{array}$ & $\begin{array}{l}\mathrm{EC}_{50}=2.12 \mu \mathrm{M}, \mathrm{CC}_{50}>35.53 \mu \mathrm{M}, \mathrm{SI} \\
>16.76\end{array}$ & [54] \\
\hline Chloroquine & $\begin{array}{l}\text { SARS-CoV-2 } \\
\text { Vero E6 cells (ATCC-1586) } \\
\text { CCK8 assay } \\
\text { RT-PCR (qRT-PCR) } \\
\text { Virus nucleoprotein (NP) } \\
\text { expression through } \\
\text { Immunofluorescence } \\
\text { microscopy }\end{array}$ & $\begin{array}{l}\mathrm{EC}_{50}=1.13 \mu \mathrm{M}, \mathrm{CC}_{50}>100 \mu \mathrm{M}, \mathrm{SI}> \\
88.50\end{array}$ & [54] \\
\hline Hydroxychloroquine & $\begin{array}{l}\text { SARS-CoV-2 infected Vero } \\
\text { cells } \\
\text { PBPK models }\end{array}$ & $\begin{array}{l}\text { Inhibiting SARS-CoV-2 with } \\
\mathrm{EC}_{50}=0.72 \mathrm{Mm}\end{array}$ & [55] \\
\hline Chloroquine & $\begin{array}{l}\text { SARS-CoV-2 infected Vero } \\
\text { cells } \\
\text { PBPK models }\end{array}$ & $\begin{array}{l}\text { Inhibiting SARS-CoV-2 with } \\
\mathrm{EC}_{50}=5.47 \mu \mathrm{M}\end{array}$ & [55] \\
\hline Alisporivir & $\begin{array}{l}\text { MERS-CoV infected Vero } \\
\text { cells }\end{array}$ & $\begin{array}{l}\mathrm{EC}_{50}=3.6 \pm 1.1 \mu \mathrm{M}, \quad \mathrm{CC}_{50}=26.4 \pm 1.0 \\
\mu \mathrm{M}, \mathrm{SI}=7.3\end{array}$ & [56] \\
\hline
\end{tabular}




\begin{tabular}{l|l|l|l}
\hline Antiviral & $\begin{array}{l}\text { Experimental } \\
\text { system (model cell line, in } \\
\text { silico, in vivo) }\end{array}$ & Keys findings/mechanisms insights & Authors \\
\hline Alisporivir & $\begin{array}{l}\text { SARS-CoV infected Vero E6 } \\
\text { cells }\end{array}$ & $\begin{array}{l}\mathrm{EC}_{50}=8.3 \pm 1.0 \mu \mathrm{M}, \mathrm{CC}_{50}>50 \mu \mathrm{M}, \mathrm{SI} \\
>6.0\end{array}$ & {$[56]$}
\end{tabular}

Moreover, Cao et al. [46] assessed the ability of three drugs (homoharringtonine, nitazoxanide, and hexachlorophene) to inhibit viral infection in mouse astrocytoma DBT and fibroblast $17 \mathrm{Cl}-1$ cells. Consequently, they showed dose-dependent anti-coronavirus activities

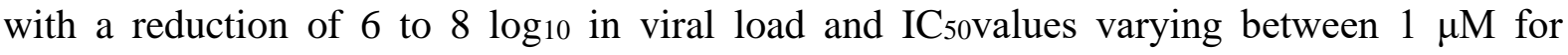
nitazoxanide and hexachlorophene, and $12 \mathrm{nM}$ for homoharringtonine. Also, the authors carried out the second part of the experiment, where they selected 11 drugs to treat cells via the inhibition of luciferase activity (1 hour before or 3 hours after viral infection) (Table 3 ). They found that these drugs had strong inhibition at different times; this indicates that they inhibit viral infection at the stage of viral replication (post-entry stage). In the same year, Cheng et al. [47] tested the effect of two thiopurine analogs (6-Mercaptopurine and 6-Thioguanine) and mycophenolic acid on MERS-CoV by inhibiting the papain-like protease ( $\mathrm{PL}^{\mathrm{pro}}$ ) of the virus, which is an important antiviral target. As a result, they showed that these three inhibitors were effective against MERS-CoV PL ${ }^{\text {pro }}$ with $\mathrm{IC}_{50 \mathrm{~S}}$ of 24.4, 26.9, and 247.6 $\mu \mathrm{M}$ for 6-thioguanine (6TG), 6-mercaptopurine (6MP), and mycophenolic acid, respectively [47]. Additionally, the interaction of these compounds with the target was competitive for 6MP and 6TG and noncompetitive for mycophenolic acid. Also, the authors reported that the binding of these inhibitors together synergistically improves their inhibitory capacity against MERS-CoV PL ${ }^{\text {pro }}$ (Table 3).

Two years later, de Wilde et al. [56] investigated the inhibitory potential of alisporivir (ALV), a cyclophilin inhibitor, on MERS- and SARS-coronavirus replication in cell culture. Three days after infection, they found that this molecule prevented virus-induced CPE (cytopathic effect) in a dose-dependent manner in MERS-CoV EMC/2012-infected Vero cells $\left(\mathrm{EC}_{50}=3.6 \mu \mathrm{M}\right)$ and MERS-CoV EMC/2012-infected Huh7 cells $\left(\mathrm{EC}_{50}=3.4 \mu \mathrm{M}\right)$. Also, they observed in VeroE6 cells, inhibition of SARS-CoV strain Frankfurt $1\left(\mathrm{EC}_{50}=8.3 \mu \mathrm{M}\right)$, and SARS-CoV strain MA-15 (mouse-adapted) $\left(\mathrm{EC}_{50}=1,3 \mu \mathrm{M}\right)$. Furthermore, at the concentration of $10 \mu \mathrm{M}$ of ALV, they noted a 4-to 5-log reduction of the virus yield (MERS-CoV) in Vero, Huh7, and LLC-MK2 cells with $\mathrm{EC}_{50}$ of 3.9, 2.8, and $4.0 \mu \mathrm{M}$, respectively [56]. The same efficacy in reducing viral production was observed in two other coronaviruses; human coronavirus 229E (HCoV-229E) and murine hepatitis virus (MHV-A59) on Huh7 and 17Cl1 cells, respectively, using different doses. Likewise, the authors tested combination therapy of ALV with ribavirin (MERS-CoV replication inhibitor) in LLC-MK2 cells, which potentiated antiviral activity. However, this association had no additive effect on SARS-CoV infection in a mouse model (Table 3).

Very recently, numerous studies, in silico, have tested synthetic compounds against the new HCoV that appeared in Wuhan (COVID-19) [45, 49-51]. Indeed, Elfikyand collaborators tested four anti-HCV molecules (IDX-184, Remidisvir, Ribavirin, Sofosbuvir) against viral RNA dependent RNA polymerase (RdRp) by molecular docking also using the structure of SARS HCoV as a model which has more than $97 \%$ of sequence identical to SARS-CoV-2 RdRp [49]. They found that these drugs were able to bind tightly to SARS-CoV-2 and SARS HCoVRdRps and therefore exhibit potent inhibition of this new $\mathrm{HCoV}$. 
Since the development of new drug therapies takes years, Smith and Smith, [50] reused already characterized small molecules, that could have an action against the novel coronavirus, by using docking calculations to identify those which are able to bind either to the viral spike protein (S-protein) or to the S protein-human ACE2 interface. Therefore, they identified seven compounds (Isoniazid pyruvate, Pemirolast, Eriodictyol, Cepharanthine, Ergoloid, Hypericin, Nitrofurantoin) capable of limiting the binding of the viral S-protein with the ACE2 receptor, thereby restricting the host-virus interactions and the SARS-CoV-2 infection pathway.

Moreover, to combat SARS-CoV-2, the NSP12-NSP7-NSP8 complex of the virus may be a potential therapeutic target. In this context, Ruan et al. [51] created two homologous models (NSP12-NSP8 interface model and NSP12-NSP7 interface model). Subsequently, they selected seven compounds (Tipranavir, Saquinavir, Tegobuvir, Lonafarnib, Olysio, Cepharanthine, Filibuvir) for the calculation of binding free energy, based on docking scores and virtual screening. They found that all of these compounds show a good combination with NSP12-NSP7-NSP8 in the homologous model. Furthermore, Zhang and colleagues identified and designed peptide drugs against SARS-CoV-2 main protease, which is also a major target, through virtual drug screening using DFCNN (densely fully connected neural network) [45]. Consequently, they noted that these drugs have the ability to bind well to this target protein.

Other recent studies have also evaluated the anti-coronavirus activity of synthetic drugs either tested for the first time or already used as antivirals on cell cultures (in vitro) [52-53] [54] [55]. Effectively, Simmons et al. [52] tested the effect of certain compounds on inhibiting cathepsin $\mathrm{L}$, a $\mathrm{pH}$-sensitive endosomal protease, and blocking the entry of SARS-CoV, using 293T ACE2 and Vero E6 cells. Indeed, compounds like MDL28170, trypsin, and leupeptin effectively prevented viral infection by inhibiting the activity of the endosomal protease during viral entry.

Sheahan and collaborators investigated the anti-MERS-CoV activity (in vitro and in vivo) of four well-known drugs as broad-spectrum antivirals like remdesivir (RDV), ritonavir (RTV), lopinavir (LPV), and interferon-beta (IFNb), by comparing the therapeutic and prophylactic efficacy of RDV with the RTV/LPV-IFNb combination [53]. Regarding in vitro antiviral tests, the authors found that RDV had significant activity on MERS-nLUC $\left(\mathrm{EC}_{50}=0.09\right.$ $\mu \mathrm{M})$ and MERS-CoV EMC 2012 strain $\left(\mathrm{EC}_{50}=0.12 \mu \mathrm{M}\right)$ in Calu-3, a human lung epithelial cell line. In parallel, RTV and LPV showed inhibitory effects against MERS-CoV of 24.9 and $11.6 \mu \mathrm{M}$, respectively, while their combinatorial effect was $8.5 \mu \mathrm{M}$. Similarly, IFNb was very effective with an $\mathrm{EC}_{50}$ of $175 \mathrm{IU} / \mathrm{mL}$, and CC50 values $>2800 \mathrm{IU} / \mathrm{mL}$, and the combination with RTV/LPV $\left(\mathrm{EC}_{50}=160 \mathrm{IU} / \mathrm{mL}\right)$ did not improve its activity. This indicates that the antiviral activity of IFNb and RDV is higher than that of RTV and LPV in vitro. On the other hand, using the Ces $1 c^{-/-}$hDPP4 mouse model, they observed that the administration of prophylactic RDV ( $25 \mathrm{mg} / \mathrm{kg}$ ) one day before infection; significantly attenuated the weight loss induced by MERS-CoV in infected animals and prevented the mortality of mice treated with a lethal dose. Simultaneously, RDV prophylaxis significantly reduced lung hemorrhage, characteristics of acute lung injury, and lung viral load $>3$ logs over the 4- and 6-days following infection. In the same animal model, therapeutic RDV substantially diminished lung hemorrhage, bodyweight loss, and virus replication during MERS-CoV infection. However, the therapeutic RTV/LPV-IFNb could not improve the previous parameters or survival after a lethal dose of the virus. Whereas the prophylactic RTV/LPV-IFNb caused a slight decrease in the lung viral load, and the IFNb alone did not affect the virus replication. Additionally, other researchers evaluated the in vitro antiviral efficiency of seven drugs on a clinical isolate of the novel Wuhan 
coronavirus [54]. As a result, they recorded that the drugs tested were able to decrease viral infection at different concentrations, namely 109.50, 95.96, 61.88, 22.50, 2.12, 0.77, and 1.13 $\mu \mathrm{M}$ for ribavirin, penciclovir, favipiravir, nafamostat, nitazoxanide, remdesivir, and chloroquine, respectively. This showed that remdesivir and chloroquine were the most potent inhibitors against SARS-CoV-2. In addition, chloroquine and its derivative (hydroxychloroquine), at increasing concentrations, were investigated in vitro for their inhibitory power against SARS-CoV-2 using infected Vero cells [55]. They reported that both molecules had a good activity with the ability to reduce viral replication in a dose-dependent manner. Likewise, hydroxychloroquine $\left(\mathrm{EC}_{50}=0.72 \mu \mathrm{M}\right)$ was more powerful than chloroquine $\left(\mathrm{EC}_{50}=5.47 \mu \mathrm{M}\right)$ to block virus infection.

\section{Therapeutic strategies for clinical studies to combat Covid-19}

The high mortality rate with the absence of effective treatments to combat COVID-19 has stimulated a number of research groups to start clinical trials quickly by exploiting all possible strategies. Many of the clinical trials are underway today. These are different therapeutic strategies such as the use of antiviral molecules with a wide spectrum of action, traditional natural molecules and / preparations especially based on traditional Chinese medicine, monoclonal antibodies directed in particular against the mediators of the immune system, mesenchymal cells as cell therapy, plasma therapy, and SARS-CoV-2 antigen vaccine trials.

\subsection{Specific antiviral drugs.}

With the emergence of COVID-19 pandemic, several clinical trials have been taken place to found clinically active drugs against SRAS-CoV-2 from old antiviral drugs. Indeed, several patents on clinical trials were deposed at different clinical phases (Table 4). As summarized in Table 5, these clinical patents include numerous drugs and/or combination of drugs such as arbidol hydrochloride tablets, ASC09/Ritonavir, lopinavir/ritonavir, aviptadil, azithromycin/chloroquine, baricitinib, bromhexine hydrochloride, carrimycin, colchicine, darunavir, dexamethasone, escin, fingolimod, and glucocorticoid. These drugs are in different clinical trials and could give promising applications in the future. For example, Azithromycin and Chloroquine used to fight against COVID-19 (to decrease COVID-19 complications) has been confirmed into phase 4 of clinical trials, which has been experienced on a large number of patients (NCT04322396). Moreover, other drugs such as arbidol hydrochloride tablets were also developed into phase 4 of clinical trials with promising results on SARS-CoV-2.

Table 4. Clinical trial patients of synthetic drugs targeted SARS-CoV2.

\begin{tabular}{|c|c|c|c|c|c|c|}
\hline $\begin{array}{l}\text { Patent } \\
\text { number }\end{array}$ & Patent title & $\begin{array}{l}\text { Target/ke } \\
\text { y results }\end{array}$ & Organization & $\begin{array}{l}\text { Priority } \\
\text { date }\end{array}$ & Phase & Links \\
\hline $\begin{array}{l}\text { NCT04325 } \\
633\end{array}$ & $\begin{array}{l}\text { Efficacy of Addition of } \\
\text { Naproxen in the Treatment } \\
\text { of Critically Ill Patients } \\
\text { Hospitalized for COVID-19 } \\
\text { Infection (ENACOVID). }\end{array}$ & $\begin{array}{l}\text { Virus } \\
\text { nucleoprot } \\
\text { ein. }\end{array}$ & $\begin{array}{l}\text { Assistance } \\
\text { Publique - } \\
\text { Hôpitaux de } \\
\text { Paris. }\end{array}$ & 20200327 & 3 & $\begin{array}{l}\text { https://clinicaltrials.gov/c } \\
\text { t2/show/NCT04325633?c } \\
\text { ond=COVID- } \\
\text { 19\&draw=2\&rank=5 }\end{array}$ \\
\hline $\begin{array}{l}\text { NCT04304 } \\
313\end{array}$ & $\begin{array}{l}\text { A Pilot Study of Sildenafil } \\
\text { in COVID-19. }\end{array}$ & $\begin{array}{l}\text { Not } \\
\text { reported. }\end{array}$ & $\begin{array}{l}\text { Tongji } \\
\text { Hospital. }\end{array}$ & 20200317 & 3 & $\begin{array}{l}\text { https://clinicaltrials.gov/c } \\
\text { t2/show/NCT04304313?c } \\
\text { ond=COVID- } \\
\text { 19\&draw }=3 \& \text { rank=13 }\end{array}$ \\
\hline $\begin{array}{l}\text { NCT04304 } \\
053\end{array}$ & $\begin{array}{l}\text { Treatment of } \text { COVID-19 } \\
\text { Cases } \\
\text { Chemoprophylaxis and } \\
\text { Contacts as Prevention } \\
(\text { HCQ4COV19) }\end{array}$ & $\begin{array}{l}\text { Decrease in } \\
\text { viral load } \\
\text { levels. }\end{array}$ & $\begin{array}{l}\text { Fundacio } \\
\text { Lluita Contra } \\
\text { la SIDA. }\end{array}$ & 20200324 & 3 & $\begin{array}{l}\text { https://clinicaltrials.gov/c } \\
\text { t2/show/NCT04304053?c } \\
\text { ond=COVID- } \\
\text { 19\&draw }=3 \& \text { rank=16 }\end{array}$ \\
\hline
\end{tabular}




\begin{tabular}{|c|c|c|c|c|c|c|}
\hline $\begin{array}{l}\text { Patent } \\
\text { number }\end{array}$ & Patent title & $\begin{array}{l}\text { Target/ke } \\
\text { y results }\end{array}$ & Organization & $\begin{array}{l}\text { Priority } \\
\text { date }\end{array}$ & Phase & Links \\
\hline $\begin{array}{l}\text { NCT04321 } \\
993\end{array}$ & $\begin{array}{l}\text { Treatment of Moderate to } \\
\text { Severe Coronavirus Disease } \\
\text { (COVID-19) in } \\
\text { Hospitalized Patients. }\end{array}$ & $\begin{array}{l}\text { Not } \\
\text { reported. }\end{array}$ & $\begin{array}{l}\text { Dalhousie } \\
\text { University. }\end{array}$ & 20200311 & 2 & $\begin{array}{l}\text { https://clinicaltrials.gov/c } \\
\text { t2/show/NCT04321993?c } \\
\text { ond=COVID- } \\
\text { 19\&draw }=3 \& \text { rank }=18\end{array}$ \\
\hline $\begin{array}{l}\text { NCT04313 } \\
023\end{array}$ & $\begin{array}{l}\text { The Use PUL-042 } \\
\text { Inhalation Solution to } \\
\text { Prevent COVID-19 in } \\
\text { Adults Exposed to SARS- } \\
\text { CoV-2. }\end{array}$ & Prevention. & $\begin{array}{l}\text { Pulmotect, } \\
\text { Inc. }\end{array}$ & 20200324 & 2 & $\begin{array}{l}\text { https://clinicaltrials.gov/c } \\
\text { t2/show/NCT04313023?c } \\
\text { ond=COVID- } \\
\text { 19\&draw=3\&rank=19 }\end{array}$ \\
\hline $\begin{array}{l}\text { NCT04307 } \\
693\end{array}$ & $\begin{array}{lr}\text { Comparison } & \text { of } \\
\text { Lopinavir/Ritonavir } & \text { or } \\
\text { Hydroxychloroquine } & \text { in } \\
\text { Patients With } & \text { Mild } \\
\text { Coronavirus } & \text { Disease } \\
\text { (COVID-19). } & \\
\end{array}$ & $\begin{array}{l}\text { Decrease in } \\
\text { viral load } \\
\text { levels. }\end{array}$ & $\begin{array}{l}\text { Asan Medical } \\
\text { Center. }\end{array}$ & 20200313 & 2 & $\begin{array}{l}\text { https://clinicaltrials.gov/c } \\
\text { t2/show/NCT04307693?c } \\
\text { ond=COVID- } \\
\text { 19\&draw=3\&rank=20 }\end{array}$ \\
\hline $\begin{array}{l}\text { NCT04323 } \\
631\end{array}$ & $\begin{array}{l}\text { Hydroxychloroquine for the } \\
\text { Treatment of Patients With } \\
\text { Mild to Moderate COVID- } \\
19 \text { to Prevent Progression to } \\
\text { Severe Infection or Death. }\end{array}$ & $\begin{array}{l}\text { Decrease in } \\
\text { viral load } \\
\text { levels. }\end{array}$ & $\begin{array}{l}\text { Rambam } \\
\text { Health Care } \\
\text { Campus. }\end{array}$ & 20200326 & 1 & $\begin{array}{l}\text { https://clinicaltrials.gov/c } \\
\text { t2/show/NCT04323631?c } \\
\text { ond=COVID- } \\
\text { 19\&draw=4\&rank=21 }\end{array}$ \\
\hline $\begin{array}{l}\text { NCT04292 } \\
899\end{array}$ & $\begin{array}{l}\text { Study to Evaluate the Safety } \\
\text { and Antiviral Activity of } \\
\text { Remdesivir (GS-5734TM) in } \\
\text { Participants With Severe } \\
\text { Coronavirus } \\
\text { (COVID-19). Disease }\end{array}$ & $\begin{array}{l}\text { Not } \\
\text { reported. }\end{array}$ & $\begin{array}{l}\text { Gilead } \\
\text { Sciences. }\end{array}$ & 20200402 & 3 & $\begin{array}{l}\text { https://clinicaltrials.gov/c } \\
\text { t2/show/NCT04292899?c } \\
\text { ond=COVID- } \\
\text { 19\&draw=4\&rank=22 }\end{array}$ \\
\hline $\begin{array}{l}\text { NCT04312 } \\
997\end{array}$ & $\begin{array}{l}\text { The Use of PUL-042 } \\
\text { Inhalation Solution to } \\
\text { Reduce the Severity of } \\
\text { COVID-19 in Adults } \\
\text { Positive for SARS-CoV-2 } \\
\text { Infection. }\end{array}$ & $\begin{array}{l}\text { Improved } \\
\text { clinical } \\
\text { outcome. }\end{array}$ & $\begin{array}{l}\text { Pulmotect, } \\
\text { Inc. }\end{array}$ & 20200324 & 2 & $\begin{array}{l}\text { https://clinicaltrials.gov/c } \\
\text { t2/show/NCT04312997?c } \\
\text { ond=COVID- } \\
\text { 19\&draw=4\&rank=23 }\end{array}$ \\
\hline $\begin{array}{l}\text { NCT04292 } \\
730\end{array}$ & $\begin{array}{l}\text { Study to Evaluate the Safety } \\
\text { and Antiviral Activity of } \\
\text { Remdesivir (GS-5734TM) in } \\
\text { Participants With Moderate } \\
\text { Coronavirus Disease } \\
\text { (COVID-19) Compared to } \\
\text { Standard of Care Treatment. }\end{array}$ & $\begin{array}{l}\text { Not } \\
\text { reported. }\end{array}$ & $\begin{array}{l}\text { Gilead } \\
\text { Sciences. }\end{array}$ & 20200402 & 3 & $\begin{array}{l}\text { https://clinicaltrials.gov/c } \\
\text { t2/show/NCT04292730?c } \\
\text { ond=COVID- } \\
\text { 19\&draw=4\&rank=24 }\end{array}$ \\
\hline $\begin{array}{l}\text { NCT04273 } \\
529\end{array}$ & $\begin{array}{l}\text { The Efficacy and Safety of } \\
\text { Thalidomide in the } \\
\text { Adjuvant Treatment of } \\
\text { Moderate New Coronavirus } \\
\text { (COVID-19) Pneumonia. }\end{array}$ & $\begin{array}{l}\text { Improve } \\
\text { lung } \\
\text { function. }\end{array}$ & $\begin{array}{l}\text { First Affiliated } \\
\text { Hospital of } \\
\text { Wenzhou } \\
\text { Medical } \\
\text { University. } \\
\end{array}$ & 20200221 & 2 & $\begin{array}{l}\text { https://clinicaltrials.gov/c } \\
\text { t2/show/NCT04273529?c } \\
\text { ond=COVID- } \\
\text { 19\&draw=4\&rank=29 }\end{array}$ \\
\hline $\begin{array}{l}\text { NCT04273 } \\
581\end{array}$ & $\begin{array}{l}\text { The Efficacy and Safety of } \\
\text { Thalidomide Combined } \\
\text { With Low-dose Hormones } \\
\text { in the Treatment of Severe } \\
\text { COVID-19. }\end{array}$ & $\begin{array}{l}\text { Improve } \\
\text { lung } \\
\text { function. }\end{array}$ & $\begin{array}{l}\text { First Affiliated } \\
\text { Hospital of } \\
\text { Wenzhou } \\
\text { Medical } \\
\text { University. } \\
\end{array}$ & 20200221 & 2 & $\begin{array}{l}\text { https://clinicaltrials.gov/c } \\
\text { t2/show/NCT04273581?c } \\
\text { ond=COVID- } \\
\text { 19\&draw=4\&rank=30 }\end{array}$ \\
\hline $\begin{array}{l}\text { NCT04280 } \\
588\end{array}$ & Fingolimod in COVID-19. & $\begin{array}{l}\text { Immunolo } \\
\text { gy } \\
\text { modulation } \\
\text {. }\end{array}$ & $\begin{array}{l}\text { First Affiliated } \\
\text { Hospital of } \\
\text { Fujian } \\
\text { Medical } \\
\text { University. } \\
\end{array}$ & 20200221 & 2 & $\begin{array}{l}\text { https://clinicaltrials.gov/c } \\
\text { t2/show/NCT04280588?c } \\
\text { ond=COVID- } \\
\text { 19\&draw=5\&rank=33 }\end{array}$ \\
\hline $\begin{array}{l}\text { NCT04315 } \\
896\end{array}$ & $\begin{array}{l}\text { Hydroxychloroquine } \\
\text { Treatment for Severe } \\
\text { COVID-19 Pulmonary } \\
\text { Infection (HYDRA Trial) } \\
\text { (HYDRA). }\end{array}$ & $\begin{array}{l}\text { Reduced } \\
\text { hospital } \\
\text { mortality in } \\
\text { patients } \\
\text { with severe } \\
\text { respiratory } \\
\text { COVID-19 } \\
\text { disease. }\end{array}$ & $\begin{array}{l}\text { National } \\
\text { Institute of } \\
\text { Respiratory } \\
\text { Diseases, } \\
\text { Mexico. }\end{array}$ & 20200220 & 3 & $\begin{array}{l}\text { https://clinicaltrials.gov/c } \\
\text { t2/show/NCT04315896?c } \\
\text { ond=COVID- } \\
\text { 19\&draw=5\&rank=34 }\end{array}$ \\
\hline $\begin{array}{l}\text { NCT04325 } \\
061\end{array}$ & $\begin{array}{l}\text { Efficacy of Dexamethasone } \\
\text { Treatment for Patients With } \\
\text { ARDS Caused by COVID- } \\
19 \text { (DEXA-COVID19). }\end{array}$ & $\begin{array}{l}\text { Reduce the } \\
\text { duration of } \\
\text { mechanical } \\
\text { ventilation } \\
\text { and } \\
\text { hospital } \\
\text { mortality. }\end{array}$ & $\begin{array}{l}\text { Dr. Negrin } \\
\text { University } \\
\text { Hospital. }\end{array}$ & 20200401 & 4 & $\begin{array}{l}\text { https://clinicaltrials.gov/c } \\
\text { t2/show/NCT04325061?c } \\
\text { ond=COVID- } \\
\text { 19\&draw=5\&rank=35 }\end{array}$ \\
\hline $\begin{array}{l}\text { NCT04317 } \\
040\end{array}$ & $\begin{array}{l}\text { CD24Fc as a Non-antiviral } \\
\text { Immunomodulator in } \\
\text { COVID-19 Treatment } \\
\text { (SAC-COVID). }\end{array}$ & $\begin{array}{l}\text { Not } \\
\text { reported. }\end{array}$ & $\begin{array}{l}\text { OncoImmune, } \\
\text { Inc. }\end{array}$ & 20200323 & 3 & $\begin{array}{l}\text { https://clinicaltrials.gov/c } \\
\text { t2/show/NCT04317040?c } \\
\text { ond=COVID- } \\
\text { 19\&draw }=5 \& \text { rank=37 }\end{array}$ \\
\hline $\begin{array}{l}\text { NCT04286 } \\
503\end{array}$ & $\begin{array}{l}\text { The Clinical Study of } \\
\text { Carrimycin on Treatment } \\
\text { Patients With COVID- } 19 .\end{array}$ & $\begin{array}{l}\text { Not } \\
\text { reported. }\end{array}$ & $\begin{array}{l}\text { Beijing } \\
\text { YouAn } \\
\text { Hospital. }\end{array}$ & 20200227 & 4 & $\begin{array}{l}\text { https://clinicaltrials.gov/c } \\
\text { t2/show/NCT04286503?c } \\
\text { ond=COVID- } \\
\text { 19\&draw }=5 \& \text { rank }=40\end{array}$ \\
\hline
\end{tabular}




\begin{tabular}{|c|c|c|c|c|c|c|}
\hline $\begin{array}{l}\text { Patent } \\
\text { number }\end{array}$ & Patent title & $\begin{array}{l}\text { Target/ke } \\
\text { y results }\end{array}$ & Organization & $\begin{array}{l}\text { Priority } \\
\text { date }\end{array}$ & Phase & Links \\
\hline $\begin{array}{l}\text { NCT04318 } \\
444\end{array}$ & $\begin{array}{l}\text { Hydroxychloroquine Post } \\
\text { Exposure Prophylaxis for } \\
\text { Coronavirus Disease } \\
\text { (COVID-19). }\end{array}$ & $\begin{array}{l}\text { Reduce the } \\
\text { risk of } \\
\text { developing } \\
\text { symptoms } \\
\text { of COVID- } \\
19 \text { among } \\
\text { people at } \\
\text { high risk of } \\
\text { infection. }\end{array}$ & $\begin{array}{l}\text { Columbia } \\
\text { University. }\end{array}$ & 20200325 & 2 and 3 & $\begin{array}{l}\text { https://clinicaltrials.gov/c } \\
\text { t2/show/NCT04318444?c } \\
\text { ond=COVID- } \\
\text { 19\&draw=6\&rank=43 }\end{array}$ \\
\hline $\begin{array}{l}\text { NCT04318 } \\
015\end{array}$ & $\begin{array}{l}\text { Hydroxychloroquine } \\
\text { Chemoprophylaxis in } \\
\text { Healthcare Personnel in } \\
\text { Contact With COVID-19 } \\
\text { Patients (PHYDRA Trial) } \\
\text { (PHYDRA). }\end{array}$ & $\begin{array}{l}\text { Reduce the } \\
\text { risk of } \\
\text { developing } \\
\text { symptoms } \\
\text { of COVID- } \\
19\end{array}$ & $\begin{array}{l}\text { National } \\
\text { Institute of } \\
\text { Respiratory } \\
\text { Diseases, } \\
\text { Mexico. }\end{array}$ & 20200323 & 3 & $\begin{array}{l}\text { https://clinicaltrials.gov/c } \\
\text { t2/show/NCT04318015?c } \\
\text { ond=COVID- } \\
\text { 19\&draw=6\&rank=44 }\end{array}$ \\
\hline $\begin{array}{l}\text { NCT04295 } \\
551\end{array}$ & $\begin{array}{l}\text { Multicenter Clinical Study } \\
\text { on the Efficacy and Safety } \\
\text { of Xiyanping Injection in } \\
\text { the Treatment of New } \\
\text { Coronavirus Infection } \\
\text { Pneumonia (General and } \\
\text { Severe). }\end{array}$ & $\begin{array}{l}\text { Not } \\
\text { reported. }\end{array}$ & $\begin{array}{l}\text { Jiangxi } \\
\text { Qingfeng } \\
\text { Pharmaceutica } \\
\text { 1 Co. Ltd. }\end{array}$ & 20200304 & $\begin{array}{l}\text { Not } \\
\text { Applicable }\end{array}$ & $\begin{array}{l}\text { https://clinicaltrials.gov/c } \\
\text { t2/show/NCT04295551?c } \\
\text { ond=COVID- } \\
\text { 19\&draw=7\&rank=60 }\end{array}$ \\
\hline $\begin{array}{l}\text { NCT04303 } \\
507\end{array}$ & $\begin{array}{l}\text { Chloroquine/ } \\
\text { Hydroxychloroquine } \\
\text { Prevention of Coronavirus } \\
\text { Disease (COVID-19) in the } \\
\text { Healthcare Setting } \\
\text { (COPCOV). }\end{array}$ & $\begin{array}{l}\text { Reduce the } \\
\text { risk of } \\
\text { developing } \\
\text { symptoms } \\
\text { of COVID- } \\
19\end{array}$ & $\begin{array}{l}\text { University of } \\
\text { Oxford. }\end{array}$ & 20200327 & $\begin{array}{l}\text { Not } \\
\text { Applicable }\end{array}$ & $\begin{array}{l}\text { https://clinicaltrials.gov/c } \\
\text { t2/show/NCT04303507?c } \\
\text { ond=COVID- } \\
\text { 19\&draw }=8\end{array}$ \\
\hline $\begin{array}{l}\text { NCT04273 } \\
763\end{array}$ & $\begin{array}{l}\text { Evaluating the Efficacy and } \\
\text { Safety of Bromhexine } \\
\text { Hydrochloride Tablets } \\
\text { Combined with Standard } \\
\text { Treatment/ } \\
\text { Treatment in Patients with } \\
\text { Suspected and Mild Novel } \\
\text { Coronavirus Pneumonia } \\
(\text { COVID-19). }\end{array}$ & $\begin{array}{l}\text { Not } \\
\text { reported. }\end{array}$ & $\begin{array}{l}\text { Second } \\
\text { Affiliated } \\
\text { Hospital of } \\
\text { Wenzhou } \\
\text { Medical } \\
\text { University. }\end{array}$ & 20200323 & $\begin{array}{l}\text { Not } \\
\text { Applicable }\end{array}$ & $\begin{array}{l}\text { https://clinicaltrials.gov/c } \\
\text { t2/show/NCT04273763?c } \\
\text { ond=COVID- } \\
\text { 19\&draw }=8\end{array}$ \\
\hline $\begin{array}{l}\text { NCT04303 } \\
299\end{array}$ & $\begin{array}{l}\text { Various Combination of } \\
\text { Protease } \\
\text { Inhibitors, } \\
\text { and Hydroxychloroquine } \\
\text { for Treatment of COVID19: } \\
\text { A Randomized Control } \\
\text { Trial (THDMS-COVID19). }\end{array}$ & $\begin{array}{l}\text { Reduce the } \\
\text { risk of } \\
\text { developing } \\
\text { symptoms } \\
\text { of COVID- } \\
19\end{array}$ & $\begin{array}{l}\text { Rajavithi } \\
\text { Hospital. }\end{array}$ & 20200325 & 3 & $\begin{array}{l}\text { https://clinicaltrials.gov/c } \\
\text { t2/show/NCT04303299?c } \\
\text { ond=COVID- } \\
\text { 19\&draw =8 }\end{array}$ \\
\hline $\begin{array}{l}\text { NCT04312 } \\
009\end{array}$ & $\begin{array}{l}\text { Losartan for Patients With } \\
\text { COVID-19 Requiring } \\
\text { Hospitalization. }\end{array}$ & $\begin{array}{l}\text { Not } \\
\text { reported. }\end{array}$ & $\begin{array}{l}\text { University of } \\
\text { Minnesota. }\end{array}$ & 20200323 & 2 & $\begin{array}{l}\text { https://clinicaltrials.gov/c } \\
\text { t2/show/NCT04312009?c } \\
\text { ond=COVID- } \\
\text { 19\&draw=11\&rank=93 }\end{array}$ \\
\hline $\begin{array}{l}\text { NCT04252 } \\
664\end{array}$ & $\begin{array}{l}\text { Mild/Moderate 2019-nCoV } \\
\text { Remdesivir RCT }\end{array}$ & $\begin{array}{l}\text { Not } \\
\text { reported. }\end{array}$ & $\begin{array}{l}\text { Capital } \\
\text { Medical } \\
\text { University. }\end{array}$ & 20200224 & 3 & $\begin{array}{l}\text { https://clinicaltrials.gov/c } \\
\text { t2/show/NCT04252664?c } \\
\text { ond=COVID- } \\
\text { 19\&draw=10\&rank=90 }\end{array}$ \\
\hline $\begin{array}{l}\text { NCT04315 } \\
948\end{array}$ & $\begin{array}{l}\text { Trial of Treatments for } \\
\text { COVID-19 in Hospitalized } \\
\text { Adults (DisCoVeRy). }\end{array}$ & $\begin{array}{l}\text { Not } \\
\text { reported. }\end{array}$ & $\begin{array}{l}\text { Institut } \\
\text { National de la } \\
\text { Santé Et de la } \\
\text { Recherche } \\
\text { Médicale, } \\
\text { France. }\end{array}$ & 20200325 & 3 & $\begin{array}{l}\text { https://clinicaltrials.gov/c } \\
\text { t2/show/NCT04315948?c } \\
\text { ond=COVID- } \\
\text { 19\&draw=11\&rank=94 }\end{array}$ \\
\hline $\begin{array}{l}\text { NCT04311 } \\
177\end{array}$ & $\begin{array}{l}\text { Losartan for Patients With } \\
\text { COVID-19 Not Requiring } \\
\text { Hospitalization. }\end{array}$ & $\begin{array}{l}\text { Not } \\
\text { reported. }\end{array}$ & $\begin{array}{l}\text { University of } \\
\text { Minnesota. }\end{array}$ & 20200323 & 2 & $\begin{array}{l}\text { https://clinicaltrials.gov/c } \\
\text { t2/show/NCT04311177?c } \\
\text { ond=COVID- } \\
\text { 19\&draw=11\&rank=95 }\end{array}$ \\
\hline $\begin{array}{l}\text { NCT04255 } \\
017\end{array}$ & $\begin{array}{l}\text { A } \\
\text { Prospective/Retrospective, } \\
\text { Randomized Controlled } \\
\text { Clinical Study of Antiviral } \\
\text { Therapy in the 2019-nCoV } \\
\text { Pneumonia. }\end{array}$ & $\begin{array}{l}\text { Not } \\
\text { reported. }\end{array}$ & $\begin{array}{l}\text { Tongji } \\
\text { Hospital. }\end{array}$ & 20200317 & 4 & $\begin{array}{l}\text { https://clinicaltrials.gov/c } \\
\text { t2/show/NCT04255017?c } \\
\text { ond=COVID- } \\
\text { 19\&draw }=11 \& \text { rank=99 }\end{array}$ \\
\hline $\begin{array}{l}\text { NCT04254 } \\
874\end{array}$ & $\begin{array}{l}\text { A } \\
\text { Prospective/Retrospective, } \\
\text { Randomized Controlled } \\
\text { Clinical Study of Interferon } \\
\text { Atomization in the 2019- } \\
\text { nCoV Pneumonia }\end{array}$ & $\begin{array}{l}\text { Not } \\
\text { reported. }\end{array}$ & $\begin{array}{l}\text { Tongji } \\
\text { Hospital. }\end{array}$ & 20200317 & 4 & $\begin{array}{l}\text { https://clinicaltrials.gov/c } \\
\text { t2/show/NCT04254874?c } \\
\text { ond=COVID- } \\
\text { 19\&draw }=11 \& \text { rank=100 }\end{array}$ \\
\hline $\begin{array}{l}\text { NCT04323 } \\
761\end{array}$ & $\begin{array}{lr}\text { Expanded } & \text { Access } \\
\text { Treatment } & \text { Protocol: } \\
\text { Remdesivir } & \text { (RDV; GS- }\end{array}$ & $\begin{array}{l}\text { Not } \\
\text { reported. }\end{array}$ & $\begin{array}{l}\text { Gilead } \\
\text { Sciences. }\end{array}$ & 20200402 & $\begin{array}{l}\text { Not } \\
\text { Applicable }\end{array}$ & $\begin{array}{l}\text { https://clinicaltrials.gov/c } \\
\text { t2/show/NCT04323761?c }\end{array}$ \\
\hline
\end{tabular}




\begin{tabular}{|c|c|c|c|c|c|c|}
\hline $\begin{array}{l}\text { Patent } \\
\text { number }\end{array}$ & Patent title & $\begin{array}{l}\text { Target } / \mathbf{k e} \\
\text { y results }\end{array}$ & Organization & $\begin{array}{l}\text { Priority } \\
\text { date }\end{array}$ & Phase & Links \\
\hline & $\begin{array}{l}\text { 5734) for the Treatment of } \\
\text { SARS-CoV2 (CoV) } \\
\text { Infection. }\end{array}$ & & & & & $\begin{array}{l}\text { ond=COVID- } \\
19 \& \text { draw }=12 \& \text { rank }=103\end{array}$ \\
\hline $\begin{array}{l}\text { NCT04261 } \\
270\end{array}$ & $\begin{array}{l}\text { A Randomized, Open, } \\
\text { Controlled Clinical Study to } \\
\text { Evaluate the Efficacy of } \\
\text { ASC09F and Ritonavir for } \\
\text { 2019-nCoV Pneumonia. }\end{array}$ & $\begin{array}{l}\text { Not } \\
\text { reported. }\end{array}$ & $\begin{array}{l}\text { Tongji } \\
\text { Hospital. }\end{array}$ & 20200317 & 3 & $\begin{array}{l}\text { https://clinicaltrials.gov/c } \\
\text { t2/show/NCT04261270?c } \\
\text { ond=COVID- } \\
\text { 19\&draw=12\&rank=104 }\end{array}$ \\
\hline $\begin{array}{l}\text { NCT04311 } \\
697\end{array}$ & $\begin{array}{lr}\text { Intravenous } & \text { Aviptadil for } \\
\text { COVID-19 } & \text { Associated } \\
\text { Acute Respiratory Distress } \\
\text { (COVID-AIV). }\end{array}$ & $\begin{array}{l}\text { Not } \\
\text { reported. }\end{array}$ & NeuroRx, Inc. & 20200326 & 2 & $\begin{array}{l}\text { https://clinicaltrials.gov/c } \\
\text { t2/show/NCT04311697?c } \\
\text { ond=COVID- } \\
\text { 19\&draw=12\&rank=105 }\end{array}$ \\
\hline $\begin{array}{l}\text { NCT02735 } \\
707\end{array}$ & $\begin{array}{lr}\text { Randomized, } & \text { Embedded, } \\
\text { Multifactorial } & \text { Adaptive } \\
\text { Platform } & \text { Trial for } \\
\text { Community- } & \text { Acquired } \\
\text { Pneumonia } & \text { (REMAP- } \\
\text { CAP). } & \\
\end{array}$ & $\begin{array}{l}\text { Not } \\
\text { reported. }\end{array}$ & MJM Bonten. & 20200330 & 4 & $\begin{array}{l}\text { https://clinicaltrials.gov/c } \\
\text { t2/show/NCT02735707?c } \\
\text { ond=COVID- } \\
\text { 19\&draw=12\&rank=107 }\end{array}$ \\
\hline $\begin{array}{l}\text { NCT04263 } \\
402\end{array}$ & $\begin{array}{l}\text { The Efficacy of Different } \\
\text { Hormone Doses in 2019- } \\
\text { nCoV Severe Pneumonia. }\end{array}$ & $\begin{array}{l}\text { Not } \\
\text { reported. }\end{array}$ & $\begin{array}{l}\text { Tongji } \\
\text { Hospital. }\end{array}$ & 20200317 & 4 & $\begin{array}{l}\text { https://clinicaltrials.gov/c } \\
\text { t2/show/NCT04263402?c } \\
\text { ond=COVID- } \\
\text { 19\&draw=12\&rank=108 }\end{array}$ \\
\hline $\begin{array}{l}\text { NCT04305 } \\
457\end{array}$ & $\begin{array}{l}\text { Nitric Oxide Gas Inhalation } \\
\text { Therapy for Mild/Moderate } \\
\text { COVID-19 (NoCovid). }\end{array}$ & $\begin{array}{l}\text { Not } \\
\text { reported. }\end{array}$ & $\begin{array}{l}\text { Massachusetts } \\
\text { General } \\
\text { Hospital. }\end{array}$ & 20200324 & 2 & $\begin{array}{l}\text { https://clinicaltrials.gov/c } \\
\text { t2/show/NCT04305457?c } \\
\text { ond=COVID- } \\
\text { 19\&draw=13\&rank=112 }\end{array}$ \\
\hline $\begin{array}{l}\text { NCT04324 } \\
463\end{array}$ & $\begin{array}{l}\text { Anti-Coronavirus Therapies } \\
\text { to Prevent Progression of } \\
\text { Coronavirus Disease } 2019 \\
\text { (COVID-19) Trial (ACT } \\
\text { COVID19). }\end{array}$ & $\begin{array}{l}\text { Not } \\
\text { reported. }\end{array}$ & $\begin{array}{l}\text { Population } \\
\text { Health } \\
\text { Research } \\
\text { Institute. }\end{array}$ & 20200327 & 3 & $\begin{array}{l}\text { https://clinicaltrials.gov/c } \\
\text { t2/show/NCT04324463?c } \\
\text { ond=COVID- } \\
\text { 19\&draw=13\&rank=113 }\end{array}$ \\
\hline $\begin{array}{l}\text { NCT04320 } \\
277\end{array}$ & $\begin{array}{l}\text { Baricitinib in Symptomatic } \\
\text { Patients Infected by } \\
\text { COVID-19: an Open-label, } \\
\text { Pilot Study. (BARI- } \\
\text { COVID). }\end{array}$ & $\begin{array}{l}\text { Not } \\
\text { reported. }\end{array}$ & $\begin{array}{l}\text { Hospital of } \\
\text { Prato. }\end{array}$ & 20200324 & 3 & $\begin{array}{l}\text { https://clinicaltrials.gov/c } \\
\text { t2/show/NCT04320277?c } \\
\text { ond=COVID- } \\
\text { 19\&draw=13\&rank=114 }\end{array}$ \\
\hline $\begin{array}{l}\text { NCT04280 } \\
705\end{array}$ & $\begin{array}{ll}\text { Adaptive } & \text { COVID-19 } \\
\text { Treatment Trial (ACTT). }\end{array}$ & $\begin{array}{l}\text { Not } \\
\text { reported. }\end{array}$ & $\begin{array}{l}\text { National } \\
\text { Institute of } \\
\text { Allergy and } \\
\text { Infectious } \\
\text { Diseases } \\
\text { (NIAID). } \\
\end{array}$ & 20200327 & 3 & $\begin{array}{l}\text { https://clinicaltrials.gov/c } \\
\text { t2/show/NCT04280705?c } \\
\text { ond=COVID- } \\
\text { 19\&draw=13\&rank=117 }\end{array}$ \\
\hline $\begin{array}{l}\text { NCT04279 } \\
197\end{array}$ & $\begin{array}{l}\text { Treatment of Pulmonary } \\
\text { Fibrosis Due to 2019-nCoV } \\
\text { Pneumonia With Fuzheng } \\
\text { Huayu. }\end{array}$ & $\begin{array}{l}\text { Not } \\
\text { reported. }\end{array}$ & $\begin{array}{l}\text { ShuGuang } \\
\text { Hospital. }\end{array}$ & 20200221 & 2 & $\begin{array}{l}\text { https://clinicaltrials.gov/c } \\
\text { t2/show/NCT04279197?c } \\
\text { ond=COVID- } \\
\text { 19\&draw=13\&rank=118 }\end{array}$ \\
\hline $\begin{array}{l}\text { NCT04321 } \\
174\end{array}$ & \begin{tabular}{lrr} 
COVID-19 & \multicolumn{2}{c}{ Ring-based } \\
Prevention Trial & With \\
Lopinavir/Ritonavir & \\
(CORIPREV-LR).
\end{tabular} & $\begin{array}{l}\text { Not } \\
\text { reported. }\end{array}$ & $\begin{array}{l}\text { Darrell Tan, } \\
\text { St. Michael's } \\
\text { Hospital, } \\
\text { Toronto. }\end{array}$ & 20200325 & 3 & $\begin{array}{l}\text { https://clinicaltrials.gov/c } \\
\text { t2/show/NCT04321174?c } \\
\text { ond=COVID- } \\
\text { 19\&draw=13\&rank=120 }\end{array}$ \\
\hline $\begin{array}{l}\text { NCT04323 } \\
592\end{array}$ & $\begin{array}{lr}\text { Efficacy } & \text { of } \\
\text { Methylprednisolone for } \\
\text { Patients With COVID-19 } \\
\text { Severe Acute Respiratory } \\
\text { Syndrome (MP-C19). }\end{array}$ & $\begin{array}{l}\text { Not } \\
\text { reported. }\end{array}$ & $\begin{array}{l}\text { University of } \\
\text { Trieste. }\end{array}$ & 20200327 & 2 and 3 & $\begin{array}{l}\text { https://clinicaltrials.gov/c } \\
\text { t2/show/NCT04323592?c } \\
\text { ond=COVID- } \\
\text { 19\&draw=14\&rank=123 }\end{array}$ \\
\hline $\begin{array}{l}\text { NCT04322 } \\
565\end{array}$ & $\begin{array}{l}\text { Colchicine } \\
\text { Efficacy } \\
\text { COVID-19 Pneumonia. }\end{array}$ & $\begin{array}{l}\text { Not } \\
\text { reported. }\end{array}$ & $\begin{array}{l}\text { Lucio } \\
\text { Manenti, } \\
\text { Azienda } \\
\text { Ospedaliero- } \\
\text { Universitaria } \\
\text { di Parma } \\
\end{array}$ & 20200326 & 2 & $\begin{array}{l}\text { https://clinicaltrials.gov/c } \\
\text { t2/show/NCT04322565?c } \\
\text { ond=COVID- } \\
\text { 19\&draw=14\&rank=124 }\end{array}$ \\
\hline $\begin{array}{l}\text { NCT04312 } \\
243\end{array}$ & $\begin{array}{l}\text { NO Prevention of COVID- } \\
19 \text { for Healthcare Providers } \\
\text { (NOpreventCOVID). }\end{array}$ & $\begin{array}{l}\text { Not } \\
\text { reported. }\end{array}$ & $\begin{array}{l}\text { Massachusetts } \\
\text { General } \\
\text { Hospital. }\end{array}$ & 20200318 & 2 & $\begin{array}{l}\text { https://clinicaltrials.gov/c } \\
\text { t2/show/NCT04312243?c } \\
\text { ond=COVID- } \\
\text { 19\&draw=14\&rank=127 }\end{array}$ \\
\hline $\begin{array}{l}\text { NCT04293 } \\
887\end{array}$ & $\begin{array}{l}\text { Efficacy and Safety of IFN- } \\
\alpha 2 \beta \text { in the Treatment of } \\
\text { Novel Coronavirus Patients. }\end{array}$ & $\begin{array}{l}\text { Not } \\
\text { reported. }\end{array}$ & $\begin{array}{l}\text { Tongji } \\
\text { Hospital. }\end{array}$ & 20200303 & 1 & $\begin{array}{l}\text { https://clinicaltrials.gov/c } \\
\text { t2/show/NCT04293887?c } \\
\text { ond=COVID- } \\
\text { 19\&draw=14\&rank=128 }\end{array}$ \\
\hline $\begin{array}{l}\text { NCT04321 } \\
616\end{array}$ & $\begin{array}{l}\text { The Efficacy of Different } \\
\text { Anti-viral Drugs in (Severe } \\
\text { Acuter Respiratory } \\
\text { Syndrome-Corona Virus-2) } \\
\text { SARS-CoV-2. }\end{array}$ & $\begin{array}{l}\text { Not } \\
\text { reported. }\end{array}$ & $\begin{array}{l}\text { Oslo } \\
\text { University } \\
\text { Hospital. }\end{array}$ & 20200325 & 2 and 3 & $\begin{array}{l}\text { https://clinicaltrials.gov/c } \\
\text { t2/show/NCT04321616?c } \\
\text { ond=COVID- } \\
\text { 19\&draw=14\&rank=130 }\end{array}$ \\
\hline $\begin{array}{l}\text { NCT04290 } \\
871\end{array}$ & $\begin{array}{l}\text { Nitric Oxide Gas Inhalation } \\
\text { for } \quad \text { Severe } \quad \text { Acute }\end{array}$ & $\begin{array}{l}\text { Not } \\
\text { reported. }\end{array}$ & $\begin{array}{l}\text { Xijing } \\
\text { Hospital. }\end{array}$ & 20200324 & 2 & $\begin{array}{l}\text { https://clinicaltrials.gov/c } \\
\text { t2/show/NCT04290871?c }\end{array}$ \\
\hline
\end{tabular}




\begin{tabular}{|c|c|c|c|c|c|c|}
\hline $\begin{array}{l}\text { Patent } \\
\text { number }\end{array}$ & Patent title & $\begin{array}{l}\text { Target/ke } \\
\text { y results }\end{array}$ & Organization & $\begin{array}{l}\text { Priority } \\
\text { date }\end{array}$ & Phase & Links \\
\hline & $\begin{array}{l}\text { Respiratory Syndrome in } \\
\text { COVID- } 19 . \\
\text { (NOSARSCOVID). }\end{array}$ & & & & & $\begin{array}{l}\text { ond=COVID- } \\
19 \& \text { draw }=15 \& \text { rank=137 }\end{array}$ \\
\hline $\begin{array}{l}\text { NCT04320 } \\
238\end{array}$ &  & $\begin{array}{l}\text { Not } \\
\text { reported. }\end{array}$ & $\begin{array}{l}\text { Shanghai Jiao } \\
\text { Tong } \\
\text { University } \\
\text { School of } \\
\text { Medicine. }\end{array}$ & 20200331 & 3 & $\begin{array}{l}\text { https://clinicaltrials.gov/c } \\
\text { t2/show/NCT04320238?c } \\
\text { ond=COVID- } \\
\text { 19\&draw=15\&rank=139 }\end{array}$ \\
\hline $\begin{array}{l}\text { NCT04322 } \\
396\end{array}$ & $\begin{array}{l}\text { Proactive Prophylaxis With } \\
\text { Azithromycin and } \\
\text { Chloroquine in Hospitalized } \\
\text { Patients With COVID-19 } \\
\text { (ProPAC-COVID). }\end{array}$ & $\begin{array}{l}\text { Decreased } \\
\text { COVID-19 } \\
\text { complicati } \\
\text { ons }\end{array}$ & $\begin{array}{l}\text { Chronic } \\
\text { Obstructive } \\
\text { Pulmonary } \\
\text { Disease Trial } \\
\text { Network, } \\
\text { Denmark. } \\
\end{array}$ & 20200326 & 4 & $\begin{array}{l}\text { https://clinicaltrials.gov/c } \\
\text { t2/show/NCT04322396?c } \\
\text { ond=COVID- } \\
\text { 19\&draw=16\&rank=147 }\end{array}$ \\
\hline $\begin{array}{l}\text { NCT04325 } \\
893\end{array}$ & $\begin{array}{l}\text { Hydroxychloroquine } \\
\text { Versus Placebo in Patients } \\
\text { Presenting COVID-19 } \\
\text { Infection and at Risk of } \\
\text { Secondary Complication: a } \\
\text { Prospective, Multicentre, } \\
\text { Randomised, Double-blind } \\
\text { Study (HYCOVID). }\end{array}$ & $\begin{array}{l}\text { Not } \\
\text { reported. }\end{array}$ & $\begin{array}{l}\text { University } \\
\text { Hospital, } \\
\text { Angers }\end{array}$ & 20200330 & 3 & $\begin{array}{l}\text { https://clinicaltrials.gov/c } \\
\text { t2/show/NCT04325893?c } \\
\text { ond=COVID- } \\
\text { 19\&draw=16\&rank=150 }\end{array}$ \\
\hline $\begin{array}{l}\text { NCT04321 } \\
278\end{array}$ & $\begin{array}{l}\text { Safety and Efficacy of } \\
\text { Hydroxychloroquine } \\
\text { Associated } \\
\text { Azithromycin in SARS- } \\
\text { CoV2 Virus (Coalition } \\
\text { Covid-19 Brasil II). }\end{array}$ & $\begin{array}{l}\text { Not } \\
\text { reported. }\end{array}$ & $\begin{array}{l}\text { Hospital } \\
\text { Israelita } \\
\text { Albert } \\
\text { Einstein. }\end{array}$ & 20200401 & 3 & $\begin{array}{l}\text { https://clinicaltrials.gov/c } \\
\text { t2/show/NCT04321278?c } \\
\text { ond=COVID- } \\
\text { 19\&draw=17\&rank=151 }\end{array}$ \\
\hline $\begin{array}{l}\text { NCT04260 } \\
594\end{array}$ & $\begin{array}{l}\text { Clinical Study of Arbidol } \\
\text { Hydrochloride Tablets in } \\
\text { the Treatment of Pneumonia } \\
\text { Caused by Novel } \\
\text { Coronavirus. }\end{array}$ & $\begin{array}{l}\text { Not } \\
\text { reported. }\end{array}$ & $\begin{array}{l}\text { Jieming QU, } \\
\text { Ruijin } \\
\text { Hospital. }\end{array}$ & 20200207 & 4 & $\begin{array}{l}\text { https://clinicaltrials.gov/c } \\
\text { t2/show/NCT04260594?c } \\
\text { ond=COVID- } \\
\text { 19\&draw }=17 \& \text { rank }=152\end{array}$ \\
\hline $\begin{array}{l}\text { NCT04326 } \\
426\end{array}$ & $\begin{array}{l}\text { COVIDL1: A Study to } \\
\text { Investigate the Efficacy of } \\
\text { Tradipitant in Treating } \\
\text { Severe or Critical COVID- } \\
19 \text { Infection. }\end{array}$ & $\begin{array}{l}\text { Not } \\
\text { reported. }\end{array}$ & $\begin{array}{l}\text { Vanda } \\
\text { Pharmaceutica } \\
\text { ls }\end{array}$ & 20200330 & 3 & $\begin{array}{l}\text { https://clinicaltrials.gov/c } \\
\text { t2/show/NCT04326426?c } \\
\text { ond=COVID- } \\
\text { 19\&draw }=17 \& \text { rank }=154\end{array}$ \\
\hline $\begin{array}{l}\text { NCT04290 } \\
858\end{array}$ & $\begin{array}{l}\text { Nitric Oxide Gas Inhalation } \\
\text { Therapy for Mild/Moderate } \\
\text { COVID19 Infection } \\
\text { (NoCovid). }\end{array}$ & $\begin{array}{l}\text { Not } \\
\text { reported. }\end{array}$ & $\begin{array}{l}\text { Xijing } \\
\text { Hospital. }\end{array}$ & 20200324 & 2 & $\begin{array}{l}\text { https://clinicaltrials.gov/c } \\
\text { t2/show/NCT04290858?c } \\
\text { ond=COVID- } \\
\text { 19\&draw=17\&rank=157 }\end{array}$ \\
\hline $\begin{array}{l}\text { NCT04257 } \\
656\end{array}$ & $\begin{array}{l}\text { Severe 2019-nCoV } \\
\text { Remdesivir RCT. }\end{array}$ & $\begin{array}{l}\text { Not } \\
\text { reported. }\end{array}$ & $\begin{array}{l}\text { Capital } \\
\text { Medical } \\
\text { University. }\end{array}$ & 20200224 & 3 & $\begin{array}{l}\text { https://clinicaltrials.gov/c } \\
\text { t2/show/NCT04257656?c } \\
\text { ond=COVID- } \\
\text { 19\&draw=17\&rank=158 }\end{array}$ \\
\hline $\begin{array}{l}\text { NCT04306 } \\
393\end{array}$ & $\begin{array}{l}\text { Nitric Oxide Gas Inhalation } \\
\text { in Severe Acute Respiratory } \\
\text { Syndrome in COVID-19 } \\
\text { (NOSARSCOVID). }\end{array}$ & $\begin{array}{l}\text { Not } \\
\text { reported. }\end{array}$ & $\begin{array}{l}\text { Massachusetts } \\
\text { General } \\
\text { Hospital. }\end{array}$ & 20200324 & 2 & $\begin{array}{l}\text { https://clinicaltrials.gov/c } \\
\text { t2/show/NCT04306393?c } \\
\text { ond=COVID- } \\
\text { 19\&draw=18\&rank=163 }\end{array}$ \\
\hline $\begin{array}{l}\text { NCT04322 } \\
344\end{array}$ & $\begin{array}{l}\text { Escin in Patients With } \\
\text { Covid-19 Infection (add-on- } \\
\text { COV2). }\end{array}$ & $\begin{array}{l}\text { Not } \\
\text { reported. }\end{array}$ & $\begin{array}{l}\text { University of } \\
\text { Catanzaro. }\end{array}$ & 20200327 & 2 and 3 & $\begin{array}{l}\text { https://clinicaltrials.gov/c } \\
\text { t2/show/NCT04322344?c } \\
\text { ond=COVID- } \\
\text { 19\&draw=18\&rank=164 }\end{array}$ \\
\hline $\begin{array}{l}\text { NCT04322 } \\
773\end{array}$ & $\begin{array}{lr}\text { Anti-il6 } & \text { Treatment of } \\
\text { Serious COVID-19 Disease } \\
\text { With } & \text { Threatening } \\
\text { Respiratory } & \text { Failure } \\
\text { (TOCIVID). } & \\
\end{array}$ & $\begin{array}{l}\text { Not } \\
\text { reported. }\end{array}$ & $\begin{array}{l}\text { Frederiksberg } \\
\text { University } \\
\text { Hospital. }\end{array}$ & 20200330 & 2 & $\begin{array}{l}\text { https://clinicaltrials.gov/c } \\
\text { t2/show/NCT04322773?c } \\
\text { ond=COVID- } \\
\text { 19\&draw=18\&rank=165 }\end{array}$ \\
\hline $\begin{array}{l}\text { NCT04322 } \\
786\end{array}$ & $\begin{array}{l}\text { The Use of Angiotensin } \\
\text { Converting Enzyme } \\
\text { Inhibitors and Incident } \\
\text { Respiratory Infections, Are } \\
\text { They Harmful or } \\
\text { Protective? }\end{array}$ & $\begin{array}{l}\text { Not } \\
\text { reported. }\end{array}$ & $\begin{array}{l}\text { University } \\
\text { College, } \\
\text { London. }\end{array}$ & 20200326 & $\begin{array}{l}\text { Not } \\
\text { Applicable }\end{array}$ & $\begin{array}{l}\text { https://clinicaltrials.gov/c } \\
\text { t2/show/NCT04322786?c } \\
\text { ond=COVID- } \\
\text { 19\&draw=18\&rank=167 }\end{array}$ \\
\hline $\begin{array}{l}\text { NCT04322 } \\
123\end{array}$ & $\begin{array}{l}\text { Safety and Efficacy of } \\
\text { Hydroxychloroquine } \\
\text { Associated } \\
\text { Azythromycin in SARS- } \\
\text { Cov-2 Virus (Coalition-I). }\end{array}$ & $\begin{array}{l}\text { Not } \\
\text { reported. }\end{array}$ & $\begin{array}{l}\text { Hospital do } \\
\text { Coracao. }\end{array}$ & 20200326 & 3 & $\begin{array}{l}\text { https://clinicaltrials.gov/c } \\
\text { t2/show/NCT04322123?c } \\
\text { ond=COVID- } \\
\text { 19\&draw=18\&rank=168 }\end{array}$ \\
\hline $\begin{array}{l}\text { NCT04261 } \\
907\end{array}$ & $\begin{array}{l}\text { Evaluating and Comparing } \\
\text { the Safety and Efficiency of } \\
\text { ASC09/Ritonavir and } \\
\text { Lopinavir/Ritonavir for } \\
\text { Novel Coronavirus } \\
\text { Infection. }\end{array}$ & $\begin{array}{l}\text { Not } \\
\text { reported. }\end{array}$ & $\begin{array}{l}\text { First Affiliated } \\
\text { Hospital of } \\
\text { Zhejiang } \\
\text { University. }\end{array}$ & 20200210 & $\begin{array}{l}\text { Not } \\
\text { Applicable }\end{array}$ & $\begin{array}{l}\text { https://clinicaltrials.gov/c } \\
\text { t2/show/NCT04261907?c } \\
\text { ond=COVID- } \\
\text { 19\&draw=19\&rank=174 }\end{array}$ \\
\hline
\end{tabular}




\begin{tabular}{|c|c|c|c|c|c|c|}
\hline $\begin{array}{l}\text { Patent } \\
\text { number }\end{array}$ & Patent title & $\begin{array}{l}\text { Target/ke } \\
\text { y results }\end{array}$ & Organization & $\begin{array}{l}\text { Priority } \\
\text { date }\end{array}$ & Phase & Links \\
\hline $\begin{array}{l}\text { NCT04302 } \\
766\end{array}$ & $\begin{array}{l}\text { Expanded } \quad \text { Access } \\
\text { Remdesivir } \quad \text { (RDV; GS- } \\
\left.5734^{\mathrm{TM}}\right) .\end{array}$ & $\begin{array}{l}\text { Not } \\
\text { reported. }\end{array}$ & $\begin{array}{l}\text { U.S. Army } \\
\text { Medical } \\
\text { Research and } \\
\text { Development } \\
\text { Command. }\end{array}$ & 20200320 & $\begin{array}{l}\text { Not } \\
\text { Applicable }\end{array}$ & $\begin{array}{l}\text { https://clinicaltrials.gov/c } \\
\text { t2/show/NCT04302766?c } \\
\text { ond=COVID- } \\
\text { 19\&draw=20\&rank=181 }\end{array}$ \\
\hline $\begin{array}{l}\text { NCT04323 } \\
527\end{array}$ & $\begin{array}{l}\text { Chloroquine Diphosphate } \\
\text { for the Treatment of Severe } \\
\text { Acute Respiratory } \\
\text { Syndrome Secondary to } \\
\text { SARS-CoV2 } \\
\text { (CloroCOVID19). }\end{array}$ & $\begin{array}{l}\text { Not } \\
\text { reported. }\end{array}$ & $\begin{array}{l}\text { Fundação de } \\
\text { Medicina } \\
\text { Tropical Dr. } \\
\text { Heitor Vieira } \\
\text { Dourado }\end{array}$ & 20200330 & 2 & $\begin{array}{l}\text { https://clinicaltrials.gov/c } \\
\text { t2/show/NCT04323527?c } \\
\text { ond=COVID- } \\
\text { 19\&draw=20\&rank=182 }\end{array}$ \\
\hline $\begin{array}{l}\text { NCT04275 } \\
388\end{array}$ & $\begin{array}{l}\text { Xiyanping Injection for the } \\
\text { Treatment of } \begin{array}{r}\text { New } \\
\text { Coronavirus } \\
\text { Pneumonia. }\end{array} \\
\text { Infected }\end{array}$ & $\begin{array}{l}\text { Not } \\
\text { reported. }\end{array}$ & $\begin{array}{l}\text { Jiangxi } \\
\text { Qingfeng } \\
\text { Pharmaceutica } \\
\text { 1 Co. Ltd. } \\
\end{array}$ & 20200219 & $\begin{array}{l}\text { Not } \\
\text { Applicable }\end{array}$ & $\begin{array}{l}\text { https://clinicaltrials.gov/c } \\
\text { t2/show/NCT04275388?c } \\
\text { ond=COVID- } \\
\text { 19\&draw=20\&rank=183 }\end{array}$ \\
\hline $\begin{array}{l}\text { NCT03331 } \\
445\end{array}$ & $\begin{array}{l}\text { Inhaled Gaseous Nitric } \\
\text { Oxide (gNO) Antimicrobial } \\
\text { Treatment of Difficult } \\
\text { Bacterial and Viral Lung } \\
\text { (COVID-19) Infections } \\
\text { (NONTM). }\end{array}$ & $\begin{array}{l}\text { Not } \\
\text { reported. }\end{array}$ & $\begin{array}{l}\text { University of } \\
\text { British } \\
\text { Columbia. }\end{array}$ & 20200331 & 2 & $\begin{array}{l}\text { https://clinicaltrials.gov/c } \\
\text { t2/show/NCT03331445?c } \\
\text { ond=COVID- } \\
\text { 19\&draw=20\&rank=186 }\end{array}$ \\
\hline $\begin{array}{l}\text { NCT04322 } \\
682\end{array}$ & $\begin{array}{lr}\text { Colchicine } & \text { Coronavirus } \\
\text { SARS-CoV2 } & \text { Trial } \\
\text { (COLCORONA) } & \text { (COVID- } \\
19) . & \\
\end{array}$ & $\begin{array}{l}\text { Not } \\
\text { reported. }\end{array}$ & $\begin{array}{l}\text { Montreal } \\
\text { Heart Institute. }\end{array}$ & 20200327 & 3 & $\begin{array}{l}\text { https://clinicaltrials.gov/c } \\
\text { t2/show/NCT04322682?c } \\
\text { ond=COVID- } \\
\text { 19\&draw=20\&rank=188 }\end{array}$ \\
\hline $\begin{array}{l}\text { NCT04252 } \\
274\end{array}$ & $\begin{array}{l}\text { Efficacy and Safety of } \\
\text { Darunavir and Cobicistat } \\
\text { for Treatment of Pneumonia } \\
\text { Caused by 2019-nCoV } \\
\text { (DACO-nCoV). }\end{array}$ & $\begin{array}{l}\text { Not } \\
\text { reported. }\end{array}$ & $\begin{array}{l}\text { Shanghai } \\
\text { Public Health } \\
\text { Clinical } \\
\text { Center. }\end{array}$ & 20200304 & 3 & $\begin{array}{l}\text { https://clinicaltrials.gov/c } \\
\text { t2/show/NCT04252274?c } \\
\text { ond=COVID- } \\
\text { 19\&draw=21\&rank=195 }\end{array}$ \\
\hline $\begin{array}{l}\text { NCT04261 } \\
517\end{array}$ & $\begin{array}{l}\text { Efficacy and Safety of } \\
\text { Hydroxychloroquine for } \\
\text { Treatment of Pneumonia } \\
\text { Caused by 2019-nCoV ( } \\
\text { HC-nCoV). }\end{array}$ & $\begin{array}{l}\text { Not } \\
\text { reported. }\end{array}$ & $\begin{array}{l}\text { Shanghai } \\
\text { Public Health } \\
\text { Clinical } \\
\text { Center. }\end{array}$ & 20200324 & 3 & $\begin{array}{l}\text { https://clinicaltrials.gov/c } \\
\text { t2/show/NCT04261517?c } \\
\text { ond=COVID- } \\
\text { 19\&draw=21\&rank=196 }\end{array}$ \\
\hline $\begin{array}{l}\text { NCT04244 } \\
591\end{array}$ & $\begin{array}{l}\text { Glucocorticoid Therapy for } \\
\text { Novel Coronavirus } \\
\text { Critically Ill Patients With } \\
\text { Severe Acute Respiratory } \\
\text { Failure (Steroids-SARI). }\end{array}$ & $\begin{array}{l}\text { Not } \\
\text { reported. }\end{array}$ & $\begin{array}{l}\text { Peking Union } \\
\text { Medical } \\
\text { College } \\
\text { Hospital. }\end{array}$ & 20200213 & 2 and 3 & $\begin{array}{l}\text { https://clinicaltrials.gov/c } \\
\text { t2/show/NCT04244591?c } \\
\text { ond=COVID- } \\
\text { 19\&draw=23\&rank=211 }\end{array}$ \\
\hline $\begin{array}{l}\text { NCT04316 } \\
377\end{array}$ & \begin{tabular}{ll} 
Norwegian & \multicolumn{2}{l}{ Coronavirus } \\
Disease 2019 & Study (NO \\
COVID-19). &
\end{tabular} & $\begin{array}{l}\text { Not } \\
\text { reported. }\end{array}$ & $\begin{array}{l}\text { University } \\
\text { Hospital, } \\
\text { Akershus. }\end{array}$ & 20200320 & 4 & $\begin{array}{l}\text { https://clinicaltrials.gov/c } \\
\text { t2/show/NCT04316377?c } \\
\text { ond=COVID- } \\
\text { 19\&draw=23\&rank=212 }\end{array}$ \\
\hline $\begin{array}{l}\text { NCT04276 } \\
688\end{array}$ & $\begin{array}{l}\text { Lopinavir/ } \\
\text { Ritonavir, } \\
\text { Ribavirin and IFN-beta } \\
\text { Combination for nCoV } \\
\text { Treatment. }\end{array}$ & $\begin{array}{l}\text { Not } \\
\text { reported. }\end{array}$ & $\begin{array}{l}\text { The } \\
\text { University of } \\
\text { Hong Kong. }\end{array}$ & 20200228 & 2 & $\begin{array}{l}\text { https://clinicaltrials.gov/c } \\
\text { t2/show/NCT04276688?c } \\
\text { ond=COVID- } \\
\text { 19\&draw=5\&rank=213 }\end{array}$ \\
\hline $\begin{array}{l}\text { NCT04308 } \\
668\end{array}$ & $\begin{array}{l}\text { Post-exposure Prophylaxis / } \\
\text { Preemptive Therapy for } \\
\text { SARS-Coronavirus-2 } \\
\text { (COVID-19 PEP). }\end{array}$ & $\begin{array}{l}\text { Not } \\
\text { reported. }\end{array}$ & $\begin{array}{l}\text { University of } \\
\text { Minnesota. }\end{array}$ & 20200327 & 3 & $\begin{array}{l}\text { https://clinicaltrials.gov/c } \\
\text { t2/show/NCT04308668?c } \\
\text { ond=COVID- } \\
\text { 19\&draw }=5 \& \text { rank=217 }\end{array}$ \\
\hline $\begin{array}{l}\text { NCT04328 } \\
467\end{array}$ & $\begin{array}{l}\text { Pre-exposure Prophylaxis } \\
\text { for SARS-Coronavirus- } 2 \text {. }\end{array}$ & $\begin{array}{l}\text { Not } \\
\text { reported. }\end{array}$ & $\begin{array}{l}\text { University of } \\
\text { Minnesota. }\end{array}$ & 20200406 & 3 & $\begin{array}{l}\text { https://clinicaltrials.gov/c } \\
\text { t2/show/NCT04328467?c } \\
\text { ond=COVID- } \\
\text { 19\&draw }=4\end{array}$ \\
\hline
\end{tabular}

\subsection{Natural substances.}

Several patents, in particular, Chinese evolving the anti-COVID-19 effects of medicinal plants from China, are filed today in the various clinical phases (Table 5). The action of these plant mixtures has not been specified. However, these plants are known for their antioxidant and anti-inflammatory properties, which could either decrease the promoter's action of ROS on the inflammatory process or inhibit the inflammation itself. Among the patents filed are nutritional supplements, traditional Chinese medicine, honey, and ascorbic acid. 
Table 5. Clinical trial patents of natural targeted SARS-CoV2.

\begin{tabular}{|c|c|c|c|c|c|}
\hline $\begin{array}{l}\text { Patent } \\
\text { number }\end{array}$ & Patent title & Organization & $\begin{array}{l}\text { Priority } \\
\text { date }\end{array}$ & Phase & Links \\
\hline NCT04323228 & $\begin{array}{l}\text { Anti- } \\
\text { inflammatory/Antioxidant } \\
\text { Oral Nutrition } \\
\text { Supplementation in } \\
\text { COVID-19 } \\
\text { (ONSCOVID19). }\end{array}$ & $\begin{array}{l}\text { King Saud } \\
\text { University. }\end{array}$ & 20200327 & 4 & $\begin{array}{l}\text { https://clinicaltrials.gov/ct } \\
\text { 2/show/NCT04323228?co } \\
\text { nd=COVID- } \\
\text { 19\&draw=2\&rank=3 }\end{array}$ \\
\hline NCT04323332 & $\begin{array}{llr}\text { Traditional } & \text { Chinese } \\
\text { Medicine for } & \text { Severe } \\
\text { COVID-19. } & & \\
& \end{array}$ & $\begin{array}{l}\text { Xiyuan Hospital } \\
\text { of } \quad \text { China } \\
\text { Academy of } \\
\text { Chinese Medical } \\
\text { Sciences. }\end{array}$ & 20200326 & 3 & $\begin{array}{l}\text { https://clinicaltrials.gov/ct } \\
\text { 2/show/NCT04323332?co } \\
\text { nd=COVID- } \\
\text { 19\&draw=2\&rank=4 }\end{array}$ \\
\hline NCT04306497 & $\begin{array}{lrr}\text { Clinical } & \text { Trial on } \\
\text { Regularity } & \text { of } & \text { Traditional } \\
\text { Chinese } & \text { Medicines } \\
\text { Syndrome } & \text { and } \\
\text { Differentiation } & \text { Treatment } \\
\text { of } & \text { COVID-19. } \\
\text { (CTOROTSADTOC). }\end{array}$ & $\begin{array}{l}\text { Jiangsu Famous } \\
\text { Medical } \\
\text { Technology Co., } \\
\text { Ltd. }\end{array}$ & 20200317 & $\begin{array}{l}\text { Not } \\
\text { applicable }\end{array}$ & $\begin{array}{l}\text { https://clinicaltrials.gov/ct } \\
\text { 2/show/NCT04306497?co } \\
\text { nd=COVID- } \\
\text { 19\&draw=2\&rank=7 }\end{array}$ \\
\hline NCT04308317 & $\begin{array}{l}\text { Tetrandrine Tablets Used } \\
\text { in the Treatment of } \\
\text { COVID-19 (TT-NPC). }\end{array}$ & $\begin{array}{l}\text { Henan } \\
\text { Provincial } \\
\text { People's } \\
\text { Hospital. } \\
\end{array}$ & 20200316 & 4 & $\begin{array}{l}\text { https://clinicaltrials.gov/ct } \\
\text { 2/show/NCT04308317?co } \\
\text { nd=COVID- } \\
\text { 19\&draw=5\&rank=31 }\end{array}$ \\
\hline NCT04323345 & $\begin{array}{l}\text { Efficacy of Natural Honey } \\
\text { Treatment in Patients } \\
\text { With Novel Coronavirus. }\end{array}$ & $\begin{array}{l}\text { Misr University } \\
\text { for Science and } \\
\text { Technology. }\end{array}$ & 20200326 & 3 & $\begin{array}{l}\text { https://clinicaltrials.gov/ct } \\
\text { 2/show/NCT04323345?co } \\
\text { nd=COVID- } \\
\text { 19\&draw=6\&rank=42 }\end{array}$ \\
\hline NCT04323514 & $\begin{array}{l}\text { Use of Ascorbic Acid in } \\
\text { Patients With COVID } 19 .\end{array}$ & $\begin{array}{l}\text { University of } \\
\text { Palermo }\end{array}$ & 20200326 & $\begin{array}{l}\text { Not } \\
\text { applicable }\end{array}$ & $\begin{array}{l}\text { https://clinicaltrials.gov/ct } \\
\text { 2/show/NCT04323514?co } \\
\text { nd=COVID- } \\
\text { 19\&draw=7\&rank=51 }\end{array}$ \\
\hline NCT04278963 & $\begin{array}{l}\text { Yinhu } \\
\text { Decoction for the } \\
\text { Treatment of Mild / } \\
\text { Common CoVID-19. }\end{array}$ & $\begin{array}{l}\text { China Academy } \\
\text { of Chinese } \\
\text { Medical } \\
\text { Sciences } \\
\end{array}$ & 20200317 & 2 and 3 & $\begin{array}{l}\text { https://clinicaltrials.gov/ct } \\
\text { 2/show/NCT04278963?co } \\
\text { nd=COVID- } \\
\text { 19\&draw=8\&rank=64 }\end{array}$ \\
\hline NCT04310865 & $\begin{array}{l}\text { Yinhu Qingwen Granula } \\
\text { for the Treatment of } \\
\text { Severe CoVID-19. }\end{array}$ & $\begin{array}{l}\text { China Academy } \\
\text { of Chinese } \\
\text { Medical } \\
\text { Sciences. }\end{array}$ & 20200317 & 2 and 3 & $\begin{array}{l}\text { https://clinicaltrials.gov/ct } \\
\text { 2/show/NCT04310865?co } \\
\text { nd=COVID-19\&draw=8 }\end{array}$ \\
\hline NCT04285190 & $\begin{array}{l}\text { The Effect of T89 on } \\
\text { Improving } \\
\text { Saturation and Clinical } \\
\text { Symptoms in Patients } \\
\text { With COVID-19. }\end{array}$ & $\begin{array}{l}\text { Tasly } \\
\text { Pharmaceuticals, } \\
\text { Inc. }\end{array}$ & 20200226 & $\begin{array}{l}\text { Not } \\
\text { applicable }\end{array}$ & $\begin{array}{l}\text { https://clinicaltrials.gov/ct } \\
\text { 2/show/NCT04285190?co } \\
\text { nd=COVID- } \\
\text { 19\&draw }=10 \& \text { rank=82 }\end{array}$ \\
\hline NCT04264533 & $\begin{array}{l}\text { Vitamin C Infusion for the } \\
\text { Treatment of Severe } \\
\text { 2019-nCoV } \\
\text { Pneumonia. }\end{array}$ & $\begin{array}{l}\text { Zhongnan } \\
\text { Hospital. }\end{array}$ & 20200310 & 2 & $\begin{array}{l}\text { https://clinicaltrials.gov/ct } \\
\text { 2/show/NCT04264533?co } \\
\text { nd=COVID- } \\
\text { 19\&draw=19\&rank=180 }\end{array}$ \\
\hline NCT04251871 & $\begin{array}{l}\text { Treatment and Prevention } \\
\text { of Traditional Chinese } \\
\text { Medicines on 2019-nCoV } \\
\text { Infection. }\end{array}$ & $\begin{array}{l}\text { Beijing } \quad 302 \\
\text { Hospital. }\end{array}$ & 20200205 & $\begin{array}{l}\text { Not } \\
\text { applicable }\end{array}$ & $\begin{array}{l}\text { https://clinicaltrials.gov/ct } \\
\text { 2/show/NCT04251871?co } \\
\text { nd=COVID- } \\
\text { 19\&draw=21\&rank=198 }\end{array}$ \\
\hline NCT03680274 & $\begin{array}{lr}\text { Lessening } & \text { Organ } \\
\text { Dysfunction } & \text { With } \\
\text { VITamin C (LOVIT). }\end{array}$ & $\begin{array}{l}\text { Université de } \\
\text { Sherbrooke. }\end{array}$ & 20200324 & 3 & $\begin{array}{l}\text { https://clinicaltrials.gov/ct } \\
\text { 2/show/NCT03680274?co } \\
\text { nd=COVID- } \\
\text { 19\&draw=5\&rank=215 }\end{array}$ \\
\hline
\end{tabular}

\subsection{Specific antibody.}

Among the therapeutic strategies that are under development against COVID-19, antibodies represent a promising choice. Indeed, several patents evolving the clinical effects of antibodies against COVID-19 disease are today in the various clinical phases (Table 6). Antibodies neutralizing IL-6, such as Tocilizumab, Sarilumab, and Emapalumab, are in clinical phases II/III (Table 6). The monoclonal antibody Bevacizumab directed against Vascular 
endothelial growth factor is developed by the organization Qilu Hospital of Shandong University and is now in phases II/III. Mepolizumab is also a monoclonal antibody, blocks the CD147 receptor, is developed by Tang-Du Hospital in the initial clinical phases I/II (Table 6). The complement system has also been targeted by Eculizumab-like antibodies which are under development by Hudson Medical. In addition, other types of antibodies with an immunomodulatory and anti-inflammatory effect are under development (Table 6).

Table 6. Clinical trial patents of antibody-targeted SARS-CoV2.

\begin{tabular}{|c|c|c|c|c|c|c|}
\hline $\begin{array}{l}\text { Patent } \\
\text { number }\end{array}$ & Patent title & $\begin{array}{l}\text { Target/key } \\
\text { results }\end{array}$ & $\begin{array}{l}\text { Organizat } \\
\text { ion }\end{array}$ & $\begin{array}{l}\text { Priority } \\
\text { date }\end{array}$ & Phase & Links \\
\hline $\begin{array}{l}\text { NCT043 } \\
17092\end{array}$ & $\begin{array}{l}\text { Tocilizumab } \\
\text { in COVID- } \\
19 \\
\text { Pneumonia } \\
\text { (TOCIVID- } \\
19 \text { ) } \\
\text { (TOCIVID- } \\
19 \text { ). }\end{array}$ & $\begin{array}{l}\text { Interleukin-6 } \\
\text { (IL-6) }\end{array}$ & $\begin{array}{l}\text { National } \\
\text { Cancer } \\
\text { Institute, } \\
\text { Naples. }\end{array}$ & 20200320 & 2 & $\begin{array}{l}\text { https://clinicaltrials.gov/ct2/show } \\
\text { /NCT04317092?cond=COVID- } \\
\text { 19\&draw=3\&rank=11 }\end{array}$ \\
\hline $\begin{array}{l}\text { NCT043 } \\
15298\end{array}$ & $\begin{array}{l}\text { Evaluation } \\
\text { of the } \\
\text { Efficacy and } \\
\text { Safety of } \\
\text { Sarilumab in } \\
\text { Hospitalized } \\
\text { Patients } \\
\text { With } \\
\text { COVID-19. }\end{array}$ & $\begin{array}{l}\text { Interleukin-6 } \\
\text { (IL-6) }\end{array}$ & $\begin{array}{l}\text { Regeneron } \\
\text { Pharmaceu } \\
\text { ticals. }\end{array}$ & 20200330 & 2 and 3 & $\begin{array}{l}\text { https://clinicaltrials.gov/ct2/show } \\
\text { /NCT04315298?cond=COVID- } \\
\text { 19\&draw=3\&rank=12 }\end{array}$ \\
\hline $\begin{array}{l}\text { NCT043 } \\
05106\end{array}$ & $\begin{array}{l}\text { Bevacizuma } \\
\mathrm{b} \text { in Severe } \\
\text { or Critically } \\
\text { Severe } \\
\text { Patients } \\
\text { With } \\
\text { COVID-19 } \\
\text { Pneumonia- } \\
\text { RCT } \\
\text { (BEST- } \\
\text { RCT). }\end{array}$ & $\begin{array}{l}\text { Vascular } \\
\text { endothelial } \\
\text { growth } \\
\text { factor } \\
\text { (VEGF). }\end{array}$ & $\begin{array}{l}\text { Qilu } \\
\text { Hospital of } \\
\text { Shandong } \\
\text { University. }\end{array}$ & 20200326 & $\begin{array}{l}\text { Not } \\
\text { applicable }\end{array}$ & $\begin{array}{l}\text { https://clinicaltrials.gov/ct2/show } \\
\text { /NCT04305106?cond=COVID- } \\
\text { 19\&draw=4\&rank=26 }\end{array}$ \\
\hline $\begin{array}{l}\text { NCT043 } \\
20615\end{array}$ & $\begin{array}{l}\text { A Study to } \\
\text { Evaluate the } \\
\text { Safety and } \\
\text { Efficacy of } \\
\text { Tocilizumab } \\
\text { in Patients } \\
\text { With Severe } \\
\text { COVID-19 } \\
\text { Pneumonia } \\
\text { (COVACTA } \\
\text { ). }\end{array}$ & $\begin{array}{l}\text { Interleukin-6 } \\
\text { (IL-6) }\end{array}$ & $\begin{array}{l}\text { Hoffmann- } \\
\text { La Roche. }\end{array}$ & 20200330 & 3 & $\begin{array}{l}\text { https://clinicaltrials.gov/ct2/show } \\
\text { /NCT04320615?cond=COVID- } \\
\text { 19\&draw=4\&rank=27 }\end{array}$ \\
\hline $\begin{array}{l}\text { NCT043 } \\
10228\end{array}$ & $\begin{array}{l}\text { Favipiravir } \\
\text { Combined } \\
\text { with } \\
\text { Tocilizumab } \\
\text { in the } \\
\text { Treatment of } \\
\text { Corona } \\
\text { Virus } \\
\text { Disease } \\
2019 .\end{array}$ & $\begin{array}{l}\text { Interleukin-6 } \\
\text { (IL-6) }\end{array}$ & $\begin{array}{l}\text { Guiqiang } \\
\text { Wang, } \\
\text { Peking } \\
\text { University } \\
\text { First } \\
\text { Hospital. }\end{array}$ & 20200317 & $\begin{array}{l}\text { Not } \\
\text { applicable }\end{array}$ & $\begin{array}{l}\text { https://clinicaltrials.gov/ct2/show } \\
\text { /NCT04310228?cond=COVID- } \\
\text { 19\&draw=7\&rank=58 }\end{array}$ \\
\hline $\begin{array}{l}\text { NCT043 } \\
24021\end{array}$ & $\begin{array}{l}\text { Efficacy and } \\
\text { Safety of } \\
\text { Emapaluma } \\
\text { b and } \\
\text { Anakinra in } \\
\text { Reducing } \\
\text { Hyperinflam }\end{array}$ & $\begin{array}{l}\text { Interleukin } 1 \\
\text { receptor } \\
\text { antagonist } \\
\text { protein. }\end{array}$ & $\begin{array}{l}\text { Swedish } \\
\text { Orphan } \\
\text { Biovitrum. }\end{array}$ & 20200327 & 2 and 3 & $\begin{array}{l}\text { https://clinicaltrials.gov/ct2/show } \\
\text { /NCT04324021 ?cond=COVID- } \\
\text { 19\&draw=8 }\end{array}$ \\
\hline
\end{tabular}




\begin{tabular}{|c|c|c|c|c|c|c|}
\hline $\begin{array}{l}\text { Patent } \\
\text { number }\end{array}$ & Patent title & $\begin{array}{l}\text { Target/key } \\
\text { results }\end{array}$ & $\begin{array}{l}\text { Organizat } \\
\text { ion }\end{array}$ & $\begin{array}{l}\text { Priority } \\
\text { date }\end{array}$ & Phase & Links \\
\hline & $\begin{array}{l}\text { mation and } \\
\text { Respiratory } \\
\text { Distress in } \\
\text { Patients } \\
\text { With } \\
\text { COVID-19 } \\
\text { Infection. }\end{array}$ & & & & & \\
\hline $\begin{array}{l}\text { NCT042 } \\
68537\end{array}$ & $\begin{array}{l}\text { Immunoregu } \\
\text { latory } \\
\text { Therapy for } \\
\text { 2019-nCoV. }\end{array}$ & $\begin{array}{l}\text { Interleukin-6 } \\
\text { (IL-6) }\end{array}$ & $\begin{array}{l}\text { Southeast } \\
\text { University, } \\
\text { China. }\end{array}$ & 20200213 & 2 & $\begin{array}{l}\text { https://clinicaltrials.gov/ct2/show } \\
\text { /NCT04268537?cond=COVID- } \\
\text { 19\&draw=10\&rank=86 }\end{array}$ \\
\hline $\begin{array}{l}\text { NCT043 } \\
06705\end{array}$ & $\begin{array}{l}\text { Tocilizumab } \\
\text { vs CRRT in } \\
\text { Management } \\
\text { of Cytokine } \\
\text { Release } \\
\text { Syndrome } \\
\text { (CRS) in } \\
\text { COVID-19 } \\
\text { (TACOS). }\end{array}$ & $\begin{array}{l}\text { Interleukin-6 } \\
\text { (IL-6) }\end{array}$ & $\begin{array}{l}\text { Tongji } \\
\text { Hospital. }\end{array}$ & 20200317 & $\begin{array}{l}\text { Not } \\
\text { applicable }\end{array}$ & $\begin{array}{l}\text { https://clinicaltrials.gov/ct2/show } \\
\text { /NCT04306705?cond=COVID- } \\
\text { 19\&draw=10\&rank=87 }\end{array}$ \\
\hline $\begin{array}{l}\text { NCT042 } \\
61426\end{array}$ & $\begin{array}{l}\text { The Efficacy } \\
\text { of } \\
\text { Intravenous } \\
\text { Immunoglob } \\
\text { ulin Therapy } \\
\text { for Severe } \\
\text { 2019-nCoV } \\
\text { Infected } \\
\text { Pneumonia. }\end{array}$ & $\begin{array}{l}\text { Proving } \\
\text { passive } \\
\text { immunity } \\
\text { and anti- } \\
\text { inflammator } \\
\text { y, } \\
\text { immunomod } \\
\text { ulatory } \\
\text { effect. }\end{array}$ & $\begin{array}{l}\text { Peking } \\
\text { Union } \\
\text { Medical } \\
\text { College } \\
\text { Hospital. }\end{array}$ & 20200207 & 2 and 3 & $\begin{array}{l}\text { https://clinicaltrials.gov/ct2/show } \\
\text { /NCT04261426? cond=COVID- } \\
\text { 19\&draw=11\&rank=98 }\end{array}$ \\
\hline $\begin{array}{l}\text { NCT042 } \\
75414\end{array}$ & $\begin{array}{l}\text { Bevacizuma } \\
\mathrm{b} \text { in Severe } \\
\text { or Critical } \\
\text { Patients } \\
\text { With } \\
\text { COVID-19 } \\
\text { Pneumonia } \\
\text { (BEST-CP). }\end{array}$ & VEGF & $\begin{array}{l}\text { Qilu } \\
\text { Hospital of } \\
\text { Shandong } \\
\text { University. }\end{array}$ & 20200219 & 2 and 3 & $\begin{array}{l}\text { https://clinicaltrials.gov/ct2/show } \\
\text { /NCT04275414?cond=COVID- } \\
\text { 19\&draw=12\&rank=101 }\end{array}$ \\
\hline $\begin{array}{l}\text { NCT042 } \\
64858\end{array}$ & $\begin{array}{l}\text { Treatment of } \\
\text { Acute } \\
\text { Severe } \\
\text { 2019-nCoV } \\
\text { Pneumonia } \\
\text { With } \\
\text { Immunoglob } \\
\text { ulin From } \\
\text { Cured } \\
\text { Patients. }\end{array}$ & $\begin{array}{l}\text { Immunoglob } \\
\text { ulin }\end{array}$ & $\begin{array}{l}\text { Wuhan } \\
\text { Union } \\
\text { Hospital, } \\
\text { China. }\end{array}$ & 20200317 & $\begin{array}{l}\text { Not } \\
\text { applicable }\end{array}$ & $\begin{array}{l}\text { https://clinicaltrials.gov/ct2/show } \\
\text { /NCT04264858?cond=COVID- } \\
\text { 19\&draw=14\&rank=125 }\end{array}$ \\
\hline $\begin{array}{l}\text { NCT043 } \\
24073\end{array}$ & $\begin{array}{l}\text { Cohort } \\
\text { Multiple } \\
\text { Randomized } \\
\text { Controlled } \\
\text { Trials Open- } \\
\text { label of } \\
\text { Immune } \\
\text { Modulatory } \\
\text { Drugs and } \\
\text { Other } \\
\text { Treatments } \\
\text { in COVID- } \\
\text { 19 Patients - } \\
\text { Sarilumab } \\
\text { Trial } \\
\text { CORIMUN } \\
\text { O-19 - SARI } \\
\text { (CORIMUN } \\
\text { O-SARI). }\end{array}$ & $\begin{array}{l}\text { sIL-6R } \alpha \text { and } \\
\text { mIL-6R } \alpha .\end{array}$ & $\begin{array}{l}\text { Assistance } \\
\text { Publique - } \\
\text { Hôpitaux } \\
\text { de Paris. }\end{array}$ & 20200401 & 2 and 3 & $\begin{array}{l}\text { https://clinicaltrials.gov/ct2/show } \\
\text { /NCT04324073?cond=COVID- } \\
\text { 19\&draw=16\&rank=149 }\end{array}$ \\
\hline
\end{tabular}




\begin{tabular}{|c|c|c|c|c|c|c|}
\hline $\begin{array}{l}\text { Patent } \\
\text { number }\end{array}$ & Patent title & $\begin{array}{l}\text { Target/key } \\
\text { results }\end{array}$ & $\begin{array}{l}\text { Organizat } \\
\text { ion }\end{array}$ & $\begin{array}{l}\text { Priority } \\
\text { date }\end{array}$ & Phase & Links \\
\hline $\begin{array}{l}\text { NCT042 } \\
88713\end{array}$ & $\begin{array}{l}\text { Eculizumab } \\
\text { (Soliris) in } \\
\text { Covid-19 } \\
\text { Infected } \\
\text { Patients } \\
\text { (SOLID- } \\
\text { C19). }\end{array}$ & $\begin{array}{l}\text { Complement } \\
\text { system }\end{array}$ & $\begin{array}{l}\text { Hudson } \\
\text { Medical. }\end{array}$ & 20200330 & $\begin{array}{l}\text { Not } \\
\text { applicable }\end{array}$ & $\begin{array}{l}\text { https://clinicaltrials.gov/ct2/show } \\
\text { /NCT04288713?cond=COVID- } \\
\text { 19\&draw=17\&rank=160 }\end{array}$ \\
\hline $\begin{array}{l}\text { NCT043 } \\
15480\end{array}$ & $\begin{array}{l}\text { Tocilizumab } \\
\text { for SARS- } \\
\text { CoV2 } \\
\text { Severe } \\
\text { Pneumonitis }\end{array}$ & $\begin{array}{l}\text { Interleukin-6 } \\
\text { (IL-6) }\end{array}$ & $\begin{array}{l}\text { Università } \\
\text { Politecnica } \\
\text { delle } \\
\text { Marche. }\end{array}$ & 20200319 & 2 & $\begin{array}{l}\text { https://clinicaltrials.gov/ct2/show } \\
\text { /NCT04315480?cond=COVID- } \\
\text { 19\&draw=20\&rank }=190\end{array}$ \\
\hline $\begin{array}{l}\text { NCT042 } \\
75245\end{array}$ & $\begin{array}{l}\text { Clinical } \\
\text { Study of } \\
\text { Anti-CD147 } \\
\text { Humanized } \\
\text { Meplazumab } \\
\text { for Injection } \\
\text { to Treat } \\
\text { With 2019- } \\
\text { nCoV } \\
\text { Pneumonia. }\end{array}$ & CD147. & $\begin{array}{l}\text { Tang-Du } \\
\text { Hospital. }\end{array}$ & 20200219 & 1 and 2 & $\begin{array}{l}\text { https://clinicaltrials.gov/ct2/show } \\
\text { /NCT04275245?cond=COVID- } \\
\text { 19\&draw=21\&rank=200 }\end{array}$ \\
\hline $\begin{array}{l}\text { NCT043 } \\
22773\end{array}$ & $\begin{array}{l}\text { Anti-il6 } \\
\text { Treatment of } \\
\text { Serious } \\
\text { COVID-19 } \\
\text { Disease } \\
\text { With } \\
\text { Threatening } \\
\text { Respiratory } \\
\text { Failure } \\
\text { (TOCIVID). }\end{array}$ & $\begin{array}{l}\text { Interleukin-6 } \\
\text { (IL-6) }\end{array}$ & $\begin{array}{l}\text { Frederiksb } \\
\text { erg } \\
\text { University } \\
\text { Hospital. }\end{array}$ & 20200403 & 2 & $\begin{array}{l}\text { https://clinicaltrials.gov/ct2/show } \\
\text { /NCT04322773?cond=COVID- } \\
\text { 19\&draw=4\&rank=224 }\end{array}$ \\
\hline
\end{tabular}

\subsection{Cell therapy.}

Different patents related to the use of cell therapy as a therapeutic strategy to treat COVID-19 are presented in Table 7 As summarized, the most of these approaches use mesenchymal stem cells (MSC), and the most these patents are in only in the phase I. MSC can inhibit the overactivation of the immune system and promoting endogenous repair, and reduce non-productive inflammation and affect tissue regeneration. Other cells are developed in phase I, such as NK, which activate the adaptative immune system.

Table 7. Clinical trial patents of cell therapy targeted SARS-CoV2.

\begin{tabular}{|c|c|c|c|c|c|c|}
\hline $\begin{array}{l}\text { Patent } \\
\text { number }\end{array}$ & Patent title & $\begin{array}{l}\text { Target/key } \\
\text { results }\end{array}$ & Organization & $\begin{array}{l}\text { Priority } \\
\text { date }\end{array}$ & Phase & Links \\
\hline $\begin{array}{l}\text { NCT0431 } \\
5987\end{array}$ & $\begin{array}{l}\text { NestCell® } \\
\text { Mesenchymal } \\
\text { Stem Cell to } \\
\text { Treat Patients } \\
\text { With Severe } \\
\text { COVID-19 } \\
\text { Pneumonia } \\
\text { (HOPE) }\end{array}$ & $\begin{array}{l}\text { Inhibition of } \\
\text { the } \\
\text { overactivatio } \\
\mathrm{n} \text { of the } \\
\text { immune } \\
\text { system and } \\
\text { promoting } \\
\text { endogenous } \\
\text { repair }\end{array}$ & Azidus Brasil. & 20200331 & 1 & $\begin{array}{l}\text { https://clinicaltrials.gov/ct2/show } \\
\text { /NCT04315987?cond=COVID- } \\
\text { 19\&draw=4\&rank=25 }\end{array}$ \\
\hline $\begin{array}{l}\text { NCT0431 } \\
3322\end{array}$ & $\begin{array}{l}\text { Treatment of } \\
\text { COVID-19 } \\
\text { Patients } \\
\text { Using } \\
\text { Wharton's } \\
\text { Jelly- } \\
\text { Mesenchymal } \\
\text { Stem Cells. }\end{array}$ & $\begin{array}{l}\text { Inhibition of } \\
\text { the } \\
\text { overactivatio } \\
\mathrm{n} \text { of the } \\
\text { immune } \\
\text { system and } \\
\text { promoting } \\
\text { endogenous } \\
\text { repair }\end{array}$ & $\begin{array}{l}\text { Stem Cells } \\
\text { Arabia. }\end{array}$ & 20200318 & 1 & $\begin{array}{l}\text { https://clinicaltrials.gov/ct2/show } \\
\text { /NCT04313322?cond=COVID- } \\
\text { 19\&draw=4\&rank=28 }\end{array}$ \\
\hline
\end{tabular}




\begin{tabular}{|c|c|c|c|c|c|c|}
\hline $\begin{array}{l}\text { Patent } \\
\text { number }\end{array}$ & Patent title & $\begin{array}{l}\text { Target/key } \\
\text { results }\end{array}$ & Organization & $\begin{array}{l}\text { Priority } \\
\text { date }\end{array}$ & Phase & Links \\
\hline $\begin{array}{l}\text { NCT0428 } \\
8102\end{array}$ & $\begin{array}{l}\text { Treatment } \\
\text { With } \\
\text { Mesenchymal } \\
\text { Stem Cells for } \\
\text { Severe } \\
\text { Corona Virus } \\
\text { Disease } \\
\text { 2019(COVID } \\
\text {-19). }\end{array}$ & $\begin{array}{l}\text { Reduce non- } \\
\text { productive } \\
\text { inflammation } \\
\text { and affect } \\
\text { tissue } \\
\text { regeneration. }\end{array}$ & $\begin{array}{ll}\text { Beijing } & 302 \\
\text { Hospital. } & \end{array}$ & 20200323 & $\begin{array}{ll}1 & \text { and } \\
2 & \end{array}$ & $\begin{array}{l}\text { https://clinicaltrials.gov/ct2/show } \\
\text { /NCT04288102?cond=COVID- } \\
\text { 19\&draw=5\&rank=38 }\end{array}$ \\
\hline $\begin{array}{l}\text { NCT0430 } \\
2519\end{array}$ & $\begin{array}{l}\text { Novel } \\
\text { Coronavirus } \\
\text { Induced } \\
\text { Severe } \\
\text { Pneumonia } \\
\text { Treated by } \\
\text { Dental Pulp } \\
\text { Mesenchymal } \\
\text { Stem Cells. }\end{array}$ & $\begin{array}{l}\text { Inhibition of } \\
\text { the } \\
\text { overactivatio } \\
\mathrm{n} \text { of the } \\
\text { immune } \\
\text { system and } \\
\text { promoting } \\
\text { endogenous } \\
\text { repair }\end{array}$ & $\begin{array}{l}\text { CAR-T } \\
\text { (Shanghai) } \\
\text { Biotechnology } \\
\text { Co., Ltd. }\end{array}$ & 20200310 & 1 & $\begin{array}{l}\text { https://clinicaltrials.gov/ct2/show } \\
\text { /NCT04302519?cond=COVID- } \\
\text { 19\&draw=7\&rank=59 }\end{array}$ \\
\hline $\begin{array}{l}\text { NCT0432 } \\
1096\end{array}$ & $\begin{array}{l}\text { The Impact of } \\
\text { Camostat } \\
\text { Mesilate on } \\
\text { COVID-19 } \\
\text { Infection } \\
\text { (CamoCO- } \\
\text { 19). }\end{array}$ & Not reported. & $\begin{array}{l}\text { University of } \\
\text { Aarhus. }\end{array}$ & 20200325 & $\begin{array}{ll}1 & \text { and } \\
2 & \end{array}$ & $\begin{array}{l}\text { https://clinicaltrials.gov/ct2/show } \\
\text { /NCT04321096?cond=COVID- } \\
\text { 19\&draw=10\&rank=85 }\end{array}$ \\
\hline $\begin{array}{l}\text { NCT0427 } \\
3646\end{array}$ & $\begin{array}{l}\text { Study of } \\
\text { Human } \\
\text { Umbilical } \\
\text { Cord } \\
\text { Mesenchymal } \\
\text { Stem Cells in } \\
\text { the Treatment } \\
\text { of Novel } \\
\text { Coronavirus } \\
\text { Severe } \\
\text { Pneumonia. }\end{array}$ & $\begin{array}{l}\text { Inhibition of } \\
\text { the } \\
\text { overactivatio } \\
\mathrm{n} \text { of the } \\
\text { immune } \\
\text { system and } \\
\text { promoting } \\
\text { endogenous } \\
\text { repair }\end{array}$ & $\begin{array}{l}\text { Wuhan Union } \\
\text { Hospital, } \\
\text { China. }\end{array}$ & 20200221 & $\begin{array}{l}\text { Not } \\
\text { applic } \\
\text { able }\end{array}$ & $\begin{array}{l}\text { https://clinicaltrials.gov/ct2/show } \\
\text { /NCT04273646?cond=COVID- } \\
\text { 19\&draw=11\&rank=96 }\end{array}$ \\
\hline $\begin{array}{l}\text { NCT0425 } \\
2118\end{array}$ & $\begin{array}{l}\text { Mesenchymal } \\
\text { Stem Cell } \\
\text { Treatment for } \\
\text { Pneumonia } \\
\text { Patients } \\
\text { Infected With } \\
2019 \text { Novel } \\
\text { Coronavirus. }\end{array}$ & $\begin{array}{l}\text { Inhibition of } \\
\text { the } \\
\text { overactivatio } \\
\mathrm{n} \text { of the } \\
\text { immune } \\
\text { system and } \\
\text { promoting } \\
\text { endogenous } \\
\text { repair }\end{array}$ & $\begin{array}{ll}\text { Beijing } & 302 \\
\text { Hospital. } & \end{array}$ & 20200226 & 1 & $\begin{array}{l}\text { https://clinicaltrials.gov/ct2/show } \\
\text { /NCT04252118?cond=COVID- } \\
\text { 19\&draw=11\&rank=97 }\end{array}$ \\
\hline $\begin{array}{l}\text { NCT0426 } \\
9525\end{array}$ & $\begin{array}{l}\text { Umbilical } \\
\text { Cord(UC)- } \\
\text { Derived } \\
\text { Mesenchymal } \\
\text { Stem } \\
\text { Cells(MSCs) } \\
\text { Treatment for } \\
\text { the 2019- } \\
\text { novel } \\
\text { Coronavirus( } \\
\text { nCOV) } \\
\text { Pneumonia. }\end{array}$ & $\begin{array}{l}\text { Inhibition of } \\
\text { the } \\
\text { overactivatio } \\
\mathrm{n} \text { of the } \\
\text { immune } \\
\text { system and } \\
\text { promoting } \\
\text { endogenous } \\
\text { repair }\end{array}$ & $\begin{array}{l}\text { Zhongnan } \\
\text { Hospital of } \\
\text { Wuhan } \\
\text { University. }\end{array}$ & 20200217 & 2 & $\begin{array}{l}\text { https://clinicaltrials.gov/ct2/show } \\
\text { /NCT04269525?cond=COVID- } \\
\text { 19\&draw=19\&rank=175 }\end{array}$ \\
\hline $\begin{array}{l}\text { NCT0427 } \\
6987\end{array}$ & $\begin{array}{l}\text { A Pilot } \\
\text { Clinical } \\
\text { Study on } \\
\text { Inhalation of } \\
\text { Mesenchymal } \\
\text { Stem Cells } \\
\text { Exosomes } \\
\text { Treating } \\
\text { Severe Novel } \\
\text { Coronavirus } \\
\text { Pneumonia. }\end{array}$ & $\begin{array}{l}\text { Inhibition of } \\
\text { the } \\
\text { overactivatio } \\
\mathrm{n} \text { of the } \\
\text { immune } \\
\text { system and } \\
\text { promoting } \\
\text { endogenous } \\
\text { repair }\end{array}$ & $\begin{array}{l}\text { Ruijin } \\
\text { Hospital. }\end{array}$ & 20200225 & 1 & $\begin{array}{l}\text { https://clinicaltrials.gov/ct2/show } \\
\text { /NCT04276987?cond=COVID- } \\
\text { 19\&draw=5\&rank=220 }\end{array}$ \\
\hline
\end{tabular}




\begin{tabular}{|c|c|c|c|c|c|c|}
\hline $\begin{array}{l}\text { Patent } \\
\text { number }\end{array}$ & Patent title & $\begin{array}{l}\text { Target/key } \\
\text { results }\end{array}$ & Organization & $\begin{array}{l}\text { Priority } \\
\text { date }\end{array}$ & Phase & Links \\
\hline $\begin{array}{l}\text { NCT0429 } \\
9152\end{array}$ & $\begin{array}{l}\text { Stem Cell } \\
\text { Educator } \\
\text { Therapy Treat } \\
\text { the Viral } \\
\text { Inflammation } \\
\text { Caused by } \\
\text { Severe Acute } \\
\text { Respiratory } \\
\text { Syndrome } \\
\text { Coronavirus } \\
\text { 2. } \\
\end{array}$ & $\begin{array}{l}\text { Inhibition of } \\
\text { the } \\
\text { overactivatio } \\
\mathrm{n} \text { of the } \\
\text { immune } \\
\text { system and } \\
\text { promoting } \\
\text { endogenous } \\
\text { repair }\end{array}$ & $\begin{array}{l}\text { Tianhe Stem } \\
\text { Cell } \\
\text { Biotechnologi } \\
\text { es Inc. }\end{array}$ & 20200330 & 2 & $\begin{array}{l}\text { https://clinicaltrials.gov/ct2/show } \\
\text { /NCT04299152?cond=COVID- } \\
\text { 19\&draw=4\&rank=264 }\end{array}$ \\
\hline $\begin{array}{l}\text { NCT0428 } \\
0224\end{array}$ & $\begin{array}{l}\text { NK Cells } \\
\text { Treatment for } \\
\text { Novel } \\
\text { Coronavirus } \\
\text { Pneumonia. }\end{array}$ & $\begin{array}{l}\text { Activation of } \\
\text { adaptative } \\
\text { immune } \\
\text { system }\end{array}$ & $\begin{array}{l}\text { Xinxiang } \\
\text { medical } \\
\text { university. }\end{array}$ & 20200221 & 1 & $\begin{array}{l}\text { https://clinicaltrials.gov/ct2/show } \\
\text { /NCT04280224?cond=COVID- } \\
\text { 19\&draw=4\&rank=272 }\end{array}$ \\
\hline
\end{tabular}

\subsection{Plasma therapy.}

Another way to fight COVID-19 is to use the plasma of people who are cured of this disease and administer it to COVID-19 patients (Table 8). Certain clinical patents are filed on plasma therapy, two of which are in clinical phase III. This is a patent that evaluated the effect of plasma on immunocompromised individuals (NCT03808922) and another patent that aims to decrease the severe complications of COVID-19.

Table 8. Clinical trial patents of plasma therapy targeted SARS-CoV2.

\begin{tabular}{|c|c|c|c|c|c|}
\hline $\begin{array}{l}\text { Patent } \\
\text { number }\end{array}$ & Patent title & Organization & $\begin{array}{l}\text { Priority } \\
\text { date }\end{array}$ & Phase & Links \\
\hline $\begin{array}{l}\text { NCT04321 } \\
421\end{array}$ & $\begin{array}{l}\text { Hyperimmune } \\
\text { Plasma for } \\
\text { Critical Patients } \\
\text { With COVID-19 } \\
\text { (COV19- } \\
\text { PLASMA). }\end{array}$ & $\begin{array}{l}\text { Foundation } \\
\text { IRCCS San } \\
\text { Matteo } \\
\text { Hospital. }\end{array}$ & 20200325 & $\begin{array}{l}\text { Not } \\
\text { applicable }\end{array}$ & $\begin{array}{l}\text { https://clinicaltrials.gov/ct2/show/ } \\
\text { NCT04321421?cond=COVID- } \\
\text { 19\&draw=2\&rank=6 }\end{array}$ \\
\hline $\begin{array}{l}\text { NCT04324 } \\
996\end{array}$ & 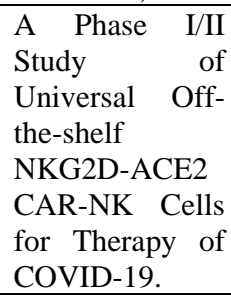 & $\begin{array}{l}\text { Chongqing } \\
\text { Public Health } \\
\text { Medical Center. }\end{array}$ & 20200327 & 1 and 2 & $\begin{array}{l}\text { https://clinicaltrials.gov/ct2/show/ } \\
\text { NCT04324996?cond=COVID- } \\
\text { 19\&draw=2\&rank=9 }\end{array}$ \\
\hline $\begin{array}{l}\text { NCT04273 } \\
321\end{array}$ & $\begin{array}{l}\text { Efficacy and } \\
\text { Safety of } \\
\text { Corticosteroids } \\
\text { in COVID-19. }\end{array}$ & $\begin{array}{l}\text { Beijing Chao } \\
\text { Yang Hospital. }\end{array}$ & 20200401 & $\begin{array}{l}\text { Not } \\
\text { applicable }\end{array}$ & $\begin{array}{l}\text { https://clinicaltrials.gov/ct2/show/ } \\
\text { NCT04273321?cond=COVID- } \\
\text { 19\&draw=6\&rank=41 }\end{array}$ \\
\hline $\begin{array}{l}\text { NCT04323 } \\
800\end{array}$ & $\begin{array}{l}\text { Efficacy and } \\
\text { Safety Human } \\
\text { Coronavirus } \\
\text { Immune Plasma } \\
\text { (HCIP) ror. } \\
\text { Control (SARS- } \\
\text { CoV-2 Non- } \\
\text { immune Plasma) } \\
\text { Among Adults } \\
\text { Exposed to } \\
\text { COVID-19 } \\
\text { (CSSC-001). }\end{array}$ &  & 20200402 & 2 & $\begin{array}{l}\text { https://clinicaltrials.gov/ct2/show/ } \\
\text { NCT04323800?cond=COVID- } \\
\text { 19\&draw }=10 \& \text { rank }=84\end{array}$ \\
\hline $\begin{array}{l}\text { NCT04325 } \\
672\end{array}$ & $\begin{array}{l}\text { Convalescent } \\
\text { Plasma to Limit } \\
\text { Coronavirus } \\
\text { Associated } \\
\text { Complications. }\end{array}$ & Mayo Clinic. & 20200327 & 3 & $\begin{array}{l}\text { https://clinicaltrials.gov/ct2/show/ } \\
\text { NCT04325672?cond=COVID- } \\
\text { 19\&draw }=19 \& \text { rank }=177\end{array}$ \\
\hline
\end{tabular}




\begin{tabular}{|c|c|c|c|c|c|}
\hline $\begin{array}{l}\text { Patent } \\
\text { number }\end{array}$ & Patent title & Organization & $\begin{array}{l}\text { Priority } \\
\text { date }\end{array}$ & Phase & Links \\
\hline $\begin{array}{l}\text { NCT03808 } \\
922\end{array}$ & $\begin{array}{lr}\text { Phase } & \text { III } \\
\text { DAS181 Lower } & \text { Loct PIV } \\
\text { Tract in } \\
\text { Infection fon } \\
\text { Immunocompro } \\
\text { mised Subjects } \\
\text { (Substudy: } \\
\text { DAS181 for } \\
\text { COVID-19): } \\
\text { RCT Study. }\end{array}$ & $\begin{array}{l}\text { Ansun } \\
\text { Biopharma, Inc. }\end{array}$ & 20200402 & 3 & $\begin{array}{l}\text { https://clinicaltrials.gov/ct2/show/ } \\
\text { NCT03808922?cond=COVID- } \\
\text { 19\&draw }=5 \& \text { rank=219 }\end{array}$ \\
\hline
\end{tabular}

\subsection{Vaccine trials.}

Some clinical vaccine trials are being evaluated with different phases (Table 9). These trials are based primarily on decreasing the complications of COVID-19 and directing the immune system against the antigens of SARS-CoV-2. So far, only two vaccine trials have reached the third clinical phase. The first trial, carried out by the Mayo Clinic organization, developed convalescent plasmas in order to limit the complications associated with the coronavirus (NCT04325672), while the second trial in clinical phase 3, evaluated the injection of Parainfluenza virus in Immunocompromised Subjects (NCT03808922). Another trial patent in phase 2 has evaluated the effect of efficacy and safety of human coronavirus immune plasma (NCT04323800).

Table 9. Clinical trial patents of vaccine strategies against SARS-CoV2.

\begin{tabular}{|c|c|c|c|c|c|c|}
\hline $\begin{array}{l}\text { Patent } \\
\text { number }\end{array}$ & Patent title & $\begin{array}{l}\text { Target/key } \\
\text { results }\end{array}$ & Organization & $\begin{array}{l}\text { Priority } \\
\text { date }\end{array}$ & Phase & Links \\
\hline $\begin{array}{l}\text { NCT04299 } \\
724\end{array}$ & $\begin{array}{l}\text { Safety and } \\
\text { Immunity of } \\
\text { Covid-19 } \\
\text { aAPC } \\
\text { Vaccine. }\end{array}$ & $\begin{array}{l}\text { Not } \\
\text { reported. }\end{array}$ & $\begin{array}{l}\text { Shenzhen } \\
\text { Geno- } \\
\text { Immune } \\
\text { Medical } \\
\text { Institute. }\end{array}$ & 20200309 & 1 & $\begin{array}{l}\text { https://clinicaltrials.gov/ct2/show/NCT04 } \\
\text { 299724?cond=COVID- } \\
\text { 19\&draw=6\&rank=47 }\end{array}$ \\
\hline $\begin{array}{l}\text { NCT04276 } \\
896\end{array}$ & $\begin{array}{l}\text { Immunity } \\
\text { and Safety of } \\
\text { Covid-19 } \\
\text { Synthetic } \\
\text { Minigene } \\
\text { Vaccine. }\end{array}$ & $\begin{array}{l}\text { Not } \\
\text { reported. }\end{array}$ & $\begin{array}{l}\text { Shenzhen } \\
\text { Geno- } \\
\text { Immune } \\
\text { Medical } \\
\text { Institute. }\end{array}$ & 20200319 & 1 and 2 & $\begin{array}{l}\text { https://clinicaltrials.gov/ct2/show/NCT04 } \\
\text { 276896?cond=COVID- } \\
\text { 19\&draw=6\&rank=50 }\end{array}$ \\
\hline $\begin{array}{l}\text { NCT04313 } \\
127\end{array}$ & $\begin{array}{l}\text { A Phase I } \\
\text { Clinical Trial } \\
\text { in 18-60 } \\
\text { Adults } \\
\text { (APICTH). }\end{array}$ & $\begin{array}{l}\text { Recombinan } \\
\text { t Novel } \\
\text { Coronavirus } \\
\text { Vaccine } \\
\text { (Adenovirus } \\
\text { Type } 5 \\
\text { Vector). }\end{array}$ & $\begin{array}{l}\text { CanSino } \\
\text { Biologics Inc. }\end{array}$ & 20200331 & 1 & $\begin{array}{l}\text { https://clinicaltrials.gov/ct2/show/NCT04 } \\
\text { 313127? cond=COVID- } \\
\text { 19\&draw=7\&rank=55 }\end{array}$ \\
\hline $\begin{array}{l}\text { NCT04324 } \\
606\end{array}$ & $\begin{array}{l}\text { A Study of a } \\
\text { Candidate } \\
\text { COVID-19 } \\
\text { Vaccine } \\
\text { (COV001). }\end{array}$ & $\begin{array}{l}\text { Not } \\
\text { reported. }\end{array}$ & $\begin{array}{l}\text { University of } \\
\text { Oxford. }\end{array}$ & 20200327 & 1 and 2 & $\begin{array}{l}\text { https://clinicaltrials.gov/ct2/show/NCT04 } \\
\text { 324606? cond=COVID- } \\
\text { 19\&draw=10\&rank=83 }\end{array}$ \\
\hline $\begin{array}{l}\text { NCT04283 } \\
461\end{array}$ & $\begin{array}{l}\text { Safety and } \\
\text { Immunogeni } \\
\text { city Study of } \\
\text { 2019-nCoV } \\
\text { Vaccine } \\
\text { (mRNA- } \\
\text { 1273) for } \\
\text { Prophylaxis } \\
\text { SARS CoV- } \\
2 \text { Infection. }\end{array}$ & $\begin{array}{l}\text { Spike } \\
\text { protein. }\end{array}$ & $\begin{array}{l}\text { National } \\
\text { Institute of } \\
\text { Allergy and } \\
\text { Infectious } \\
\text { Diseases. }\end{array}$ & 20200330 & 1 & $\begin{array}{l}\text { https://clinicaltrials.gov/ct2/show/NCT04 } \\
283461 \text { ?cond=COVID- } \\
\text { 19\&draw=20\&rank=185 }\end{array}$ \\
\hline $\begin{array}{l}\text { NCT04283 } \\
461\end{array}$ & $\begin{array}{l}\text { Safety and } \\
\text { Immunogeni } \\
\text { city Study of } \\
\text { 2019-nCoV } \\
\text { Vaccine } \\
\text { (mRNA- } \\
\text { 1273) for }\end{array}$ & $\begin{array}{l}\text { Spike } \\
\text { protein. }\end{array}$ & $\begin{array}{l}\text { National } \\
\text { Institute of } \\
\text { Allergy and } \\
\text { Infectious } \\
\text { Diseases. }\end{array}$ & 20200330 & 1 & $\begin{array}{l}\text { https://clinicaltrials.gov/ct2/show/NCT04 } \\
\text { 283461?cond=COVID- } \\
\text { 19\&draw=20\&rank }=185\end{array}$ \\
\hline
\end{tabular}




\begin{tabular}{l|l|l|l|l|l|l}
$\begin{array}{l}\text { Patent } \\
\text { number }\end{array}$ & Patent title & $\begin{array}{l}\text { Target/key } \\
\text { results }\end{array}$ & Organization & $\begin{array}{l}\text { Priority } \\
\text { date }\end{array}$ & Phase & Links \\
\hline & $\begin{array}{l}\text { Prophylaxis } \\
\text { SARS CoV- } \\
\text { 2 Infection. }\end{array}$ & & & & & \\
& & & & &
\end{tabular}

\section{Conclusions}

The COVID-19 epidemic posed a real danger with extremely powerful damage. In the absence of effective treatments such as a vaccine, the spread of the virus is continuously emerging. However, recent works that have evaluated the antiviral activity of natural and synthetic molecules against SARS-CoV-2 have shown promising results and could introduce effective drugs. In addition, the use of other old antivirals has revealed that these molecules are also effective against SARS-CoV2, which could make their use an effective means against COVID-19, as in the case of chloroquine and hydroxy-chloroquine. There are also a number of recently filed patents on various proposed therapies, such as monoclonal antibody therapy, cell therapy, plasma therapy, and vaccine trials. These patents are in the different clinical phases and will certainly lead to clinical validations in the future weeks or months.

\section{Funding}

This research received no external funding.

\section{Acknowledgments}

This research has no acknowledgment.

\section{Conflicts of Interest}

The authors declare no conflict of interest.

\section{References}

1. Gupta, V.; Know the unknown fact of novel COVID -19 corona virus. Letters in Applied NanoBioScience 2020, 9, 1083 - 1088, https://doi.org/10.33263/LIANBS92.10831088.

2. Nadjib, B.M. Effective Antiviral Activity of Essential Oils and Their Characteristic Terpenes against Coronaviruses: An Update. Journal of Pharmacology \& Clinical Toxicology 2020, 9.

3. Fischer, A.; Sellner, M.; Neranjan, S.; Lill, M.A. Inhibitors for Novel Coronavirus Protease Identified by Virtual Screening of 687 Million Compounds. Chemrvix 2020, 21, https://doi.org/10.26434/chemrxiv.11923239.

4. Phan, L.T.; Nguyen, T.V.; Luong, Q.C.; Nguyen, T.V.; Nguyen, H.T.; Le, H.Q.; Nguyen, T.T.; Cao, T.M.; Pham, Q.D. Importation and Human-to-Human Transmission of a Novel Coronavirus in Vietnam. New England Journal of Medicine 2020, 382, 872-874, https://doi.org/10.1056/NEJMc2001272.

5. Shereen, M.A.; Khan, S.; Kazmi, A.; Bashir, N.; Siddique, R. COVID-19 Infection: Origin, Transmission, and Characteristics of Human Coronaviruses. Journal of Advanced Research 2020, 24, 91-98, https://doi.org/10.1016/j.jare.2020.03.005.

6. Hong, H.; Wang, Y.; Chung, H.T.; Chen, C.J. Clinical Characteristics of Novel Coronavirus Disease 2019 (COVID-19) in Newborns, Infants and Children. Pediatrics \& Neonatology 2020, 0 , https://doi.org/10.1016/j.pedneo.2020.03.001.

7. Rothan, H.A.; Byrareddy, S.N. The Epidemiology and Pathogenesis of Coronavirus Disease (COVID-19) Outbreak. Journal of Autoimmunity 2020, 109, https://doi.org/10.1016/j.jaut.2020.102433.

8. Yang, Y.; Islam, M. S.; Wang, J.; Li, Y.; Chen, X. Traditional Chinese Medicine in the Treatment of Patients Infected with 2019-New Coronavirus (SARS-CoV-2): A Review and Perspective. Int. J. Biol. Sci. 2020, 16, 1708-1717, https://doi.org/10.7150/ijbs.45538.

9. Corman, V.M.; Landt, O.; Kaiser, M.; Molenkamp, R.; Meijer, A.; Chu, D.K.; Bleicker, T.; Brünink, S.; Schneider, J.; Schmidt, M.L.; Mulders, D.G.; Haagmans, B.L.; van der Veer, B.; van den Brink, S.; Wijsman, L.; Goderski, G.; Romette, J.L.; Ellis, J.; Zambon, M.; Peiris, M.; Goossens, H.; Reusken, C.; Koopmans, 
M. P.; Drosten, C. Detection of 2019 Novel Coronavirus (2019-NCoV) by Real-Time RT-PCR. Euro Surveill 2020, 25, https://doi.org/10.2807/1560-7917.ES.2020.25.3.2000045.

10. Zhang, L.; Liu, Y. Potential Interventions for Novel Coronavirus in China: A Systematic Review. J Med Virol 2020, 92, 479-490, https://doi.org/10.1002/jmv.25707.

11. Mohammadi, N.; Shaghaghi, N. Inhibitory Effect of Eight Secondary Metabolites from Conventional Medicinal Plants on COVID_19 Virus Protease by Molecular Docking Analysis. Preprint 2020, https://doi.org/10.26434/chemrxiv.11987475.v1.

12. Liu, C.; Zhu, X.; Lu, Y.; Jia, X.; Yang, T. Potential Treatment of Chinese and Western Medicine Targeting Nsp14 of 2019-NCoV. Chinaxiv 2020.

13. Tsai, Y.C.; Lee, C.L.; Yen, H.R.; Chang, Y.S.; Lin, Y.P.; Huang, S.H.; Lin, C.W. Antiviral Action of Tryptanthrin Isolated from Strobilanthes Cusia Leaf against Human Coronavirus NL63. Biomolecules 2020, 10, https://doi.org/10.3390/biom10030366.

14. Lin, C.W.; Tsai, F.J.; Tsai, C.H.; Lai, C.C.; Wan, L.; Ho, T.Y.; Hsieh, C.C.; Chao, P.D.L. Anti-SARS Coronavirus 3C-like Protease Effects of Isatis Indigotica Root and Plant-Derived Phenolic Compounds. Antiviral Research 2005, 68, 36-42, https://doi.org/10.1016/j.antiviral.2005.07.002.

15. Liang, W.; He, L.; Ning, P.; Lin, J.; Li, H.; Lin, Z.; Kang, K.; Zhang, Y. (+)-Catechin Inhibition of Transmissible Gastroenteritis Coronavirus in Swine Testicular Cells Is Involved Its Antioxidation. Research in Veterinary Science 2015, 103, 28-33, https://doi.org/10.1016/j.rvsc.2015.09.009.

16. Yu, M.S.; Lee, J.; Lee, J.M.; Kim, Y.; Chin, Y.W.; Jee, J.G.; Keum, Y.S.; Jeong, Y.J. Identification of Myricetin and Scutellarein as Novel Chemical Inhibitors of the SARS Coronavirus Helicase, NsP13. Bioorganic \& Medicinal Chemistry Letters 2012, 22, 4049-4054, https://doi.org/10.1016/j.bmcl.2012.04.081.

17. Cho, J.K.; Curtis-Long, M.J.; Lee, K.H.; Kim, D.W.; Ryu, H.W.; Yuk, H.J.; Park, K.H. Geranylated Flavonoids Displaying SARS-CoV Papain-like Protease Inhibition from the Fruits of Paulownia Tomentosa. Bioorganic \& Medicinal Chemistry 2013, 21, 3051-3057, https://doi.org/10.1016/j.bmc.2013.03.027.

18. Utomo, R.Y.; Ikawati, M.; Meiyanto, E. Revealing the Potency of Citrus and Galangal Constituents to Halt SARS-CoV-2 Infection. Preprint; Medicine \& Pharmacology 2020, https://doi.org/10.20944/preprints202003.0214.v1.

19. Cheng, L.; Zheng, W.; Li, M.; Huang, J.; Ma, Z. Citrus Fruits Are Rich in Flavonoids for Immunoregulation and Potential Targeting ACE2. Preprints 2020, 13.

20. Jo, S.; Kim, S.; Shin, D.H.; Kim, M.S. Inhibition of SARS-CoV 3CL Protease by Flavonoids. Journal of Enzyme Inhibition and Medicinal Chemistry 2020, 35, 145-151, https://doi.org/10.1080/14756366.2019.1690480.

21. Nguyen, T.T.H.; Woo, H.J.; Kang, H.K.; Nguyen, V.D.; Kim, Y.M.; Kim, D.W.; Ahn, S.A.; Xia, Y.; Kim, D. Flavonoid-Mediated Inhibition of SARS Coronavirus 3C-like Protease Expressed in Pichia Pastoris. Biotechnol Lett 2012, 34, 831-838, https://doi.org/10.1007/s10529-011-0845-8.

22. Ryu, Y.B.; Jeong, H.J.; Kim, J.H.; Kim, Y.M.; Park, J.Y.; Kim, D.; Naguyen, T.T.H.; Park, S.J.; Chang, J.S.; Park, K.H. Biflavonoids from Torreya Nucifera Displaying SARS-CoV 3CLpro Inhibition. Bioorganic \& Medicinal Chemistry 2010, 18, 7940-7947, https://doi.org/10.1016/j.bmc.2010.09.035.

23. Wen, C.C.; Kuo, Y.H.; Jan, J.T.; Liang, P.H.; Wang, S.Y.; Liu, H.G.; Lee, C.K.; Chang, S.T.; Kuo, C.J.; Lee, S.S.; Hou, C.C.; Hsiao, P.W.; Chien, S.C.; Shyur, L.F.; Yang, N.S. Specific Plant Terpenoids and Lignoids Possess Potent Antiviral Activities against Severe Acute Respiratory Syndrome Coronavirus. J. Med. Chem. 2007, 50, 4087-4095, https://doi.org/10.1021/jm070295s.

24. Park, J.Y.; Kim, J.H.; Kwon, J.M.; Kwon, H.J.; Jeong, H.J.; Kim, Y.M.; Kim, D.; Lee, W.S.; Ryu, Y.B. Dieckol, a SARS-CoV 3CLpro Inhibitor, Isolated from the Edible Brown Algae Ecklonia Cava. Bioorganic \& Medicinal Chemistry 2013, 21, 3730-3737, https://doi.org/10.1016/j.bmc.2013.04.026.

25. Kwon, H.J.; Ryu, Y.B.; Kim, Y.M.; Song, N.; Kim, C.Y.; Rho, M.C.; Jeong, J.H.; Cho, K.O.; Lee, W.S.; Park, S.J. In Vitro Antiviral Activity of Phlorotannins Isolated from Ecklonia Cava against Porcine Epidemic Diarrhea Coronavirus Infection and Hemagglutination. Bioorganic \& Medicinal Chemistry 2013, 21, 47064713, https://doi.org/10.1016/j.bmc.2013.04.085.

26. Khalifa, I.; Zhu, W.; Nafie, M.S.; Dutta, K.; Li, C. Anti-COVID-19 Effects of Ten Structurally Different Hydrolysable Tannins through Binding with the Catalytic-Closed Sites of COVID-19 Main Protease: An InSilico Approach. Preprint other 2020, https://doi.org/10.20944/preprints202003.0277.v1.

27. Ho, T.; Wu, S.; Chen, J.; Li, C.; Hsiang, C. Emodin Blocks the SARS Coronavirus Spike Protein and Angiotensin-Converting Enzyme 2 Interaction. Antiviral Research 2007, 74, 92-101, https://doi.org/10.1016/j.antiviral.2006.04.014.

28. Schwarz, S.; Wang, K.; Yu, W.; Sun, B.; Schwarz, W. Emodin Inhibits Current through SARS-Associated Coronavirus 3a Protein. Antiviral Research 2011, 90, 64-69, https://doi.org/10.1016/j.antiviral.2011.02.008.

29. Park, J.Y.; Ko, J.A.; Kim, D.W.; Kim, Y.M.; Kwon, H.J.; Jeong, H.J.; Kim, C.Y.; Park, K.H.; Lee, W.S.; Ryu, Y.B. Chalcones Isolated from Angelica Keiskei Inhibit Cysteine Proteases of SARS-CoV. Journal of Enzyme Inhibition and Medicinal Chemistry 2014, 31, 23-30, https://doi.org/10.3109/14756366.2014.1003215. 
30. Cheng, J.; Tang, Y.; Zhang, P. Exploring the Active Compounds of Traditional Mongolian Medicine Agsirga in Intervention of Novel Coronavirus (2019- NCoV) Based on HPLC-Q-Exactive-MS/MS and Molecular Docking Method. Chemrvix 2020, 31 .

31. Hoever, G.; Baltina, L.; Michaelis, M.; Kondratenko, R.; Baltina, L.; Tolstikov, G. A.; Doerr, H. W.; Cinatl, J. Antiviral Activity of Glycyrrhizic Acid Derivatives against SARS-Coronavirus. J. Med. Chem. 2005, 48, 1256-1259, https://doi.org/10.1021/jm0493008.

32. Park, J.Y.; Kim, J.H.; Kim, Y.M.; Jeong, H.J.; Kim, D.W.; Park, K.H.; Kwon, H.J.; Park, S.J.; Lee, W.S.; Ryu, Y.B. Tanshinones as Selective and Slow-Binding Inhibitors for SARS-CoV Cysteine Proteases. Bioorganic \& Medicinal Chemistry 2012, 20, 5928-5935, https://doi.org/10.1016/j.bmc.2012.07.038.

33. Park, J.Y.; Yuk, H.J.; Ryu, H.W.; Lim, S.H.; Kim, K.S.; Park, K.H.; Ryu, Y.B.; Lee, W.S. Evaluation of Polyphenols from Broussonetia Papyrifera as Coronavirus Protease Inhibitors. Journal of Enzyme Inhibition and Medicinal Chemistry 2017, 32, 504-512, https://doi.org/10.1080/14756366.2016.1265519.

34. Hsieh, L.E.; Lin, C.N.; Su, B.L.; Jan, T.R.; Chen, C.M.; Wang, C.H.; Lin, D.S.; Lin, C.T.; Chueh, L.L. Synergistic Antiviral Effect of Galanthus Nivalis Agglutinin and Nelfinavir against Feline Coronavirus. Antiviral Research 2010, 88, 25-30, https://doi.org/10.1016/j.antiviral.2010.06.010.

35. Jo, S.; Kim, S.; Shin, D.H.; Kim, M.S. Inhibition of SARS-CoV 3CL Protease by Flavonoids. Journal of Enzyme Inhibition and Medicinal Chemistry 2020, 35, 145-151, https://doi.org/10.1080/14756366.2019.1690480.

36. Galasiti Kankanamalage, A.C.; Kim, Y.; Damalanka, V.C.; Rathnayake, A.D.; Fehr, A.R.; Mehzabeen, N.; Battaile, K.P.; Lovell, S.; Lushington, G.H.; Perlman, S.; Chang, K.O.; Groutas, W.C. Structure-Guided Design of Potent and Permeable Inhibitors of MERS Coronavirus 3CL Protease That Utilize a Piperidine Moiety as a Novel Design Element. European Journal of Medicinal Chemistry 2018, 150, 334-346, https://doi.org/10.1016/j.ejmech.2018.03.004.

37. Ho, T.; Wu, S.; Chen, J.; Wei, Y.; Cheng, S.; Chang, Y.; Liu, H.; Hsiang, C. Design and Biological Activities of Novel Inhibitory Peptides for SARS-CoV Spike Protein and Angiotensin-Converting Enzyme 2 Interaction. Antiviral Research 2006, 69, 70-76, https://doi.org/10.1016/j.antiviral.2005.10.005.

38. Hanh Nguyen, T.T.; Ryu, H.J.; Lee, S.H.; Hwang, S.; Breton, V.; Rhee, J.H.; Kim, D. Virtual Screening Identification of Novel Severe Acute Respiratory Syndrome 3C-like Protease Inhibitors and in Vitro Confirmation. Bioorganic \& Medicinal Chemistry Letters 2011, 21, 3088-3091, https://doi.org/10.1016/j.bmcl.2011.03.034.

39. Mirza, M.U.; Froeyen, M. Structural Elucidation of SARS-CoV-2 Vital Proteins: Computational Methods Reveal Potential Drug Candidates Against Main Protease, Nsp12 RNA-Dependent RNA Polymerase and Nsp13 Helicase. Preprint life sciences 2020, https://doi.org/10.20944/preprints202003.0085.v1.

40. Karypidou, K.; Ribone, S.R.; Quevedo, M.A.; Persoons, L.; Pannecouque, C.; Helsen, C.; Claessens, F.; Dehaen, W. Synthesis, Biological Evaluation and Molecular Modeling of a Novel Series of Fused 1,2,3Triazoles as Potential Anti-Coronavirus Agents. Bioorganic \& Medicinal Chemistry Letters 2018, 28, 34723476, https://doi.org/10.1016/j.bmcl.2018.09.019.

41. Thanigaimalai, P.; Konno, S.; Yamamoto, T.; Koiwai, Y.; Taguchi, A.; Takayama, K.; Yakushiji, F.; Akaji, K.; Kiso, Y.; Kawasaki, Y.; Chen, S.E.; Naser-Tavakolian, A.; Schön, A.; Freire, E.; Hayashi, Y. Design, Synthesis, and Biological Evaluation of Novel Dipeptide-Type SARS-CoV 3CL Protease Inhibitors: Structure-Activity Relationship Study. European Journal of Medicinal Chemistry 2013, 65, 436-447, https://doi.org/10.1016/j.ejmech.2013.05.005.

42. Turlington, M.; Chun, A.; Tomar, S.; Eggler, A.; Grum-Tokars, V.; Jacobs, J.; Daniels, J. S.; Dawson, E.; Saldanha, A.; Chase, P.; Baez-Santos, Y.M.; Lindsley, C.W.; Hodder, P.; Mesecar, A.D.; Stauffer, S.R. Discovery of N-(Benzo[1,2,3]Triazol-1-Yl)-N-(Benzyl)Acetamido)Phenyl) Carboxamides as Severe Acute Respiratory Syndrome Coronavirus (SARS-CoV) 3CLpro Inhibitors: Identification of ML300 and Noncovalent Nanomolar Inhibitors with an Induced-Fit Binding. Bioorganic \& Medicinal Chemistry Letters 2013, 23, 6172-6177, https://doi.org/10.1016/j.bmcl.2013.08.112.

43. Kim, M.K.; Yu, M.S.; Park, H.R.; Kim, K.B.; Lee, C.; Cho, S.Y.; Kang, J.; Yoon, H.; Kim, D.E.; Choo, H.; Jeong, Y.J.; Chong, Y. 2,6-Bis-Arylmethyloxy-5-Hydroxychromones with Antiviral Activity against Both Hepatitis C Virus (HCV) and SARS-Associated Coronavirus (SCV). European Journal of Medicinal Chemistry 2011, 46, 5698-5704, https://doi.org/10.1016/j.ejmech.2011.09.005.

44. Yang, C.W.; Lee, Y.Z.; Kang, I.J.; Barnard, D.L.; Jan, J.T.; Lin, D.; Huang, C.W.; Yeh, T.K.; Chao, Y.S.; Lee, S.J. Identification of Phenanthroindolizines and Phenanthroquinolizidines as Novel Potent Anti-Coronaviral Agents for Porcine Enteropathogenic Coronavirus Transmissible Gastroenteritis Virus and Human Severe Acute Respiratory Syndrome Coronavirus. Antiviral Research 2010, 88, 160-168, https://doi.org/10.1016/j.antiviral.2010.08.009.

45. Zhang, H.; Saravanan, K.M.; Yang, Y.; Hossain, M.T.; Li, J.; Ren, X.; Wei, Y. Deep Learning Based Drug Screening for Novel Coronavirus 2019-NCov. Preprints https://doi.org/10.20944/preprints202002.0061.v1.

46. Cao, J.; Forrest, J.C.; Zhang, X. A Screen of the NIH Clinical Collection Small Molecule Library Identifies Potential Anti-Coronavirus Drugs. Antiviral Research 2015, 114, 1-10, https://doi.org/10.1016/j.antiviral.2014.11.010. 
47. Cheng, K.W.; Cheng, S.C.; Chen, W.Y.; Lin, M.H.; Chuang, S.J.; Cheng, I.H.; Sun, C.Y.; Chou, C.Y. Thiopurine Analogs and Mycophenolic Acid Synergistically Inhibit the Papain-like Protease of Middle East Respiratory Syndrome Coronavirus. Antiviral Research 2015, 115, 9-16, https://doi.org/10.1016/j.antiviral.2014.12.011.

48. Kim, M.K.; Yu, M.S.; Park, H.R.; Kim, K.B.; Lee, C.; Cho, S.Y.; Kang, J.; Yoon, H.; Kim, D.E.; Choo, H.; Jeong, Y.J.; Chong, Y. 2,6-Bis-Arylmethyloxy-5-Hydroxychromones with Antiviral Activity against Both Hepatitis C Virus (HCV) and SARS-Associated Coronavirus (SCV). European Journal of Medicinal Chemistry 2011, 46, 5698-5704, https://doi.org/10.1016/j.ejmech.2011.09.005.

49. Elfiky, A.A. Anti-HCV, Nucleotide Inhibitors, Repurposing against COVID-19. Life Sciences 2020, 248, https://doi.org/10.1016/j.lfs.2020.117477.

50. Smith, M.; Smith, J.C. Repurposing Therapeutics for COVID-19: Supercomputer-Based Docking to the SARS-CoV-2 Viral Spike Protein and Viral Spike Protein-Human ACE2 Interface. Chemrvix 2020, https://doi.org/10.26434/chemrxiv.11871402.v3.

51. Ruan, Z.; Liu, C.; Guo, Y.; He, Z.; Huang, X.; Jia, X.; Yang, T. Potential Inhibitors Targeting RNA-Dependent RNA Polymerase Activity (NSP12) of SARS-CoV-2. Preprints 2020, https://doi.org/10.20944/preprints202003.0024.v1.

52. Simmons, G.; Gosalia, D.N.; Rennekamp, A.J.; Reeves, J.D.; Diamond, S.L.; Bates, P. Inhibitors of Cathepsin L Prevent Severe Acute Respiratory Syndrome Coronavirus Entry. PNAS 2005, 102, 1187611881, https://doi.org/10.1073/pnas.0505577102.

53. Sheahan, T.P.; Sims, A.C.; Leist, S.R.; Schäfer, A.; Won, J.; Brown, A.J.; Montgomery, S.A.; Hogg, A.; Babusis, D.; Clarke, M.O.; Spahn, J.E.; Bauer, L.; Sellers, S.; Porter, D.; Feng, J.Y.; Cihlar, T.; Jordan, R.; Denison, M.R.; Baric, R.S. Comparative Therapeutic Efficacy of Remdesivir and Combination Lopinavir, Ritonavir, and Interferon Beta against MERS-CoV. Nature Communications 2020, 11, 1-14, https://doi.org/10.1038/s41467-019-13940-6.

54. Wang, M.; Cao, R.; Zhang, L.; Yang, X.; Liu, J.; Xu, M.; Shi, Z.; Hu, Z.; Zhong, W.; Xiao, G. Remdesivir and Chloroquine Effectively Inhibit the Recently Emerged Novel Coronavirus (2019-NCoV) in Vitro. Cell Research 2020, 30, 269-271, https://doi.org/10.1038/s41422-020-0282-0.

55. Yao, X.; Ye, F.; Zhang, M.; Cui, C.; Huang, B.; Niu, P.; Liu, X.; Zhao, L.; Dong, E.; Song, C.; Zhan, S.; Lu, R.; Li, H.; Tan, W.; Liu, D. In Vitro Antiviral Activity and Projection of Optimized Dosing Design of Hydroxychloroquine for the Treatment of Severe Acute Respiratory Syndrome Coronavirus 2 (SARS-CoV2). Clin Infect Dis 2020, https://doi.org/10.1093/cid/ciaa237.

56. de Wilde, A.H.; Falzarano, D.; Zevenhoven-Dobbe, J.C.; Beugeling, C.; Fett, C.; Martellaro, C.; Posthuma, C.C.; Feldmann, H.; Perlman, S.; Snijder, E.J. Alisporivir Inhibits MERS- and SARS-Coronavirus Replication in Cell Culture, but Not SARS-Coronavirus Infection in a Mouse Model. Virus Research 2017, 228, 7-13, https://doi.org/10.1016/j.virusres.2016.11.011.

57. Cheng, K.W.; Cheng, S.C.; Chen, W.Y.; Lin, M.H.; Chuang, S.J.; Cheng, I.H.; Sun, C.Y.; Chou, C.Y. Thiopurine Analogs and Mycophenolic Acid Synergistically Inhibit the Papain-like Protease of Middle East Respiratory Syndrome Coronavirus. Antiviral Research 2015, 115, 9-16, https://doi.org/10.1016/j.antiviral.2014.12.011. 